\title{
Layered Materials with Catalytic Applications: Pillared and Delaminated Zeolites from MWW Precursors
}

\author{
Urbano Díaz \\ Instituto de Tecnología Química (UPV-CSIC), Universidad Politéenica de Valencia, Avenida de los Naranjos s/n, \\ 46022 Valencia, Spain \\ Correspondence should be addressed to Urbano Díaz, udiaz@itq.upv.es
}

Received 21 June 2012; Accepted 26 August 2012

Academic Editors: A. Auroux and M. Cheng

Copyright (๑) 2012 Urbano Díaz. This is an open access article distributed under the Creative Commons Attribution License, which permits unrestricted use, distribution, and reproduction in any medium, provided the original work is properly cited.

Delaminated and pillared zeolites are an innovative family of molecular sieves which introduced a different concept inside the synthesis of active catalysts or inorganic supports. These types of materials exhibit an elevated accessibility due to their open structure, characterized by the high external surface area without imposed restrictions controlled by the pore sizes. These open zeolites are conformed by crystalline ordered (pillared zeolites) or disordered (delaminated zeolites) individual layers, exhibiting textural properties which are favorable to carry out catalytic processes in which it is necessary to employ catalysts with completely accessible active sites. The elevated external surface area of these zeolites is profitable to generate more specific organic-inorganic materials, acting in this case as stable inorganic matrixes. The preparation of this open type-zeolites family is based on the modification of, previously synthesized, zeolitic precursors which are preexpanded to obtain the final delaminated or pillared zeolites which exhibit very different physicochemical properties compared with the starting precursors. Along this paper, the most relevant MWW-type high accessible zeolitic materials will be considered. Their nature, characteristics, and reactivity will be shown in the function of the employed synthesis method for their preparation and the postsynthesis treatments carried out, tuning their properties.

\section{Introduction: Delamination and Pillarization Concept}

Layered inorganic precursors are structurally conformed by a consecutive repetition of individual sheets located in parallel spatial planes, being electrostatically bonded by Van der Waals interactions or hydrogen bonds along the perpendicular plane in which the layers are disposed. This structural conformation is present in a great number of inorganic materials, from the simplest such as clays or silicates to another more complex such as layered double hydroxides, metallic layered materials, or zeolitic precursors [1-4].

These layered materials exhibit the capacity to modify their structural characteristics through consecutive steps using the free space present between the contiguous inorganic layers. In this way, it is possible to obtain novel mesoporous materials due to the intercalation in the interlayered space of organic or inorganic compounds which act as pillars, avoiding the covalent connection between the inorganic layers after the removing of the ionic molecules which are compensating the surface charges present in the sheets. This type of layered solids is considered as pillared materials [5].

However, it would be feasible to advance more in this approach, starting from inorganic layered precursors, to generate another type of materials with a complete accessibility, being possible to prepare new materials where the practical totality of the initial microporous surface obtained from the collapsed layered precursors is transformed to an accessible external area. For this, the inorganic precursors are involved in "delamination" processes with the objective to separate completely the piled layers which remain, in the final materials, disordered in the space showing an organization similar to house-of-cards structures based on the random distribution of the individual inorganic layers (Figure 1) [6]. These exfoliated materials exhibit an elevated external area, showing a high accessibility for all types of reactants, preferably when they present a high molecular 


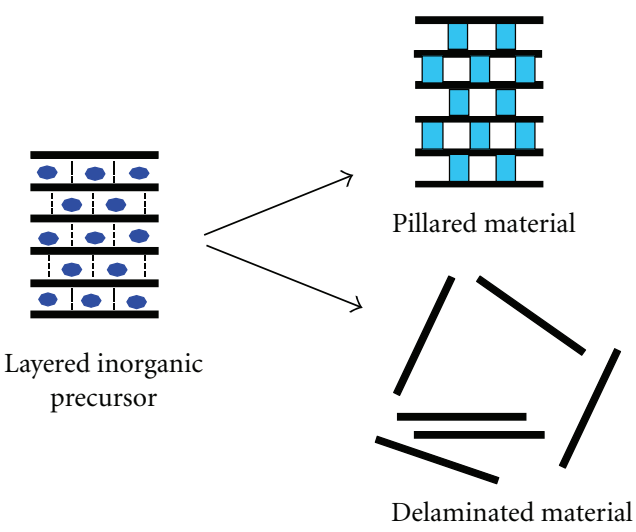

FIGURE 1: Layered materials derived from inorganic precursors.

size, which can easily interact with the active sites contained or supported onto the surface of each individual inorganic sheet. Moreover, the high external area exhibited for the delaminated materials can be used to incorporate different active sites stabilized and separated to a controlled distance onto the surface of the layers to generate multifunctional catalysts which show the advantages of accessibility, characteristic of conventional mesoporous materials, combined with the hydrothermal stability, characteristic of inorganic solids.

It is important to remark that although the delaminated materials are disordered solids, it is not correct to consider these materials as amorphous or without any type of structuration. On the contrary, although their study is not easy, it is possible to determine correctly their structural characteristics and physico-chemical properties, using and analyzing suitably the characterization results obtained such as it will be shown along this paper.

There are different approaches [7] to obtain delaminated materials from starting inorganic layered precursors, the main being the next.

(i) Chemical processes such as it is the solvation of interlayered cations which facilitates the separation between the layers due to the decrease of the attraction forces [8].

(ii) Intercalation of molecules which are located in the interlayered space increasing the separation between the inorganic layers favoring their random spatial disorder [9].

(iii) Mechanical processes such as ultrasonic methods, stirring, freeze-drying, or centrifugation systems which are mechanisms to carry out the exfoliation of the starting layered precursors [10].

Accordingly, the delamination process could be performed through one of the above explained approaches, the more suitable being the effective combination of them to obtain delaminated materials with high accessibility and a defined layered framework. The application of combined delamination methods would allow the control of the final properties exhibited by the exfoliated solids, even being adjustable the achieved delamination level, preserving the crystalline structure of each individual inorganic layer.

In the next sections, it will be considered the main delaminated and pillared MWW materials, detailing characteristic structural and physico-chemical properties, and catalytic applications.

\section{Layered Materials with MWW Topology}

Inside zeolites family, it is possible to find different examples which their final $3 \mathrm{D}$ structure is achieved through stable intermediate layered zeolitic precursors obtained during the synthesis process. After the removing of the structural directing agents (SDAs) located in the interlayer space, using normally calcination methods, it is favored the connection between the contiguous layers to generate the final zeolite. The presence of individual layers separated between them by ionic compounds, which are compensating the charges of zeolitic sheets, facilitates the swelling, pillarization, or exfoliation processes, being possible to obtain new materials with higher pore size diameters and, so, with elevated accessibility to active sites, without loss of physico-chemical properties characteristic of conventional zeolites [15].

Into the state of art, there are only three main groups of layered zeolitic precursors related with the structures MWW [16, 17], FER [18, 19], and NSI [20] considering the International Zeolites Association (IZA) nomenclature, being the two last structurally also related with the CDO and CAS frameworks, respectively. From these precursors, it is possible to obtain other pillared and delaminated materials which will be below detailed. Additionally, in the last years, interesting layered materials were also obtained from MFItype sheets $[21,22]$. Into this review, the layered materials generated from MWW ordered precursors will be considered due to the peculiar structure of the MWW individual layers which favors their high hydrothermal stability and shape selectivity. These factors joined to the high accessibility of their active sites convert this family of MWW pillared and delaminated zeolites in excellent catalysts to carry out different reactive processes in which compounds with elevated molecular sizes are present as reactants, products, or reaction intermediates.

2.1. Layered $M W W(P)$ Zeolitic Precursors and Derived $3 D$ MWW Zeolites. The layered precursors with MWW topology is conformed by parallel and ordered zeolitic layers perpendicularly disposed to axis $c$, being $2.5 \mathrm{~nm}$ the thickness of each one in which $10 \mathrm{MR}$ sinusoidal channels are present along the plane $a b$ of the individual layers. Onto the external surface of each zeolitic sheet, there are an elevated amount of silanol groups $(\mathrm{Si}-\mathrm{OH})$ which reacts, after the calcination process, with the another silanols present in contiguous layers, covalently condensing between them and facilitating the formation of 3D MWW zeolitic structure. Due to the collapse of the layers, it is favored the generation of additional second pore system conformed by supercavities delimited by 12 -member rings (MRs) from the cups located in the surface of each individual MWW layer. In Figure 2, it is 


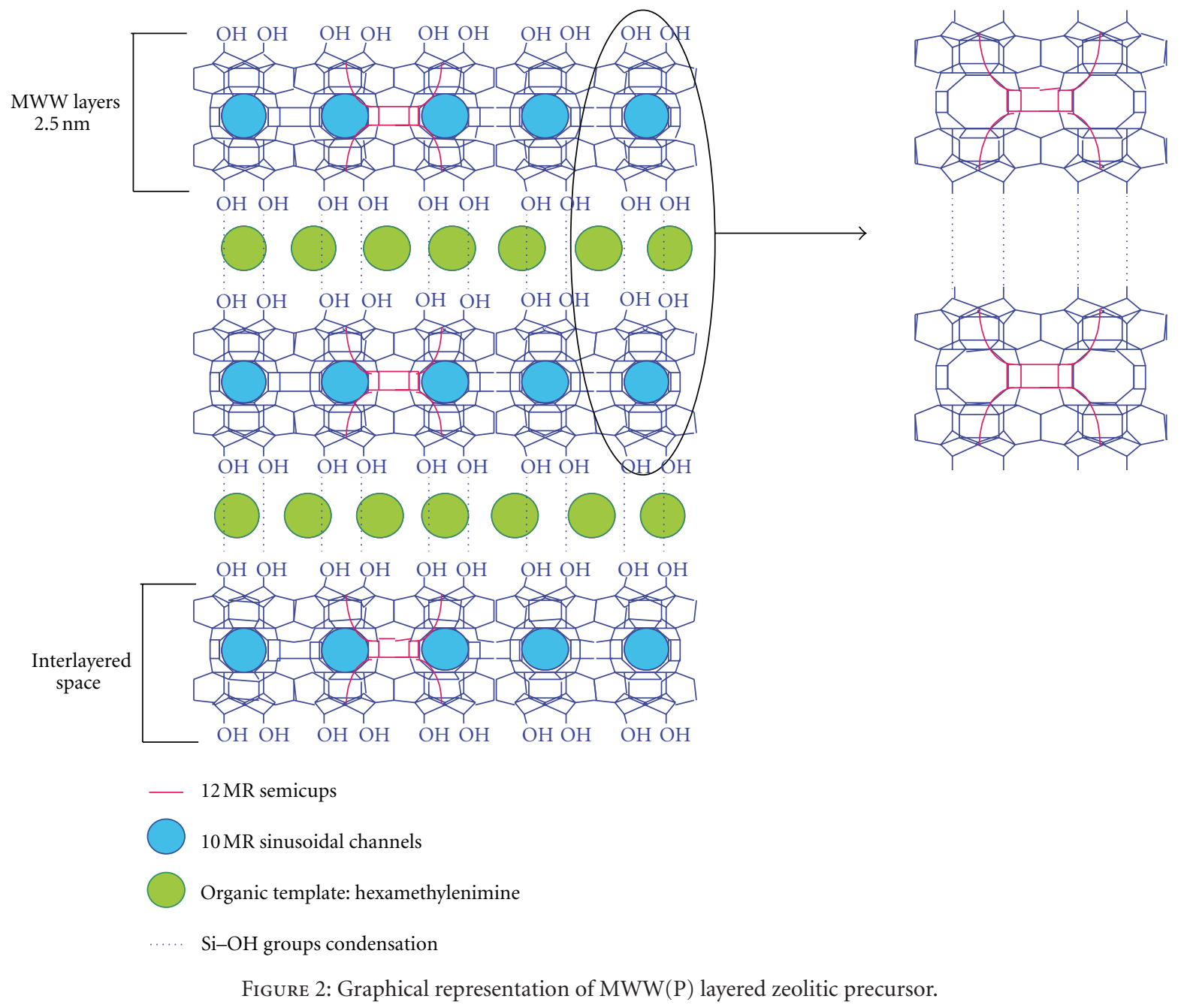

appreciated the detailed structure of this layered $\mathrm{MWW}(\mathrm{P})$ zeolitic precursor [27].

From X-ray diffraction, it is possible to evidence the collapse of the individual MWW layers after the removing of the organic template to generate a 3D zeolitic material (Figure 3). It is observed that the diffraction bands (OOl) disappear after the calcination process because these bands are indicative of the separation between the layers perpendicularly organized along to axis $c$. On the contrary, the diffraction bands ( $h 00),(0 k 0)$, and $(h k 0)$, which are intrinsic to the framework of the MWW layers, remain in the same $2 \theta$ position before and after the elimination of the interlayered template. So, Figure 3, it is appreciated that the (001) and (002) bands present in the MWW $(\mathrm{P})$ pattern, corresponding to $2.85 \mathrm{~nm}$ of separation between two contiguous layers (layer thickness plus space occupied by the organic template), disappear when the template is removed and the MWW layers are covalently connected between them [28].

The 3D MWW zeolitic material obtained after the elimination of the organic template was patented as MCM-22, in 1990 , by Rubin [31], being this structure identical to other aluminosilicate $\mathrm{PSH}-3$ previously synthesized by Puppe et al. in 1984 [32]. Both zeolites are prepared using hexamethylenimine (HMI) as structural directing agent (SDA). Studies carried out by Leonowicz et al. confirmed that the MCM-22 structure is conformed by two independent porous systems, being both accessible through $10 \mathrm{MR}$ windows. One of these systems is defined by sinusoidal and bidirectional channels with $0.52 \mathrm{~nm}$ of internal diameter. The second porous system is based on supercavities with a free internal diameter close to $0.71 \mathrm{~nm}$ delimited by $12 \mathrm{MR}$, exhibiting an internal height of $1.82 \mathrm{~nm}$. The consecutive supercavities are connected between them through $10 \mathrm{MR}$ windows. In Figure 4, it is schematically shown the structure of the zeolite MCM-22, being pointed out the two independent porous systems.

The layered $\mathrm{MWW}(\mathrm{P})$ zeolitic precursor is obtained with high crystallinity up to Si/Al molar ratios between 15 and 70 , and conforming the aluminum content decreases into the synthesis gel $(\mathrm{Si} / \mathrm{Al}>70)$ then type MFI phases are detected as impurities. Normally, the synthesis is performed in alkaline medium, using sodium as a charge compensating cation [36]. The hydrothermal crystallization occurs between 7 and 12 days at $135-150^{\circ} \mathrm{C}$ if the process is carried out in agitation conditions [37]. On the contrary, if static 


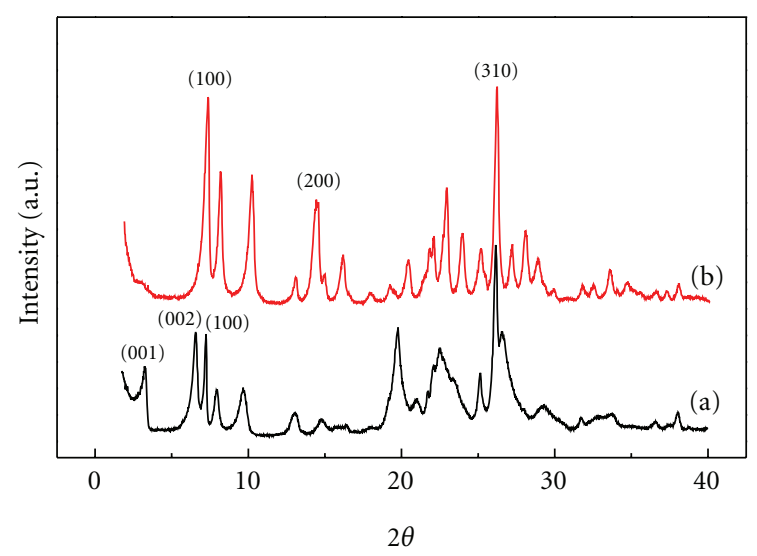

Figure 3: X-ray diffractograms of (a) MWW(P) and (b) MWW collapsed 3D structure obtained before and after the calcination process, respectively.

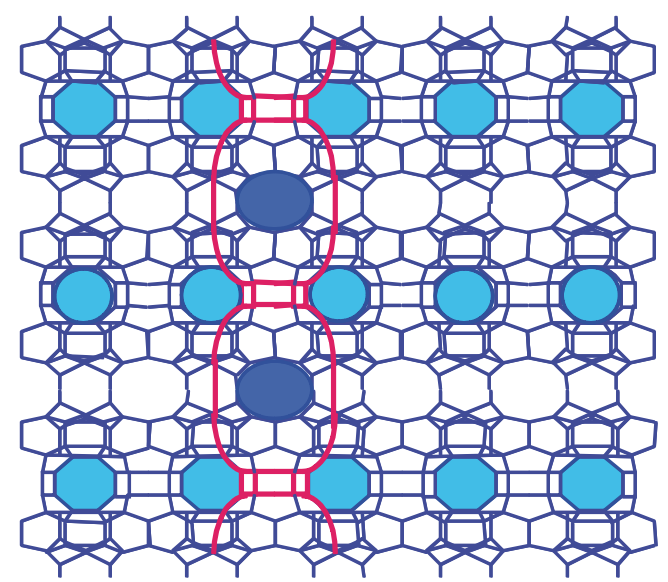

10 MR sinusoidal channels

$10 \mathrm{MR}$ windows connecting supercavities

_ Supercavities delimited by $12 \mathrm{MR}$

FIGURE 4: Graphical representation of zeolite MCM-22.

conditions are employed, the $\mathrm{MWW}(\mathrm{P})$ crystallization is more complicated, being possible the coexistence of another zeolitic phases such as Ferrierite or Mordenite [38]. However, in the last years, it has been reported the preparation of this zeolitic precursor in static conditions by previous aging of the synthesis gel at temperatures higher than $180^{\circ} \mathrm{C}$ during $4-12 \mathrm{hr}[39]$.

In 1987, Zones patented the aluminosilicate named as SSZ-25 which exhibited similar characteristics to MWW materials [43]. Initially, it was supposed that this material was formed by only one type of porous channel delimited by $12 \mathrm{MR}$ [44]. But, Aguilar et al. clearly confirmed that the SSZ-25 is an isomorphic material of MCM-22, being also obtained through the collapse of the previous synthesized layered zeolitic precursors. In this case, during the preparation of the SSZ-25 precursor, it was used potassium

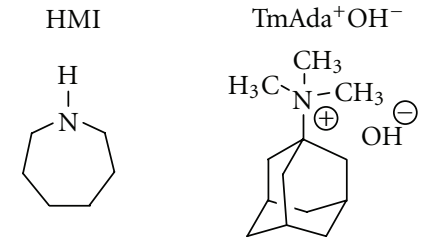

Scheme 1: Organic templates used during the synthesis of layered ITQ-1 zeolitic precursors: Hexamethylenimine (HMI) and Trimethyladamantamonium hydroxide $\left(\mathrm{TMAda}^{+} \mathrm{OH}^{-}\right)$.
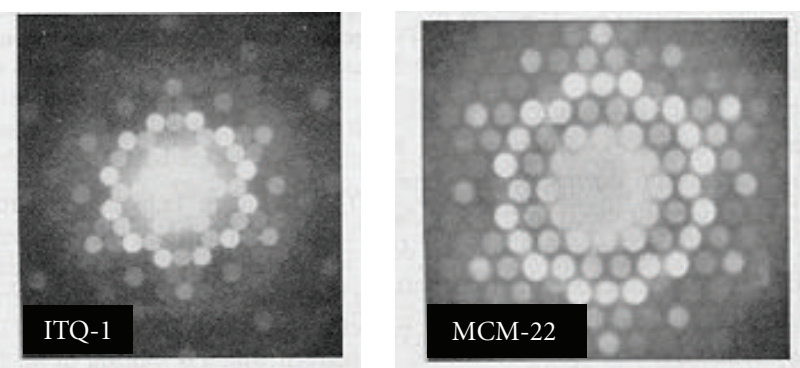

FIGURE 5: Microdiffraction spectra of ITQ-1 and MCM-22 zeolites along axis [001] (according to [11]).

instead of sodium. Moreover, the ADE employed was trimethyladamantamonium hydroxide $\left(\mathrm{TMAda}^{+} \mathrm{OH}^{-}\right)$, and not HMI, together with the presence of aluminum [45].

On the other hand, it was obtained the zeolite ITQ-1 which is also isostructural to MWW materials, being remarkable that this material is obtained from a purely siliceous layered MWW zeolitic precursor [49]. This fact represented an important novelty because the $\mathrm{MWW}(\mathrm{P})$ materials were always prepared in the presence of metallic trivalent cations [50]. During the synthesis process of ITQ-1 precursors, it is necessary to employ a mixture of two organic templates such as $\mathrm{TMAda}^{+} \mathrm{OH}^{-}$and HMI in alkaline medium (sodium cations). Specifically, the HMI molecules stabilize the $10 \mathrm{MR}$ sinusoidal channels present in the inner of MWW layers, and the TMAda ${ }^{+}$cationic species allow the formation of external cups delimited by $12 \mathrm{MR}$ located in the surface of the zeolitic sheets (Scheme 1). All these particularities were decisive to prepare MWW precursors highly crystalline with the absence of structural defects [51]. Different attempts were performed to introduce tetrahedral titanium into the structure of the purely siliceous ITQ-1 precursors, directly in the synthesis route, but the alkaline conditions present in the gel prevented the effective incorporation of titanium into the zeolitic network due to the fast precipitation of amorphous titanium silicates in this medium [52]. Additionally, combined studies of high-resolution transmission microscopy and X-ray microdiffraction confirmed unambiguously that MCM-22 and ITQ-1 materials showed identical structuration. Figure 5 shows the microdiffraction spectra of both $3 \mathrm{D}$ zeolites along to axis [001], corroborating that the symmetry P6 $\mathrm{mm}$ is the same in the two materials [11]. 


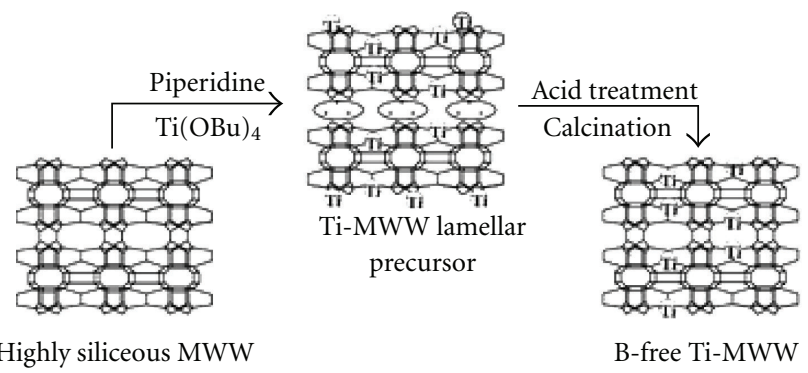

Figure 6: Synthesis route to obtain B-free Ti-MWW layered precursors (according to $[12,13])$.

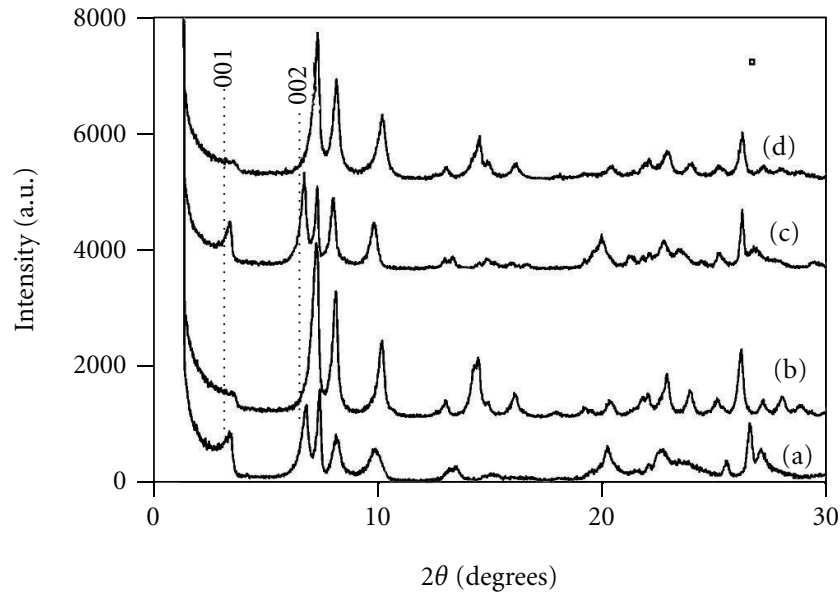

Figure 7: X-ray diffraction diffractograms of as-synthesized BMWW (Si/B = 11) (a), deboronated MWW (Si/B > 1000) (b), TiMWW $(\mathrm{Si} / \mathrm{Ti}=30)$ precursor $(\mathrm{c})$, and sample $\mathrm{c}$ treated with $2 \mathrm{M}$ $\mathrm{HNO}_{3}$ and calcined (d) (according to $[12,13]$ ).

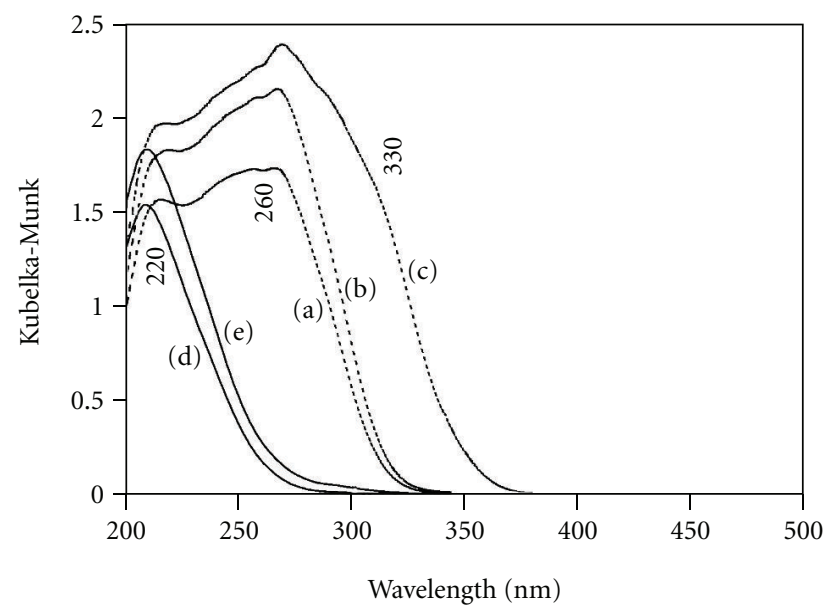

FIGURE 8: UV-visible spectra of as-synthesized Ti-MWW with Si/Ti

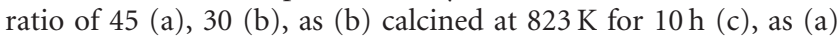
treated with $2 \mathrm{M} \mathrm{HNO}_{3}$ and calcined (d), and as (b) treated with $2 \mathrm{M} \mathrm{HNO}_{3}$ and calcined (e) (according to $[12,13]$ ).

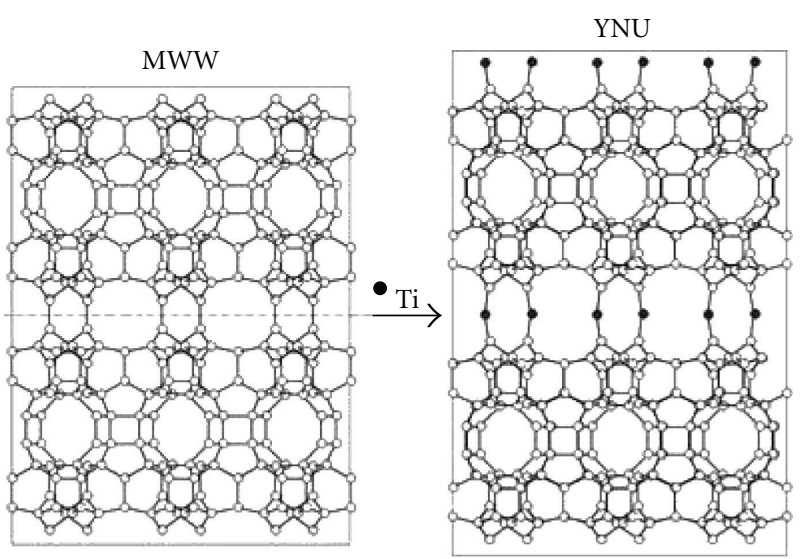

FIgURE 9: Transformation of Ti-MWW and Ti-YNU-1 materials (according to $[14]$ ).

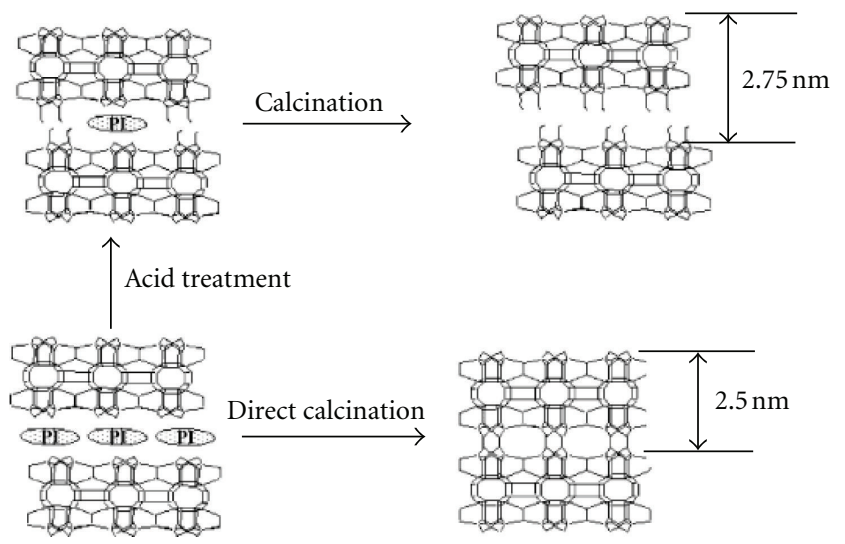

Figure 10: Formation of Ti-YNU-1 and 3D Ti-MWW, as well as their structures (according to [23]).

In 1988, Bellusi et al. prepared the microporous borosilicate named ERB-1 which is isostructural with the aluminosilicate MCM-22, being also obtained through a layered zeolitic precursor conformed by ordered MWW layers [64]. After calcination process, it is obtained the 3D MWW boron zeolite due to the removing of SDA molecules and the collapsing of the individual sheets. In this case, piperidine was used as template instead of HMI or TMAda ${ }^{+}$employed during the synthesis of MCM-22, SSZ-25, or ITQ-1. It is possible to incorporate boron in this layered borosilicate up to Si/B molar ratio of approximately 12 , being detected that different dense phases are obtained if the boron concentration is strongly reduced in the synthesis gel $(\mathrm{Si} / \mathrm{B}>50)$. Aluminum was also incorporated into the precursor network of ERB-1 materials together with the tetrahedral boron, although a high content of aluminum implies a marked decrease in the boron incorporation [65]. The influence of the sodium cations in the crystallization of ERB-1 layered precursor is not significant because in the final products it is not detected as a compensating charge ion. This fact would allow that layered zeolitic precursors with boron MWW topology could be obtained in the absence of alkaline metals, favoring the direct incorporation of tetrahedral titanium into 

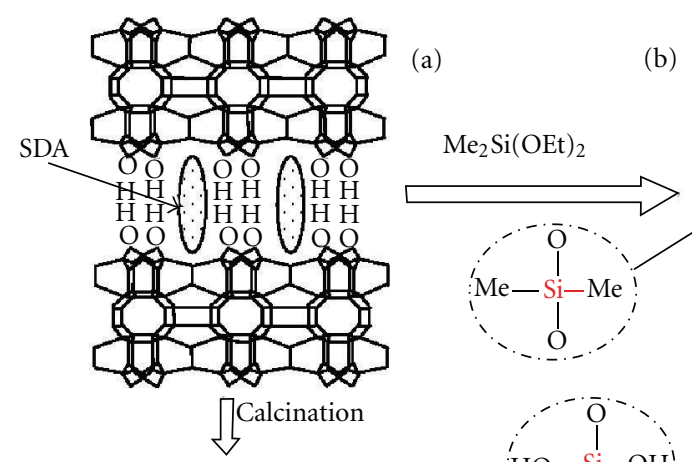

(b)
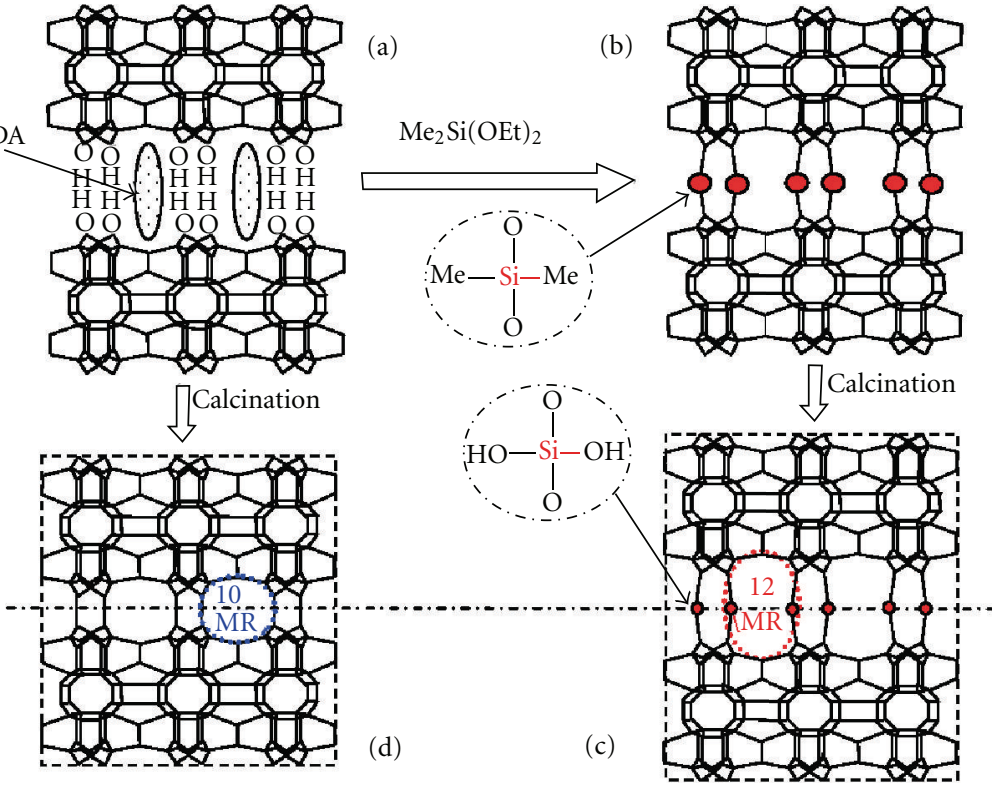

FIGURE 11: Synthesis route to obtain IEZ-MWW materials by postsynthesis treatments using dialkoxysilylated precursors (according to [24]).

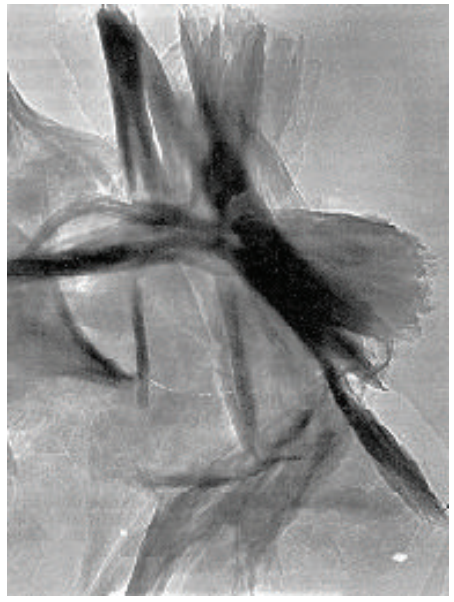

(a)

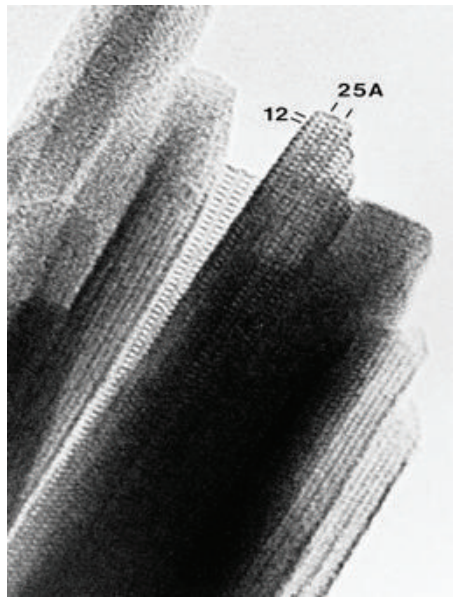

(b)

FIGURE 12: HRTEM micrographs of MCM-56 (a) (according to $[25,26]$ ) and MCM-22 (b).

the framework of this type of $2 \mathrm{D}$ materials. It is known that the presence of alkaline cations in the synthesis slurry facilitates the amorphous silicotitanates precipitation which avoids the integration of tetrahedral titanium coordinated into the network of zeolitic layers [71], being this factor not relevant in the preparation of ERB-1 layered precursors. $\mathrm{Wu}$ et al., considering this fact, synthesized, in the first time, crystalline MWW precursors containing the individual zeolitic sheets simultaneously both boron and titanium which are tetrahedrally coordinated, exhibiting $\mathrm{Si} / \mathrm{B}$ and $\mathrm{Si} / \mathrm{Ti}$ molar ratios of 12 and 51, respectively, in the final structure $[12,13]$.

Advancing inside this approach, it was prepared, from ERB-1 precursors, B-free titanosilicates with the MWW topology (Ti-MWW). In this case, the synthesis first involved the preparation of ERB-1 using piperidine or hexamethylenimine following the methods above exposed. Nextly, the borosilicates were deboronated by calcinations followed by different acid extraction steps to obtain highly siliceous solids. The silicates obtained were treated with titanium alkoxide sources in an aqueous solution of cyclic amines such as piperidine, hexamethylenimine, pyridine, and piperazine. The materials finally synthesized were a B-free zeolites with a conventional MWW lamellar organization containing tetrahedrally titanium coordinated conforming the framework of the individual zeolitic layers (Figure 6), being obtained Ti-MWW precursors through a novelty reversible structural conversion [72]. In Figure 7, X-ray patterns of the TiMWW precursors and the intermediate materials obtained during the synthesis route are shown. It is remarkably that 


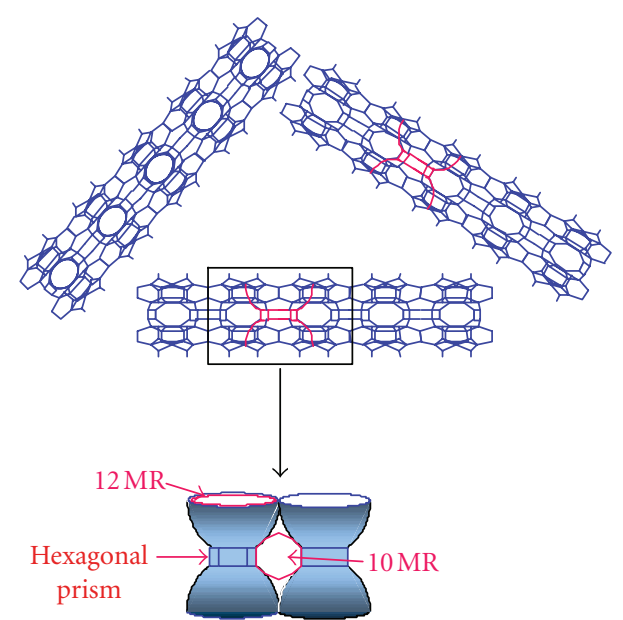

FIGURE 13: Graphical representation of the ITQ-2 delaminated zeolite.

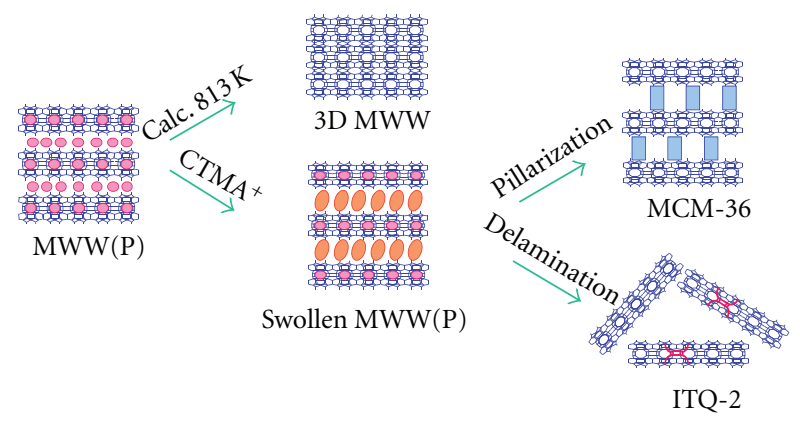

FIGURE 14: Preparation route to obtain ITQ-2 delaminated zeolite.

a final acid after the treatment of the Ti-MWW precursors is effective to remove the extraframework octahedral $\mathrm{Ti}$ species, while the tetrahedral remain even after calcination processes (Figure 8) [73]. These last lamellar titanosilicates were denoted as Ti-YNU-1 which showed a more expanded pore window between the crystalline MWW sheets due to the generation of two additional $\mathrm{T}$ sites in the interlayer space, favoring an expansion in the $c$ direction. In this material, a newly formed $12 \mathrm{MR}$ channel that is distinct from the $10 \mathrm{MR}$ of the MWW structure was detected after the removing of SDA molecules, explaining this cell expansion. Ruan et al. speculated that Ti centers could occupy the pillar sites, which have a higher steric accessibility than network positions in conventional 3D MWW or TS-1 materials (Figure 9) [14]. However, it is possible that, after the acid posttreatments carried out in the Ti-MWW precursors, stacking faults occur between the zeolitic layers in the final Ti-YNU-1 materials probably due to the presence of a high amount of silanol groups related to defect sites not occupied by Ti (Figure 10) [23]. This acid postsynthesis treatments and the reversible structural conversion from MWW precursors above exposed could be applicable to the preparation of another metalosilicates, not only containing tetrahedral titanium, as new layered materials with catalytic applications [74]. Some of the Ti-MWW precursors here described have

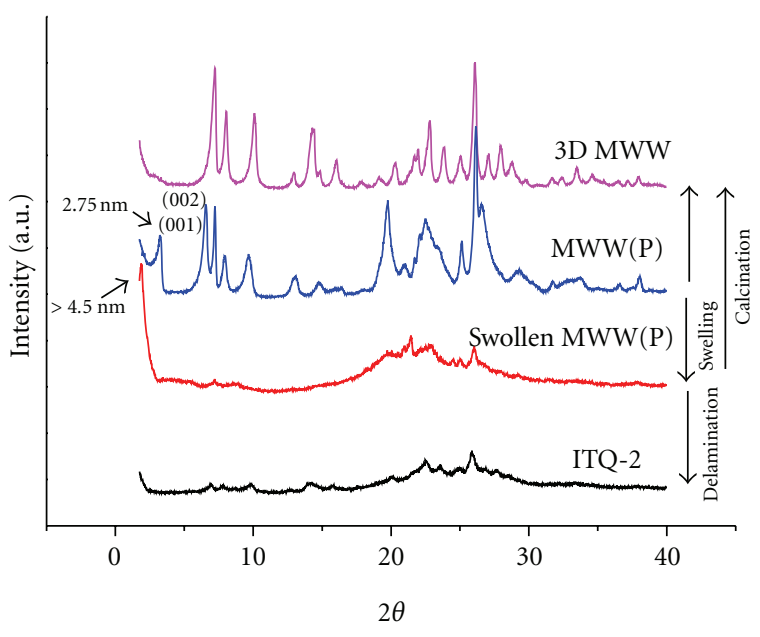

Figure 15: X-ray patterns of the layered MWW materials obtained during the preparation of ITQ-2 delaminated zeolite.

been exfoliated as will be shown in future sections of this paper.

Following the same structural approach considered by Tatsumi et al. in the Ti-YNU-1 materials above described, a new type of stabilized interlayer-expanded MWW zeolitic materials (IEZ-MWW) has been prepared by the intercalation in the interlayer space of monomeric silica puncheons between the individual MWW layers as small pillars conformed by only one silicon atom, using normally $\mathrm{SiMe}_{2} \mathrm{Cl}_{2}$ or $\mathrm{Si}(\mathrm{EtO})_{2} \mathrm{Me}_{2}$ as stabilizer agents which react with the external surface silanol groups. This way allowed, after the removing of SDA molecules through calcination processes, the generation of derived MWW materials with a novel $12 \mathrm{MR}$ microporous channel between the inorganic sheets in which the strong acidity of zeolitic nature was preserved (Figure 11). Specifically, the silylation carried out facilitates that the new type of MWW materials obtained exhibits structures with more accessible porosity, being this evidenced by the shift observed in the diffraction bands to the lower-angle region in the XRD patterns and the enlarged interlayer pores found by HRTEM images. Recently, vapor-phase silylation was used to obtain this type of IEZ-MWW layered materials [75]. This methodology has also been applied in other layered zeolitic precursors conformed by ferrieritic or CDO individual sheets [24]. Additionally, tetrahedral coordinated titanium, into the network of each MWW layers of the expanded zeolites, has also been introduced by the previous synthesis of Ti-MWW precursors in the presence of boron sources [76].

It is remarkable that different layered precursors were prepared containing tetrahedrally coordinated metals incorporated into the framework of the individual MWW layers, such as gallium [81], vanadium [82], lanthanum, or cerium [83]. Normally, the incorporation of the metallic species was achieved by hydrolysis and condensation of silicon reagents with metallic salts in moderate acidic media followed by a switch of synthesis slurries to basic conditions for hydrothermal conditions. 
On the other hand, there are other tridimensional zeolites with MWW topology which are not obtained through layered precursors, but directly during the synthesis process, such as MCM-49 [84, 85]. In this case, it was concluded that the $\mathrm{HMI} / \mathrm{Na}^{+}$molar ratio in the synthesis gel or the previous aging step favors the direct crystallization of collapsed MWW materials [86, 87]. Additionally, the MCM-56 zeolites are structurally similar to MCM-22, being obtained directly during the synthesis processes, such as MCM-49 [88]. However, in this material was observed a partial disordered organization due to the presence of curved packs of MWW sheets which provide a higher surface area compared with the 3D MCM-22 (Figure 12) [25, 26]. Recently, Corma et al. have prepared the zeolite named ITQ-30 which is similar to MCM-56 by high-throughput synthesis techniques and using $\mathrm{N}(16)$-methyl-sparteinium as SDA [89]. Similarly, Roth et al. have reported a new member of the MWW family named EMM-10 in which the layers are stacked without vertical alignment, using diquaternary ammonium molecules as template [90]. In these last cases, the analysis structural carried out between the MCM-56, ITQ-30, and EMM-10 layered zeolites shows that they are similar, being only differenced for slight modifications in the spatial organization of the piled MWW layers perpendicularly disposed to axis $c$.

2.2. ITQ-2: The First Delaminated Zeolite. Inside the family of delaminated zeolitic materials, ITQ-2 was the first described into the state of art [91]. The preparation method is based on the swelling and exfoliation of the MWW layered zeolitic precursors, previously synthesized, previously described. The solid obtained is formed by individual MWW layers of, approximately, $2.5 \mathrm{~nm}$ of thickness, exhibiting a high external and accessible surface area $\left(>700 \mathrm{~m}^{2} \mathrm{~g}^{-1}\right)$. The nanolayers are structured by a hexagonal distribution of "cups" present in both sides of the zeolitic sheets. These calices are delimited by $12 \mathrm{MR}$, showing an outer aperture of, approximately, $(0.7 \times 0.7) \mathrm{nm}$ and being connected with the cups of the opposite side, into the same MWW layer, through the double $6 \mathrm{MR}$ with a hexagonal prism conformation. Additionally, sinusoidal channels delimited by $10 \mathrm{MR}$ are present around the calices, along the internal part of each individual MWW layer. In Figure 13, it is shown the representation of the ITQ-2 delaminated zeolite.

The preparation procedure is illustrated in Figure 14 [48]. Specifically, a first swelling step is carried out using MWW zeolitic precursors in the presence of alkylammonium molecules, containing long hydrophobic chains, which act as swelling agents. Normally, hexadecyltrimtehylammonium $\left(\mathrm{CTMA}^{+} \mathrm{OH}^{-}\right)$or tetrabutylammonium $\left(\mathrm{TBA}^{+} \mathrm{OH}^{-}\right)$is used to realize this function to separate the zeolitic sheets. The swelling process can be followed by X-ray diffraction because the low-angle patterns show a marked increase in the basal space estimated from the first diffraction bands which are representative of the layered order and the interlayer separation. For example, in the case of $\mathrm{CTMA}^{+} \mathrm{OH}^{-}$, the basal space is modified from $2.7 \mathrm{~nm}$ up to $4.5 \mathrm{~nm}$, approximately, due to the intercalation of the swelling molecules

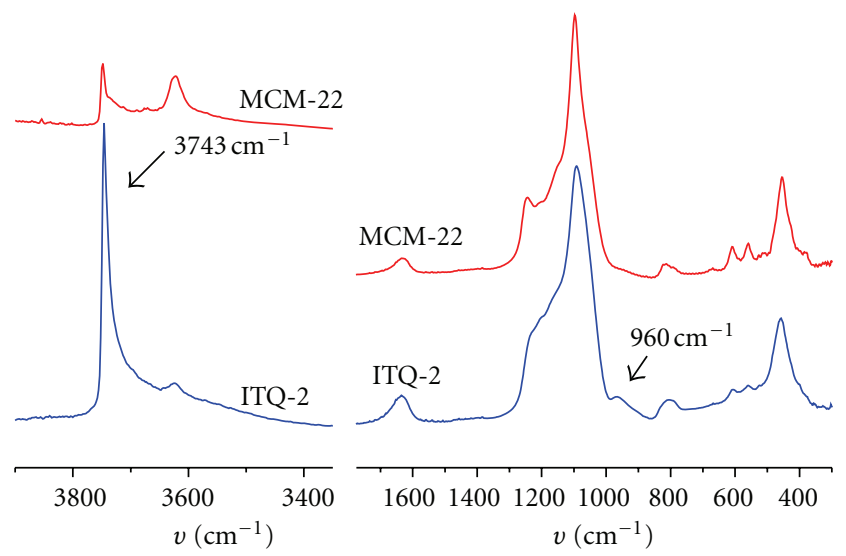

FIGURE 16: Infrared spectra of the 3D MWW and ITQ-2 zeolitic materials.

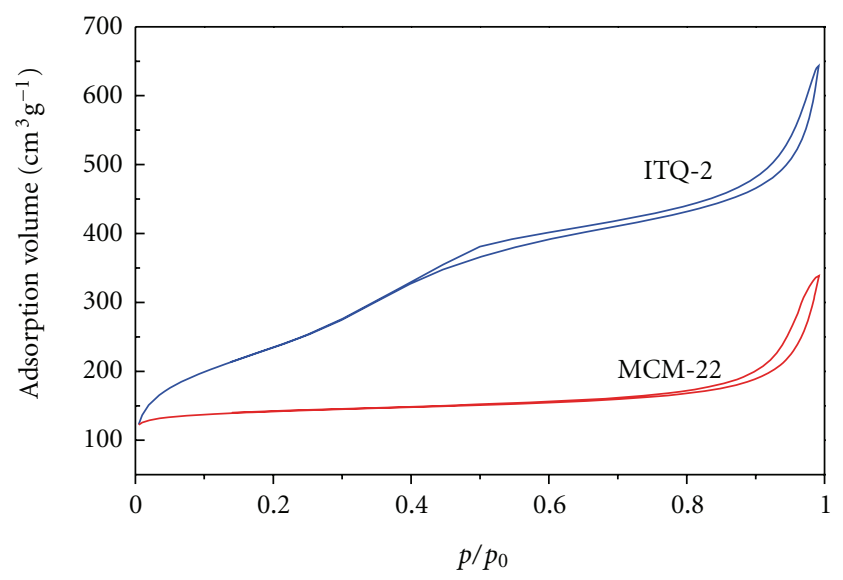

Figure 17: Nitrogen adsorption-desorption isotherms of the delaminated ITQ-2 and 3D MWW zeolites.

between the MWW layers (Figure 15). Nextly, the swollen zeolitic precursor is exfoliated through a delamination step, being possible the complete random separation in the space of the individual layers to obtain finally the zeolitic material conformed by disordered MWW sheets. This step is carried out using, preferably, ultrasonic techniques or other mechanical processes, such as vigorous stirring. Finally, the solid is recovered by successive centrifugation washings. The last step to obtain ITQ-2 delaminated materials consists in the calcination process $(813 \mathrm{~K})$ to remove the excess of organic molecules which remain from the swelling step. It is important to point out that, during the preparation route, it is decisive to control carefully the $\mathrm{pH}$ and the swelling temperature because when the synthesis is performed to $\mathrm{pHs}$ and temperatures higher than 12.5 and $80^{\circ} \mathrm{C}$, respectively, in the presence of $\mathrm{CTMA}^{+} \mathrm{OH}^{-}$, then it is favored the generation of the M41S amorphous mesoporous materials which are prepared in similar alkaline conditions together with the intervention of surfactant molecules. On the contrary, when the $\mathrm{pH}$ and swelling temperatures are lower than 12.5 and $80^{\circ} \mathrm{C}$, then the delamination process does not satisfactorily occur. 


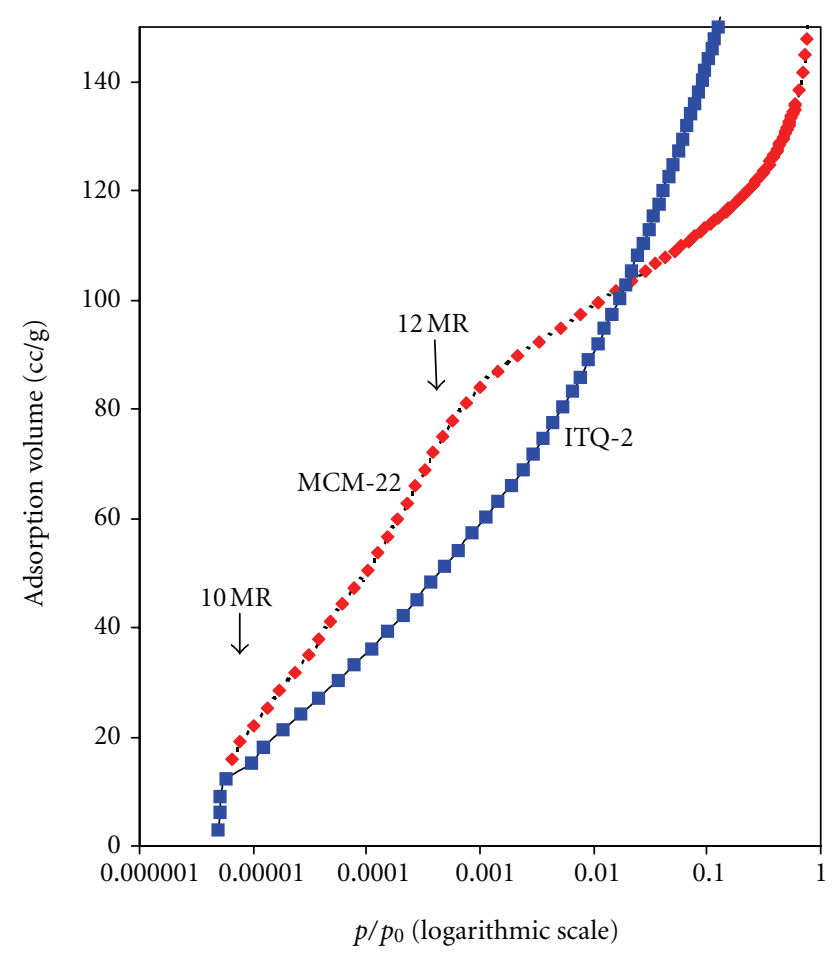

FIGURE 18: Ar adsorption isotherms of delaminated ITQ-2 and 3D MWW zeolites.

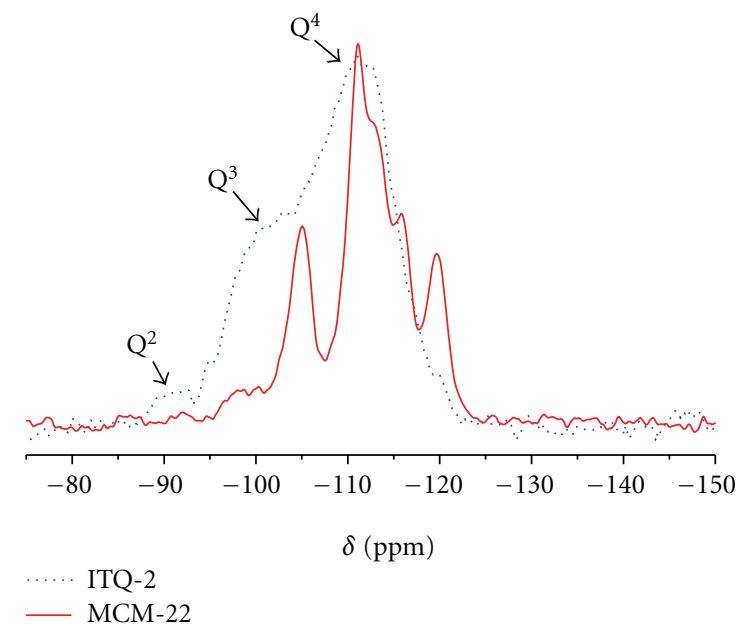

FIgURE 19: ${ }^{29} \mathrm{Si}$ NMR spectra of the ITQ-2 and 3D MWW zeolites.

Figure 15 shows the X-ray diffractograms of the different layered zeolitic materials obtained during the preparation of delaminated MWW solids [92]. Specifically, the ITQ-2 pattern does not present the two bands (001) and (002) in the $2 \theta$ range between $3^{\circ}$ and $7^{\circ}$, being this due to the order spatial loss of the individual zeolitic layers which were previously ordered perpendicularly to axis $c$ in the starting MWW precursor. This result univocally confirms that the ITQ-2 does not exhibit the characteristic regular and periodic distribution of MWW layers separated between them by $2.75 \mathrm{~nm}$ such as correspond to zeolitic materials conformed
TABle 1: Lewis y Brönsted acid sites measured by pyridine adsorption-desorption method for 3D MWW and ITQ-2 materials ${ }^{\mathrm{a}}$.

\begin{tabular}{lcccccc}
\hline \multirow{2}{*}{ Sample } & \multicolumn{5}{c}{ Acidity $\left(\mu \mathrm{molPy} \cdot \mathrm{g}^{-1}\right)$} \\
& \multicolumn{2}{c}{$150^{\circ} \mathrm{C}$} & \multicolumn{2}{c}{$250^{\circ} \mathrm{C}$} & \multicolumn{2}{c}{$350^{\circ} \mathrm{C}$} \\
& Lewis & Brönsted & Lewis & Brönsted & Lewis & Brönsted \\
\hline MWW & 23 & 39 & 15 & 24 & 14 & 15 \\
ITQ-2 & 23 & 21 & 20 & 15 & 15 & 9 \\
\hline
\end{tabular}

absorption coefficients: Lewis $\left(1455 \mathrm{~cm}^{-1}\right): 2.22 \mathrm{~cm} / \mu \mathrm{mol}$ and Brönsted $\left(1545 \mathrm{~cm}^{-1}\right): 1.67 \mathrm{~cm} / \mu \mathrm{mol}[29]$.

by disordered nanosheets. Moreover, in the ITQ-2 pattern are observed broad diffraction bands compared with the 3D MWW zeolites with the same Si/Al molar ratio, being this fact due to the strong crystal size reduction combined with the long order loss consequence of the delamination process. It is also remarkably that the diffraction bands observed in the ITQ-2 diffractogram, although the intensity appreciated is low, correspond to diffraction bands (hk0) representative of the planes $a b$ of each individual MWW layers. This fact confirms that the zeolitic framework of the sheets is preserved during the performed exfoliation route.

The appreciated characteristics observed for the ITQ-2, above commented, were completely confirmed from other spectroscopic techniques such as FT-IR. Comparing the IR spectra of the ITQ-2 and 3D MWW calcined materials shown in Figure 16, it is observed a strong increase in the amount of silanol groups (bands focused at 3743 and $960 \mathrm{~cm}^{-1}$ ) present in the delaminated material which are located in the high external surface of the individual MWW layers. Additionally, it is observed, in the delaminated material, a decrease in the total amount of Brönsted acid sites due to the presence of tetrahedral coordinated aluminum (band at $3623 \mathrm{~cm}^{-1}$ ), being this due to a partial dealumination phenomenon occurred during the exfoliation process. Consequently, it is detected a diminution in the amount of Brönsted acid sites measured by pyridine adsorption-desorption method (Table 1).

Spectroscopic studies related with the acidity of ITQ2 were carried out by Onida et al., considering several samples of ITQ-2 with different $\mathrm{Al}$ content $(\mathrm{Si} / \mathrm{Al}=50$ and 25 ) and different exfoliation degree, being characterized by IR spectroscopy and compared to 3D MWW zeolites with the same $\mathrm{Al}$ content, to evaluate the difference established between the acid sites in the function of the accessibility associated to delamination processes. Brönsted acidity was measured as the propensity of $\mathrm{OH}$ species to either protonate ammonia or captures in $\mathrm{H}$-bonds with suitable molecules (CO, $\mathrm{N}_{2}, n$-heptane, olefins, and aromatics). On the other hand, Lewis acidity was evaluated by measuring the spectra of $\mathrm{CO}$ adsorbed at room temperature. Comparison with 3D MWW samples showed that no appreciable loss in Brönsted acidity took place due to the delamination, although the bridged species $\mathrm{Si}(\mathrm{OH}) \mathrm{Al}$ exposed at the external surface disappeared, being probably converted into additional $\mathrm{AlOH}$ acid sites (Scheme 2). These species were not directly detectable through IR spectra, but indirect probes suggested 


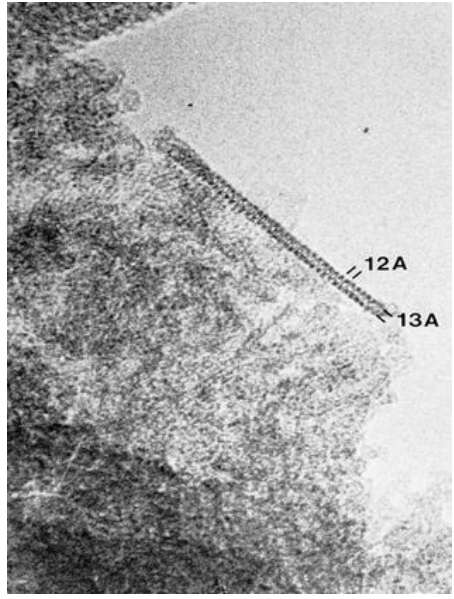

(a)

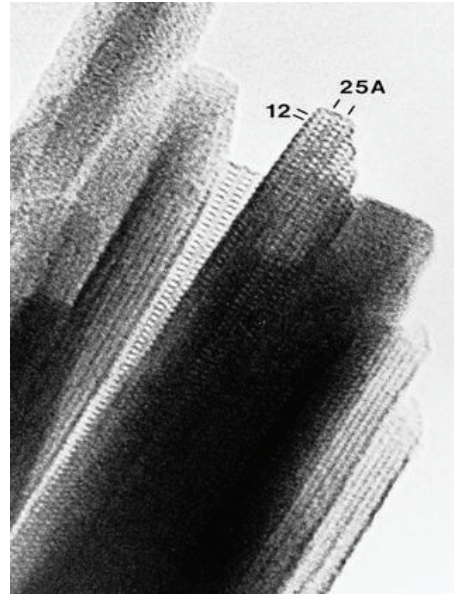

(b)

FIgURE 20: TEM micrographs of (a) ITQ-2 and (b) 3D MWW zeolites.

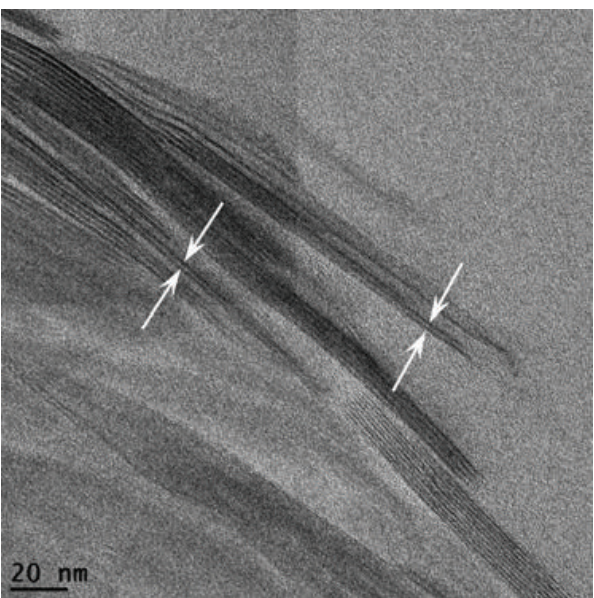

Figure 21: TEM image of as-made UCB-1 material (according to [33]).

their location at the external semicups present in the MWW external surface. Additionally, bridged $\mathrm{Si}(\mathrm{OH}) \mathrm{Al}$ species were also detected in the sinusoidal 10-MR channels included into each individual MWW layers. Definitively, external $\mathrm{AlOH}$ acidic species together with residual $\mathrm{Si}(\mathrm{OH}) \mathrm{Al}$ sites may be responsible for the catalytic efficiency of ITQ-2 delaminated zeolites [30, 93].

Inside the IR studies, the nature of external $\mathrm{SiOH}$ species present in all-silica ITQ-2 and conventional mesoporous MCM-41 materials was compared through their respective equilibrium constants of the interaction with different bases. The results showed that the $\mathrm{O}-\mathrm{H}$ stretching frequency and acidity were rigorously the same in both materials with $\mathrm{NH}_{3}$ and CO. Acetone with MCM-41 exhibited a higher O-H shift and a larger equilibrium constant. These appreciable differences were attributed to secondary interactions between $\mathrm{H}$ bonded acetone and the surrounding of the $\mathrm{SiOH}$ species, favored by the curved topology of the MCM-41 mesoporous walls, being this effect not detectable in the ITQ-2 due to the crystalline zeolitic nature of the external surface [94].
The nitrogen adsorption isotherms showed in Figure 17 confirm that the ITQ-2 zeolite exhibits a high mesoporous volume and elevated external surface area, overall when these values are compared with the collapsed MWW zeolites (Table 2), being this in consonance with zeolitic materials conformed by individual layers with a random distribution in the space, such as a conventional house-of-cards topology [95]. The results obtained from argon adsorption isotherms (Figure 18) confirm that both the structures of delaminated and 3D MWW zeolites contain microporous with $\sim 0.5 \mathrm{~nm}$ of diameter which correspond to internal $10 \mathrm{MR}$ sinusoidal channels (adsorption close to $p / p_{0}$ of $\sim 5 \times 10^{-6}$ ). A second inflexion point is additionally observed in the calcined MWW isotherm close to $p / p_{0}$ of $\sim 5 \times 10^{-3}$ due to the pores which are forming the $12 \mathrm{MR}$ supercavities. On the contrary, this slope change in the Ar adsorption isotherms is not observed in ITQ-2 because the delamination process implies the disappearance of these cavities, remaining in the external surface of each individual MWW layer a regular distribution of "cups" from the no formed super-cavities [96].

Interesting studies confirmed that the textural properties of delaminated ITQ-2 materials are strongly influenced by the role of framework aluminum. Particularly, the amount of aluminum, finally present into the network of MWW layers, was considered during different ultrasound treatments employed as exfoliation technique. The results obtained showed that the delamination process is clearly favored by a decreasing of the aluminum concentration in the MWW starting precursors ( $\mathrm{Si} / \mathrm{Al}$ ratios $>20$ ) [97], being remarkable that both in the ITQ-2 and in the respective layered $\mathrm{MWW}(\mathrm{P})$, the aluminum remains in tetrahedral coordination. This fact occurs probably because $\mathrm{Al}$ is protected during the delamination process by the organic cations used in the layered MWW precursor synthesis [98].

Additionally, the ${ }^{29} \mathrm{Si}$ NMR spectra (Figure 19) show the important strong differences between the MWW microporous and delaminated zeolites. Specifically, the spectrum of the $3 \mathrm{D}$ calcined MWW materials presents the intense bands 


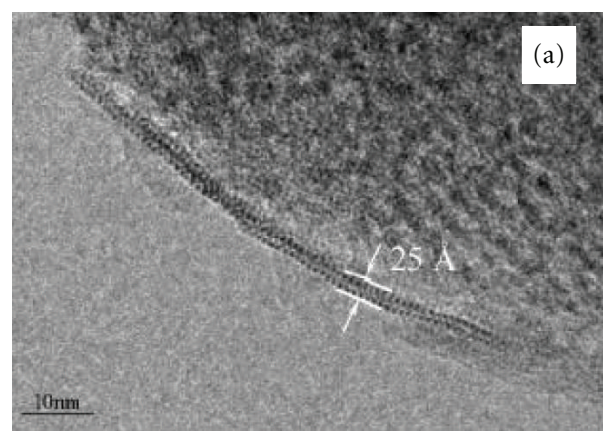

(a)

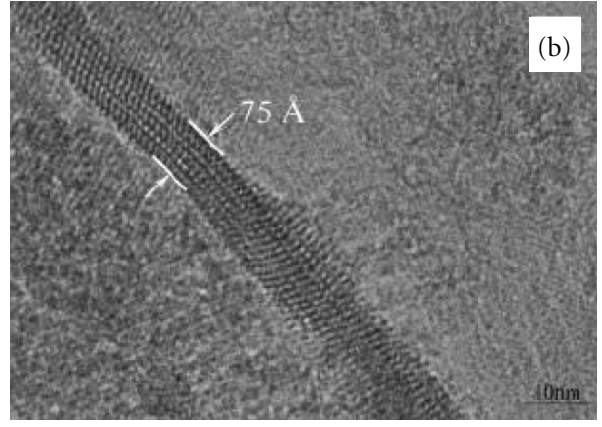

(b)

FIGURE 22: HRTEM micrographs of single sheet (a) and pack of three sheets (b) of Del-Ti-MWW (according to [34]).

TABLE 2: Textural properties of delaminated ITQ-2 and 3D MWW zeolites.

\begin{tabular}{lccccc}
\hline Samples & $S_{\text {BET }}\left(\mathrm{m}^{2} \cdot \mathrm{g}^{-1}\right)$ & $S_{\text {MIC }}\left(\mathrm{m}^{2} \cdot \mathrm{g}^{-1}\right)$ & $S_{\text {EXT }}\left(\mathrm{m}^{2} \cdot \mathrm{g}^{-1}\right)$ & $V_{\text {TOT }}\left(\mathrm{cc} \cdot \mathrm{g}^{-1}\right)$ & $V_{\text {meso }}\left(\mathrm{cc} \cdot \mathrm{g}^{-1}\right)$ \\
\hline MCM-22 & 453 & 342 & 111 & 0.524 & 0.169 \\
ITQ-2 & 840 & 50 & 790 & 0.948 & 0.853 \\
\hline
\end{tabular}

above $-100 \mathrm{ppm}$ corresponding to different crystallographic positions of $\mathrm{Si}(4 \mathrm{Si})$, that is, the $\mathrm{Q}^{4}$ silicon atoms. In the case of the ITQ-2 materials, this band is broaden, being also appreciated another intense band close to $-98 \mathrm{ppm}$ assigned to the appreciable amount of external silanol groups $\equiv \mathrm{Si}-\mathrm{OH}$, named $\mathrm{Q}^{3}$ silicon atoms which are located in the external surface area of each individual MWW layer and another additional band at $-92 \mathrm{ppm}$ due to the terminal geminal silanols, $=\mathrm{Si}(\mathrm{OH})_{2}, \mathrm{Q}^{2}$ silicon atoms present in the borders of the zeolitic nanosheets, as consequence of the generation of high accessible exfoliated materials with elevated external surface area through the delamination process.

The micrographs obtained from transmission electronic microscopy (TEM) allow the identification of MWW individual layers which are forming the delaminated ITQ-2 zeolite (Figure 20). It is possible to appreciate clearly both the homogeneous distribution of "cups" present in the external surface area of the zeolitic nanosheets, with a $(0.7 \times 0.7) \mathrm{nm}$ as dimensions, and the $10 \mathrm{MR}$ sinusoidal channels which are located along the internal part of the MWW layers. In comparison, in the 3D MWW zeolite, the external "cups" are connected between them, generating super-cavities delimited by 12 members' central rings. This characteristic morphology was confirmed by crystal structural studies from high-resolution powder X-ray diffraction data, using synchrotron radiation and employing Rietveld analyses for structure elucidation $[99,100]$.

Definitively, all the results obtained from the different characterization techniques, above exposed, clearly show that the ITQ-2 delaminated zeolite exhibits the characteristics and properties corresponding to high accessible zeolitic structure conformed by individual MWW layers with a random spatial distribution. The ITQ-2 combines the acidity and the hydrothermal stability characteristic of conventional zeolites together with the high accessibility to voluminous molecules typical of the mesoporous aluminosilicates such as M41S materials [101].

The strong alkaline conditions employed during the delamination process, overall in the swelling step, together with the ultrasonic exfoliating treatment favor the lowsilica yields obtained in the ITQ-2 materials due to the partial dissolution of MWW zeolitic layers. For this, different studies have been carried out trying to obtain well-defined and characteristic ITQ-2, employing soft conditions in the preparation method. In this sense, recently, Ogino et al. have synthesized the material so-called UCB-1 which is synthesized through the delamination of zeolite precursor MCM-22 (P), such as occurs in the conventional ITQ-2 zeolite, at pH 9 using an aqueous solution of cetyltrimethylammonium bromide, tetrabutylammonium fluoride, and tetrabutylammonium chloride. Characterization by powder $\mathrm{X}$-ray diffraction, transmission electron microscopy, nitrogen physisorption, ${ }^{29} \mathrm{Si}$ MAS NMR, and infrared spectroscopies showed similarities between UCB-1 and the previously reported delaminated ITQ-2 zeolitic material, which required a $\mathrm{pH}$ higher than 12.5 and strong sonication processes in order to achieve exfoliation. However, the reduced external surface area finally detected in the UCB1 materials, close to standard 3D MWW zeolites, would indicate that the disorder achieved with this methodology is not complete. Probably, crystals conformed by several packed and ordered MWW layers would be the individual units of this partially exfoliated material. Specifically, this methodology is based on exfoliation processes through chemical deprotection steps, involving the breaking of $\mathrm{Si}-\mathrm{O}$ and $\mathrm{Al}-\mathrm{O}$ bonds in the interlayer region. For this fluoride anion is used because it is an established reagent for the deprotection of silyl ethers and is known to form strong interactions to $\mathrm{Si}(\mathrm{IV})$ cations. Additionally, chloride is used because it is an aggressive anion for eroding anodized aluminum. So, the authors conclude hypothesizing that 

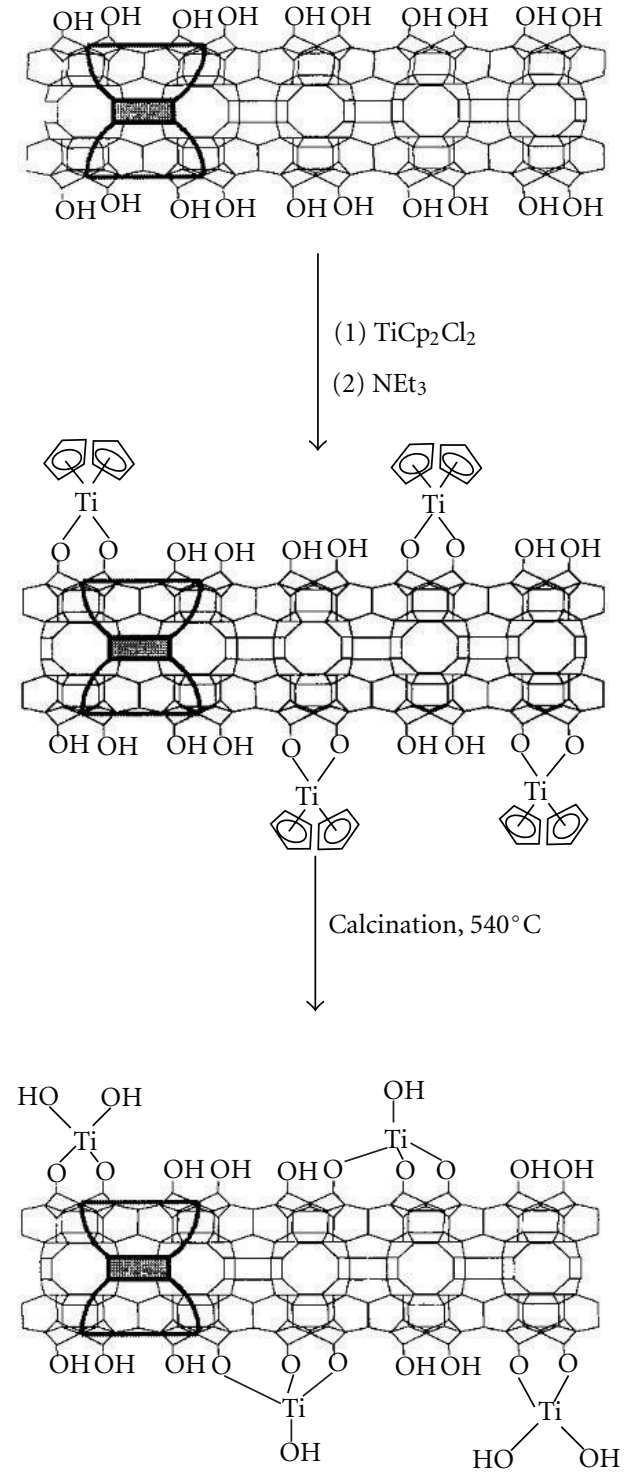

Figure 23: Grafting of titanocene on ITQ-2 external surface area (according to [35]).

delamination can be successfully conducted using a mixture of fluoride and chloride anions (Figure 21) [33].

Following this methodology based on the delamination of MWW layered precursors in soft conditions, Tsapatsis et al. identified the swelling step as decisive to avoid substantially the partial loss of crystallinity in each individual MWW layer following the standard conditions proposed by Corma et al. [102]. Specifically, the swelling method here employed did not alter drastically the crystal morphology and layer structure, preserving the nature of the MWW layers. For this, the MCM-22(P) swelling was carried out at room temperature. The low-temperature process did not disrupt the framework connectivity present in the parent MCM-22(P) material. The swollen material was partially exfoliated and the well-preserved layers were introduced into a polymer matrix to generate novel nanocomposites [42].
On the other hand, during the study above considered related with the description of MWW ordered precursors, it was remarked the preparation of Ti layered materials from Wu et al. after the combination of acidic and deboronation processes with the assistance of cyclic amine through postsynthesis treatments [72]. The delamination route carried out to exfoliate the Ti-MWW lamellar precursor allowed to obtain a new titanosilicate, named Del-Ti-MWW, with tetrahedral titanium presents into the framework of the individual zeolitic layers which was incorporated directly during the synthesis process. The delamination experiments performed with this Ti-MWW precursor showed that the amount of organic base used for supporting surfactant in swelling the layered structure should be controlled carefully to delaminate efficiently without collapsing and destroying the zeolitic structure. Moreover, additional ultrasound treatments were demonstrated as useful to exfoliate completely the swollen materials, such as it was previously indicated for the conventional purely siliceous ITQ-2 or with tetrahedral aluminum into its network. In fact, delaminated Ti-MWW zeolites were prepared with elevated surface area, higher than $1000 \mathrm{~m}^{2} \mathrm{~g}^{-1}$. The success of the delamination process was completely confirmed from TEM images which showed crystalline materials conformed by fewer sheets than 3D Ti-MWW, being even possible to appreciate single MWW sheets (Figure 22) [34]. This method could be a serious alternative to incorporate active titanium into the framework of delaminated MWW materials directly during the synthesis process, avoiding postgrafting steps to covalently anchor, onto the external surface of MWW zeolitic layers, active titanium complexes such as titanocene, which partially blocked the free porous volume (Figure 23) [35].

In this last example, it has been shown that as the external surface area exhibited by the ITQ-2 delaminated materials can be used to covalently incorporate another organic active species, organocatalysts, through the numerous accessible $\mathrm{SiOH}$ groups located on the MWW individual layers, being generated novel organic-inorganic solid materials with multiple applications, overcoming the limitations imposed by the organic, soluble compounds related with their stability and recovering. Another illustrative example, related with the preparation of hybrid organic-inorganic exfoliated derivative materials, comes from the incorporation of heterogenized porphyrins and metaloporphyrins on robust solids such as purely siliceous ITQ-2 zeolites, acting as inorganic matrixes. In this case, two different strategies for preparation of these catalysts were studied, based on direct immobilization of a functionalized porphyrin (route A) or heterogenization of an aromatic aldehyde followed by porphyrin formation (route B). The results showed that route A leads stable materials, allowing the introduction of a higher amount of active metaloporphyrin onto the support (from 0.3 to $0.4 \mathrm{mmol} \mathrm{g}^{-1}$ ). On the contrary, route B was not successful for the porphyrin formation onto the external surface of the MWW layers (Scheme 3). Definitively, this methodology, through the anchoring of organic active and soluble compounds, would be useful to generate promising hybrid heterogeneous catalysts [46]. 

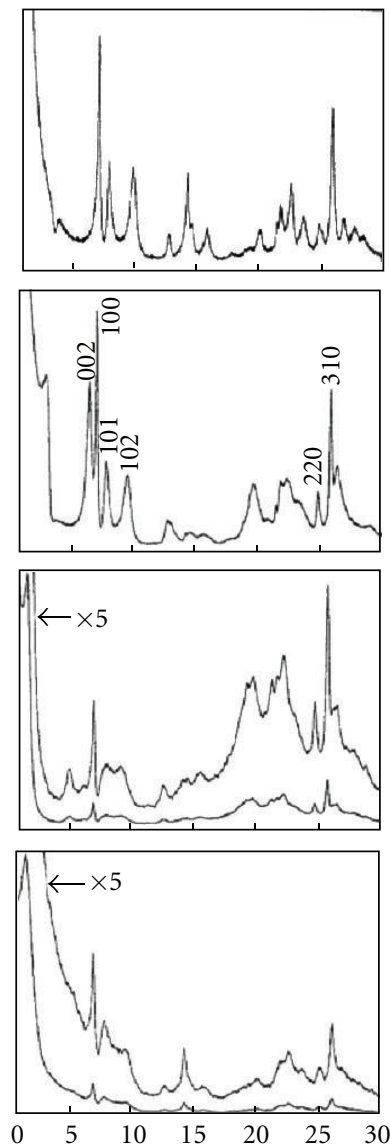

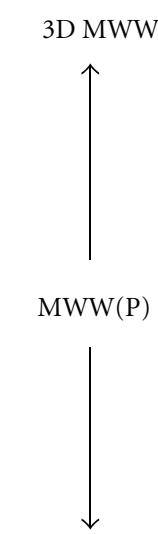

Swollen $\mathrm{MWW}(\mathrm{P})$

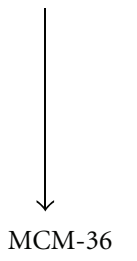

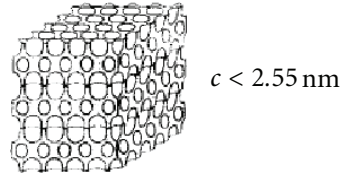
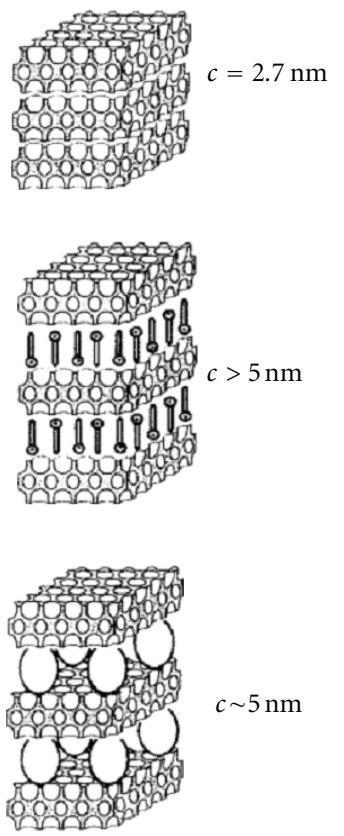

FIGURE 24: Preparation route of pillared MCM-36 zeolite and XRD patterns associated to MWW derivative materials obtained from starting layered zeolitic precursor (according to [40]).

\subsection{MCM-36: Pillared Zeolitic Material with MWW Topology.} Such as it occurs with clays, hydrotalcites, and other inorganic lamellar materials, the layered zeolitic precursors can also be successfully pillared by permanent covalent intercalation of organic or inorganic species, or the combination of them, into the interlayer space [103]. This fact would allow not only to increase the accessibility to internal space of microporous zeolites, but also to incorporate additional active sites located between the inorganic zeolitic sheets. Specifically, Kresge et al. reported the MCM-36 as the first pillared zeolite which is formed by MWW-type inorganic layers [104]. The preparation of this material is based on a starting swelling step by the cationic exchange of alkylammonium molecules $\left(\mathrm{C}_{16} \mathrm{TMA}^{+} \mathrm{OH}^{-}\right)$which are placed in the interlayer space separating the MWW layers. In a second step, the swollen precursor is pillared at an inert atmosphere using tetraethylorthosilicate (TEOS) which is finally hydrolyzed and calcined [105]. In Figure 24, the XRD patterns and the graphical representation of the different MWW derivative materials obtained from the layered zeolitic precursors are shown to finally obtain the pillared MCM-36 zeolites. It was observed that the MWW well-defined (002) diffraction band located at $1.35 \mathrm{~nm}\left(6.5^{\circ} 2 \theta\right)$ disappears during the swelling process, with an intense band at low-angles indicating that the interlayer space is strongly increased up to values higher than $5.0 \mathrm{~nm}$ being appreciated. Taking into account that each MWW individual layer presents a thickness of $2.5 \mathrm{~nm}$, the additional space of $2.5 \mathrm{~nm}$ generated between the sheets is due to the effective presence of $\mathrm{C}_{16} \mathrm{TMA}^{+}$molecules which are perpendicularly placed to the inorganic zeolitic layers. This interlayer separation is maintained after the insertion of silica pillars from TEOS to obtain finally the MCM-36 zeolite [40].

In Figure 25, the representation of the pillared MCM36 zeolite is shown. In this scheme it is evidenced the $10 \mathrm{MR}$ sinusoidal channels into the MWW zeolitic layers which remain unmodifiable. On the contrary, the delimited $12 \mathrm{MR}$ supercages, which are formed after the linkage of the MWW layers, are not formed after the pillarization process, being generated a new type of mesoporous cavities, which exhibit $2.5 \mathrm{~nm}-3.0 \mathrm{~nm}$ as pore diameter, due to the effective silica pillars intercalation. As a consequence of the pillarization, the BET surface area obtained for the MCM36 is strongly increased compared with the microporous $3 \mathrm{D}$ MWW zeolites. The main advantage of the mesoporous distribution generated in the MCM-36 was the easy accessibility achieved to internal acid active sites, overall for voluminous reactant molecules which take part in different catalytic processes [106]. On the contrary, the pillared materials, such as the MCM-36 zeolites, show the important inconvenient 


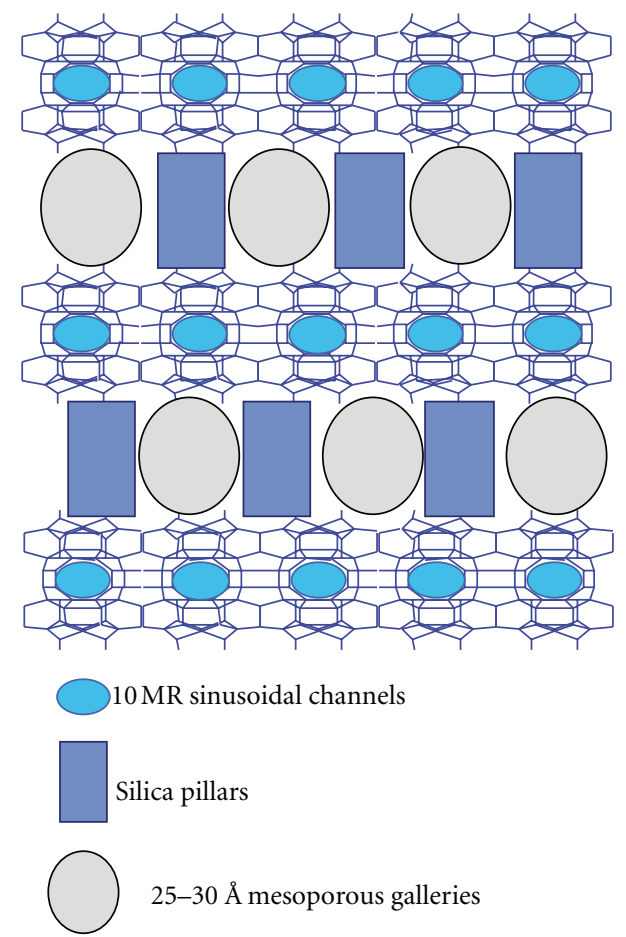

Figure 25: Graphical representation of pillared MCM-36 zeolitic material.
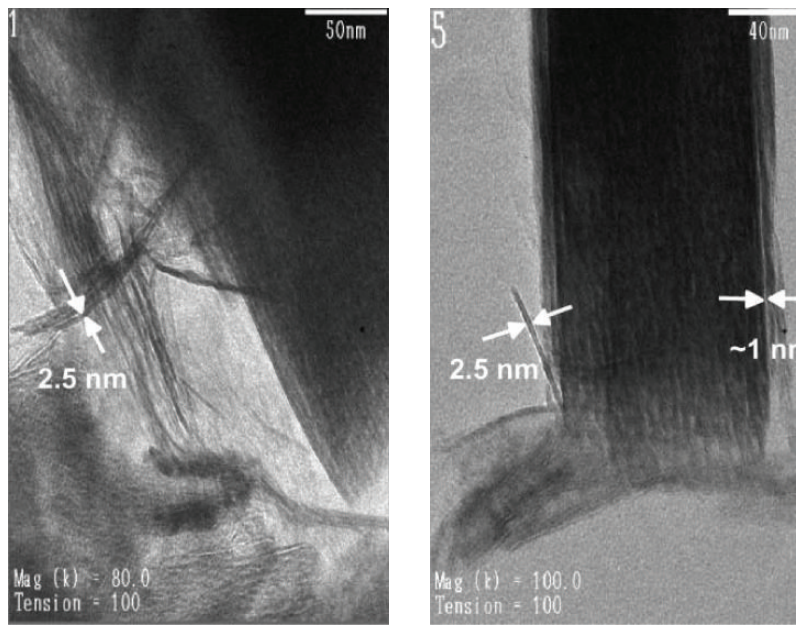

FIGURE 26: TEM images of MCM-36 derivatives pillared with intercalates $\mathrm{MgO}-\mathrm{Al}_{2} \mathrm{O}_{3}$ (according to [41]).

associated to the partial blockage of active sites, present in the external surface of MWW layers, due to the intercalation of silica pillars in the interlayer space [107].

However, this problem can be partially reduced through the intercalation of metal oxide pillars instead of silica pillars which can supply additional active sites, compensating the loss of activity due to the blockage associated to pillarization process, preserving the mesoporous textural properties. In this way, alumina and magnesia-alumina were used for pillaring the MWW layered zeolitic precursors to prepare new varieties of MCM-36 molecular sieves. Specifically,

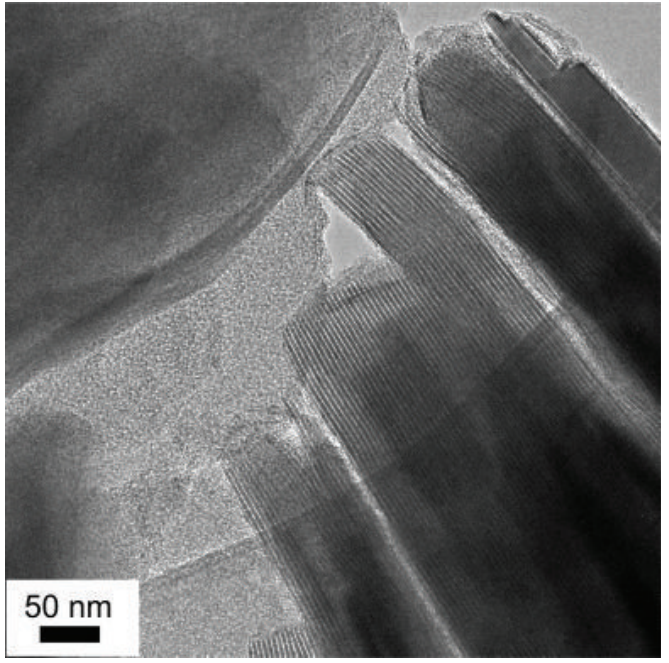

FIGURE 27: TEM image of MCM-36 obtained from MWW layered precursors swollen at room temperature (according to [42]).

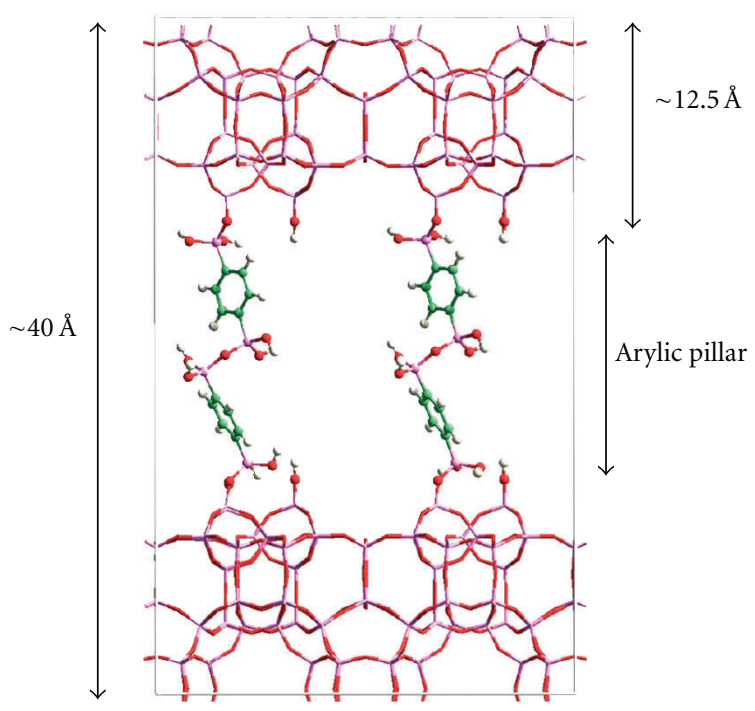

FIGURE 28: Graphical representation of a layered hybrid material obtained by pillaring with BTEB silsesquioxane molecules (according to [47]).

pillaring with alumina generates mesoporous materials with lower surface areas than those pillared with silica, being necessary elongated aging of the alumina pillaring solutions to obtain mesoporous regular materials. Application of magnesia in combination with alumina yields in a higher spatial disorder of the MWW layers. However, the employ of $\mathrm{MgO}-\mathrm{Al}_{2} \mathrm{O}_{3}$ as pillaring agents implies the preparation of MCM-36 materials with significantly higher mesoporosity (pore size diameters between 2-4 nm) compared with the use of only alumina as structural pillars (Figure 26) [41]. Following this approach, other mixed oxides were used as pillaring agents, such as $\mathrm{BaO}-\mathrm{Al}_{2} \mathrm{O}_{3}, \mathrm{Al}_{2} \mathrm{O}_{3}-\mathrm{SiO}_{2}, \mathrm{MgO}-$ $\mathrm{Al}_{2} \mathrm{O}_{3}-\mathrm{SiO}_{2}$, and $\mathrm{BaO}-\mathrm{Al}_{2} \mathrm{O}_{3}-\mathrm{SiO}_{2}$, with successful results to obtain homogeneous zeolitic materials with additional 


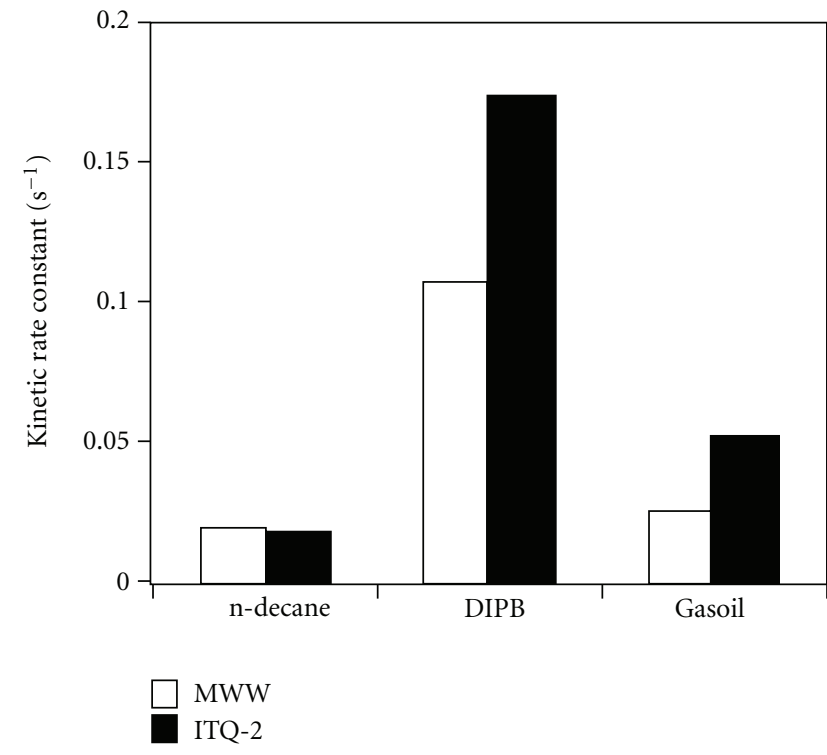

Figure 29: Comparison of the first-order kinetic rate constants for the cracking of n-decane, 1,3-diisopropylbenzene (DIPB), and vacuum gasoil over the MWW-type zeolite and ITQ-2 delaminated materials (according to [48]).

mesoporous interlayered galleries [108, 109]. These MCM36 derivatives could even be considered as acid-base bifunctional materials which would contain enhanced Lewis acidity, generated by pillaring with aluminum oxides, additional Brönsted acid sites of higher strength than the sites in the zeolitic layers, assigned to the silica-alumina clusters in the interlayer galleries, and base properties by the incorporation of alkaline earth oxide aluminates $\left(\mathrm{MgO} / \mathrm{BaO}-\mathrm{Al}_{2} \mathrm{O}_{3}\right)$ into the interlayer space $[110,111]$.

On the other hand, additional studies have been carried out with the objective to obtain the most efficient expansion methods of MWW layered zeolitic precursors, being this decisive to prepare homogeneous pillared MCM36 derivatives with higher accessibility without crystallinity and activity losses. In this sense, the employ of concentrated surfactant solutions with high $\mathrm{pH}$ provided swollen MWW materials that were successfully converted to pillared MCM36 zeolites. Specifically, optimal high $\mathrm{pH}$ of the swelling solutions was obtained by the addition of tetrapropylammonium hydroxide and by the partial conversion of the surfactant chloride into hydroxide by ion exchange. The catalytic potential of the solids was analyzed based on IR spectra and specific surface area, showing that there was an overall decrease in acid site concentration due to the incorporation of inert silica pillars. However, the MCM-36 zeolites with the highest external surface showed a marked adsorption increase of 2,6-di-tert-butyl-pyridine by 75\% compared to the starting $\mathrm{MWW}(\mathrm{P})$, which suggested an elevated accessibility of acid sites for bulky probe molecules. So, it was concluded that concentrated surfactant solutions were suitable for the effective zeolitic precursors swelling, even at room temperature, being possible the reuse of the swelling solutions to optimize a more sustainable methodology [112].
An important associated problem to the MCM-36 synthesis method is the similarity between the conditions employed (high $\mathrm{pH}$, high temperatures, and the presence of surfactants in the synthesis media) to prepare the pillared and the conventional mesoporous M41S materials. Although, the suitable combination of different characterization techniques (X-ray diffraction, sorption isotherms, and microscopic images, preferably) allows to clearly evidence the differences between the mesoporosity due to conventional M41S solids or attributed to pillaring process, significant studies have been carried out to find the optimal conditions to obtain pillared zeolites, avoiding the possible formation of standard mesoporous materials, as impurities, during the preparation of MCM-36 derivatives [113]. More specifically, the strong alkaline conditions and high temperatures used during the swelling process normally carried out can favor the disruption of the MWW layered structure and the partial dissolution of the silica zeolitic sheets composition. Taking into account this and trying to avoid this problem, Tsapatsis et al. employed mild conditions in the swelling step working meanly at room temperature, as it was above shown about the delamination process. This modified approach to swell MWW zeolitic precursors allowed to prepare MCM-36 analogue materials conformed by well-defined MWW layers which preserve their morphology and crystalline structure (Figure 27) [42].

Recently, advancing in the pillarization concept, multifunctional hybrid organic-inorganic catalytic materials with a hierarchical system of well-defined micro- and mesopores have been prepared from MWW zeolitic precursors by intercalation and stabilization in the interlayer space of aminoaryl-bridged silsesquioxanes between inorganic MWW zeolitic layers. The organic linkers were conformed by two condensed silyl-acrylic groups from disilane molecules, such as 1,4-bis(triethoxysilyl)benzene (BTEB), which reacted with the external silanol groups of the zeolitic layers. The hybrids contained micropores within the inorganic layers and a well-defined mesoporous system between the organic linkers. An amination posttreatment introduced basic groups in the organic linkers close to the acid sites present in the structural inorganic counterpart due to the presence of framework aluminum. Through this methodology it has been possible to prepare bifunctional acid-base catalysts where the acid sites are of zeolitic nature located in the inorganic building blocks and the basic sites are part of the organic structure (Figure 28). The resultant materials acted as bifunctional catalysts for performing a two-step cascade reaction that involved the hydrolysis of hemiacetals followed by Knoevenagel condensation processes, inside CC bond formation reactions [47].

\section{Catalytic Processes of Highly Accessible MWW Zeolites}

Heterogeneous catalysis is an important topic in fine and bulk chemical processes, such as pharmaceutical manufacture and petroleum refining, being hugely used as catalysts based on metal(alumino)silicates to perform these types of 


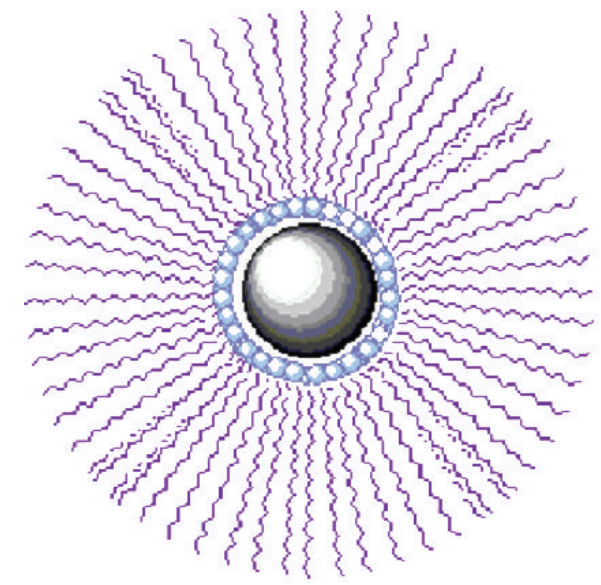

Reverse micelles
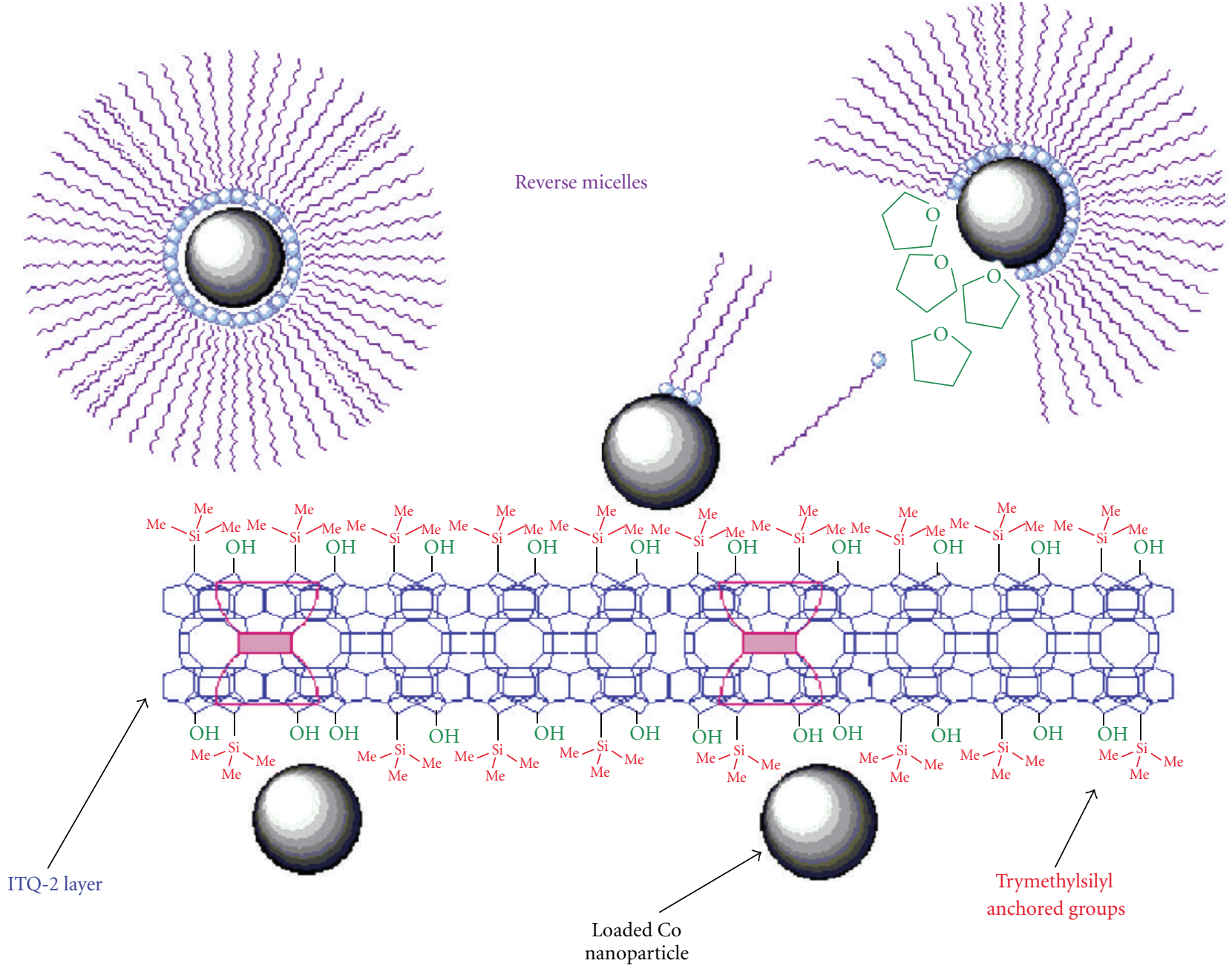

FIGURE 30: Schematic representation of the preparation of sample Co-ITQ-2 by deposition of cobalt nanoparticles synthesized ex-carrier by reverse microemulsion on the silylated ITQ-2 zeolite (according to [53]).

reactions, combining high stability with excellent activity. Inside this class of materials, zeolitic microporous crystalline solids with three-dimensional framework structures have occupied a relevant place because they exhibit a similar activity compared with soluble standard catalysts and improve the hydrothermal stability of mesoporous structures which contain amorphous walls. Further, they impart shape selectivity on the reaction products. However, the selectivity achieved through uniformly sized pores and channels, present in the structure of microporous zeolites, implies important size constraints on the accessibility to reactants, intermediates, and products. The use of open zeolites, obtained from pillaring or delaminating mechanisms, would allow expanding the number of reactions that zeolites could carry out. For this, the employ of the ITQ-2 and MCM-36 derivative zeolites as catalysts has been hugely used in the last years with excellent results $[114,115]$.

3.1. Bulk Chemical Processes. The open MWW structures, generated from ordered layered precursors, have allowed the employ of pillared and delaminated zeolites as efficient catalysts to carry out reactive processes in which take part compounds with elevated molecular sizes. The MCM-36 and ITQ-2 materials are aluminosilicates whose zeolite-type catalytic sites are contained within thin and readily accessible sheets. Several and suitable performance reactive tests showed that the pillarization and delamination processes improved the accessibility to the catalytic sites preserving their intrinsic activity.

Specifically, the catalytic potential of ITQ-2 was evidenced by means of a fixed-bed, small-scale catalyticcracking test, using $\mathrm{n}$-decane as a model feed. The conversions of the reactant observed at different contact times were used to calculate first-order rate constants, showed in Figure 29, being appreciated similar rate constants for n-decane cracking which showed that the 3D MWW-type zeolite and ITQ-2 delaminated material exhibited similar activities. So, the delamination process did not destroy the zeolitic nature of the catalytic sites in ITQ-2. However, the selectivity of ITQ-2 and the MWW-type zeolites are strongly different, catalyzing the ITQ-2 the formation of significantly more liquid and less gaseous product than 3D MWW-type 

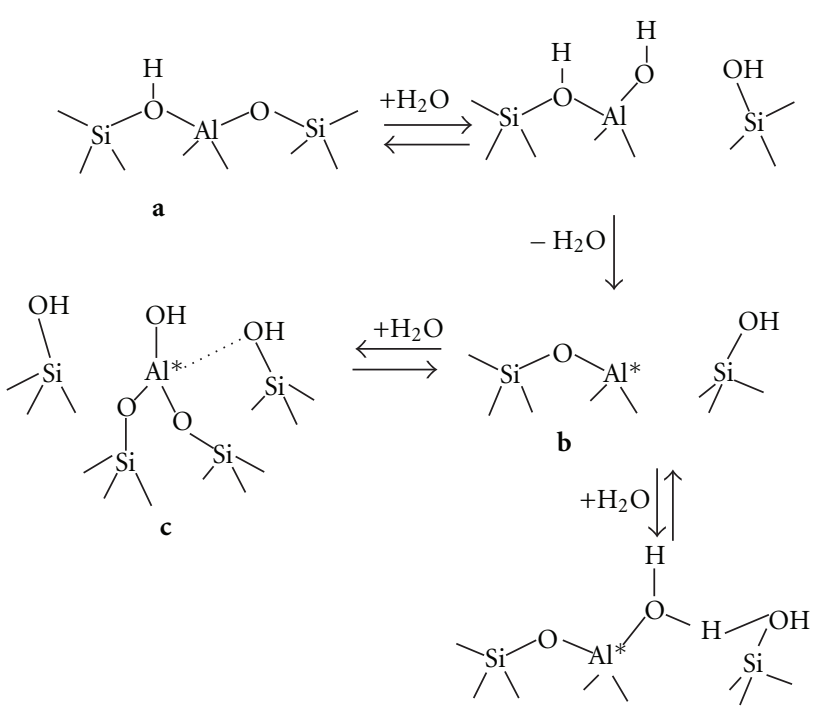

d

Scheme 2: Acidic sites generated during the delamination process to obtain ITQ-2 materials (according to [30]).

zeolites. In this case, the relative amount of gas formation provided a measure of the extent to which the initial liquid products were additionally cracked in consecutive reactions, being this fact indicative of catalytic-site accessibility. The reduced gas formation observed with ITQ-2 confirmed that a few consecutive reactions took place and the initial products diffused more rapidly in the delaminated ITQ2 than in the microporous MWW-type zeolite. Moreover, the advantages of the higher site accessibility, without the associated problems in the ITQ-2 materials, were clearly appreciated when larger molecules are used as feedstocks, such as di-isopropylbenzene and vacuum gasoil, being the ITQ-2 more active (Figure 29) as well as more selective than the MWW-type zeolite, yielding more of the valuable gasoline and diesel products and less gas and coke. In general, all these results showed the benefits due to the increased accessibility to the catalytic sites for larger organic molecules which react only at the external cups of this material $[48,95]$. Similar results were observed for cumene cracking and 1,3,5tri-isopropylbenzene dealkylation, being appreciated that the delamination processes favor the preparation of more accessible heterogeneous catalysts to bulky molecules, but weakening their acid strength [116].

Following this tendency, the ITQ-2 showed excellent results for the cracking or hydrotreating light cycle oil (LCO) fractions, which are provided directly from fluid catalytic cracking units, being the performances comparable to those obtained for pore and large pore zeolites, such as ZSM-5, MCM-22, USY, or Beta [117]. Specifically, catalysts based on $\mathrm{Ni}-\mathrm{Mo}$ and Pt supported on the delaminated ITQ-2 zeolites were prepared and their catalytic properties evaluated for the mild hydrocracking (MHC) of vacuum gas oil and aromatic hydrogenation. In the case of MHC of vacuum gas oil, NiMo/ITQ-2 displayed a higher hydrocracking activity than
$\mathrm{NiMo} / \mathrm{SiO}_{2}-\mathrm{Al}_{2} \mathrm{O}_{3}$ and $\mathrm{NiMo} / \gamma-\mathrm{Al}_{2} \mathrm{O}_{3}$ and even a higher activity than NiMo/USY. Moreover, NiMo/ITQ-2 exhibited selectivity to middle distillates intermediates between those of NiMo/USY and $\mathrm{NiMo} / \mathrm{SiO}_{2}-\mathrm{Al}_{2} \mathrm{O}_{3}$. For hydrogenation of naphthalene, Pt/ITQ-2 showed a higher activity than $\mathrm{Pt} / \gamma-\mathrm{Al}_{2} \mathrm{O}_{3}$ and $\mathrm{Pt} / \mathrm{SiO}_{2}-\mathrm{Al}_{2} \mathrm{O}_{3}$ but a lower activity than $\mathrm{Pt} / \mathrm{USY}$ with similar Pt loading (Scheme 4). This is due to the existence of Pt centers in the $10 \mathrm{MR}$ channels of ITQ2 which are not accessible to the naphthalene molecules. In fact, Pt/ITQ-2 was markedly more active than Pt/USY for the hydrogenation of benzene, which can react with the metal sites placed into the $10 \mathrm{MR}$ channels of the delaminated ITQ-2 zeolite. Furthermore, Pt/ITQ-2 exhibited the highest aromatic reduction when it was used a hydrotreated light cycle oil (HT-LCO) feedstock. In this case, the larger external surface area of ITQ-2 favored the hydrogenation of the voluminous aromatic molecules included in the HT-LCO. This behavior is explained by the characteristic structure of the delaminated ITQ-2 zeolite, which combines the efficient activity of zeolites with the desired selectivity of metallic catalysts, overcoming the diffusional problems conventionally associated microporous materials [118].

Interestingly, cobalt particles were incorporated onto the high external surface of ITQ-2 zeolites, previously silylated, through reverse-micelle synthesis, generating excellent catalysts for Fischer-Tropsch synthesis (FTS) which showed a uniform $\mathrm{Co}(0)$ particle size distribution in the $5-11 \mathrm{~nm}$ range [119]. Inside this topic, improved synthesis methodologies allowed to obtain cobalt metal nanoparticles around $4-5 \mathrm{~nm}$ in size in the core of reverse micelles on the surface of delaminated ITQ-2 zeolites. The deposition method combined with the high accessibility and stability of the support allowed breaking the dispersion-reducibility dependence inherent to very small cobalt particles, avoiding longlasting problems in studying particle size effects in highly dispersed cobalt-type Fischer-Tropsch catalysts (Figure 30) [53]. Alternatively, following this line, cobalt catalysts supported on all-silica delaminated ITQ- 2 zeolites were prepared by impregnation with aqueous $\mathrm{Co}\left(\mathrm{NO}_{3}\right)_{3}$ solutions. The results obtained under FTS conditions revealed that the high dispersion and reducibility of cobalt particles in CoITQ-2 favor the higher selectivity toward the formation of $\mathrm{C}^{5+}$ hydrocarbons, being this fact also associated to a very elevated concentration of coordinatively unsaturated $\mathrm{Co}(0)$ sites which exhibit an enhanced electron $d$ that might stabilize surface hydrocarbon intermediates favoring chain growth processes [120]. Inside these catalytic studies, CoITQ-2 behavior was considered for the direct conversion of syngas to mainly high-octane gasoline-range hydrocarbons, using the standard FTS process. Specifically, the presence of the internal 10-MR (member ring) in the MWW individual layers, as medium-pore sinusoidal channels, increased the gasoline yields, enhancing the generation of branched products. These results can be explained due to the promotion of isomerization and cracking of long-chain $\left(\mathrm{C}^{13+}\right) \mathrm{n}$-paraffins formed during the Fischer-Tropsch reaction. The activity is normally determined by the surface acidity rather than by the total amount of Brönsted acid sites, being possible to observe limitations for the diffusion of the long-chain n-paraffin 
Route A

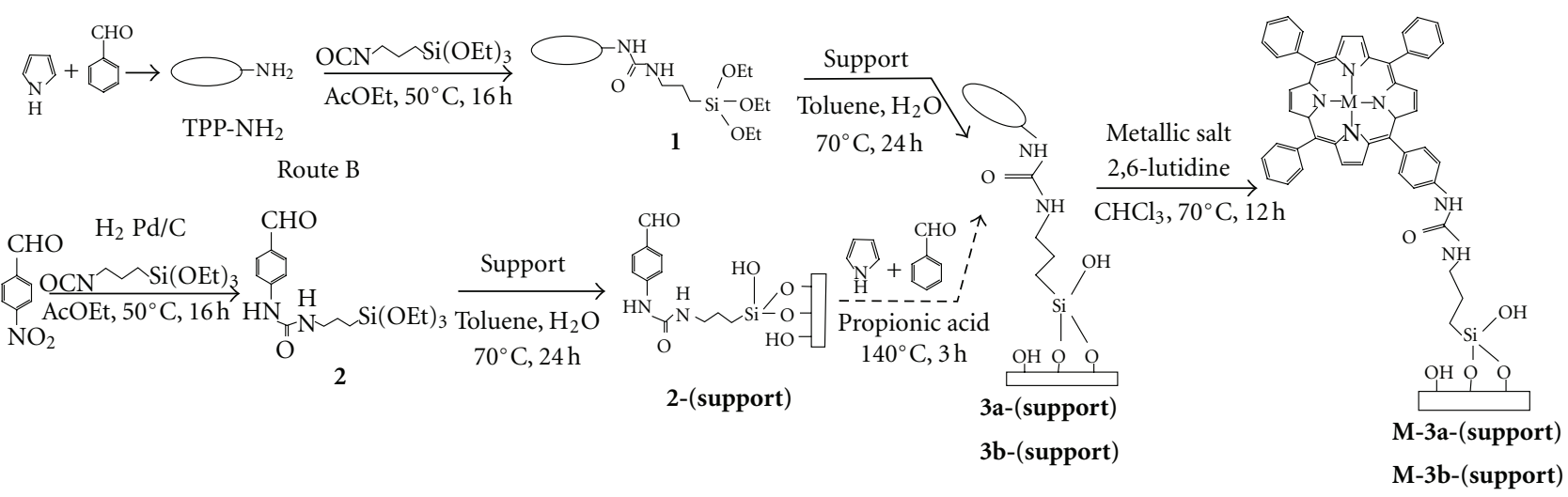

\footnotetext{
$\bigcirc=$ tetraphenylporphyrin

Metallic salt $=\mathrm{Co}(\mathrm{OAc})_{2} \cdot 4 \mathrm{H}_{2} \mathrm{O}, \mathrm{FeCl}_{2} \cdot 4 \mathrm{H}_{2} \mathrm{O}$

Support = silica gel, MCM-41, ITQ-2, ITQ-6

$\mathrm{M}=\mathrm{Co}(\mathrm{II}), \mathrm{Fe}(\mathrm{III}) \mathrm{Cl}$
}

Scheme 3: Alternative routes explored to synthesize heterogenized metalloporphyrins (according to [46]).

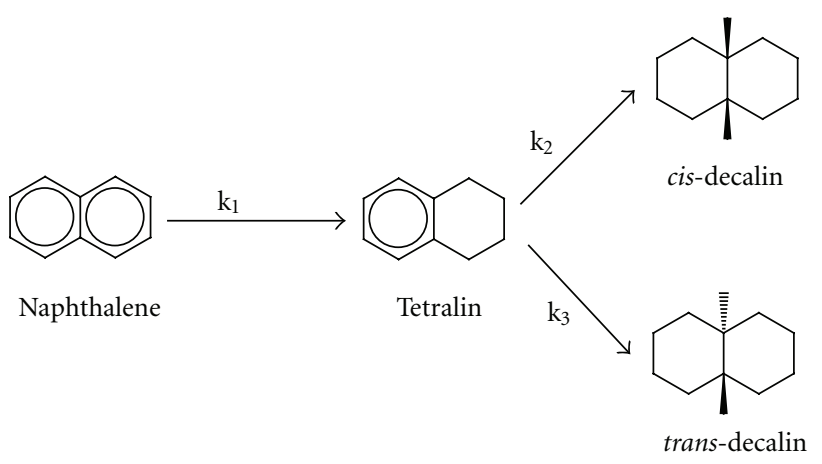

SCHEme 4: Naphthalene hydrogenation process.

through the 10-MR channels under FTS conditions. For this, the ITQ-2 materials with the largest surface area exhibited the highest initial yields of branched gasoline-range products [121].

Bifunctional ITQ-2 derivative catalysts were prepared combining the Brönsted acidity due to the framework aluminum with the presence of molybdenum onto the external surface. These delaminated zeolites were used for the methane dehydroaromatization (MDA) reaction. In this process, the Si/Al ratio, and thus the Brönsted acidity, of the zeolite affected both the conversion and the selectivity to the different products $\left(\mathrm{CO}, \mathrm{C}_{2}\right.$, benzene, toluene, and naphthalene). The highest activity and aromatics yields were obtained for the delaminated zeolite with the lowest Si/Al ratio $(\mathrm{Si} / \mathrm{Al}=15)$, exhibiting the maximum Brönsted acidity, while the highest benzene selectivity $(\sim 70 \%)$ occurred for the zeolite with $\mathrm{Si} / \mathrm{Al}=25$. The selectivity to naphthalene increased with decreasing the $\mathrm{Si} / \mathrm{Al}$ ratio, that is, with increasing the density of surface Brönsted acid sites. It was also confirmed that the reduction of surface acidity in
ITQ-2, through post-synthesis treatment with oxalic acid, strongly reduced the formation of naphthalene, resulting in enhanced benzene selectivity ( $75 \%)$ [122]. Additionally, the doping of MCM-36 with external metallic species based on molybdenum or nickel allowed the preparation of excellent catalysts methane nonoxidative aromatization [123] or ethylene oligomerization [124, 125], respectively. This fact confirmed the benefits associated to the presence of stable active metallic sites onto the accessible external surface area present in the layered materials derived from MWW precursors.

The benefits of the high surface area and the acid sites accessibility, without the associated loss of hydrothermal stability and acidic strength, exhibited by delaminated zeolites were taken as an advantage to carry out skeletal isomerization and dehydroisomerization of 1-butene and nbutene to isobutene or alkylation of toluene with methanol, avoiding in both cases the extensive coke formation, allowing easily the pore diffusion of reactants and products even in steady state (Scheme 5) [54, 126]. Following this line, alkylation of biphenyl or benzene with propylene in gas phase was also carried out using delaminated ITQ-2 and pillared MCM-36 zeolites. In this case, the influence of the peculiar disordered structure and morphology on reaction activity and selectivity was studied, being observed that the catalytic process took place mainly on the external surface, which indicates that the dimensions of intralayer sinusoidal $10 \mathrm{MR}$ channels inhibit the diffusion of the bulky reactants inside the zeolitic pores $[127,128]$.

This last reaction process was also used to compare the activity of different catalysts derived from MWW precursors, that is, MCM-22, MCM-36, and ITQ-2, for the liquid-phase phenol alkylation by $t$-butanol. The results obtained confirmed that by pillaring or delamination, the contribution of acid sites located on the external cups is increased which implied that, during the reaction process, 


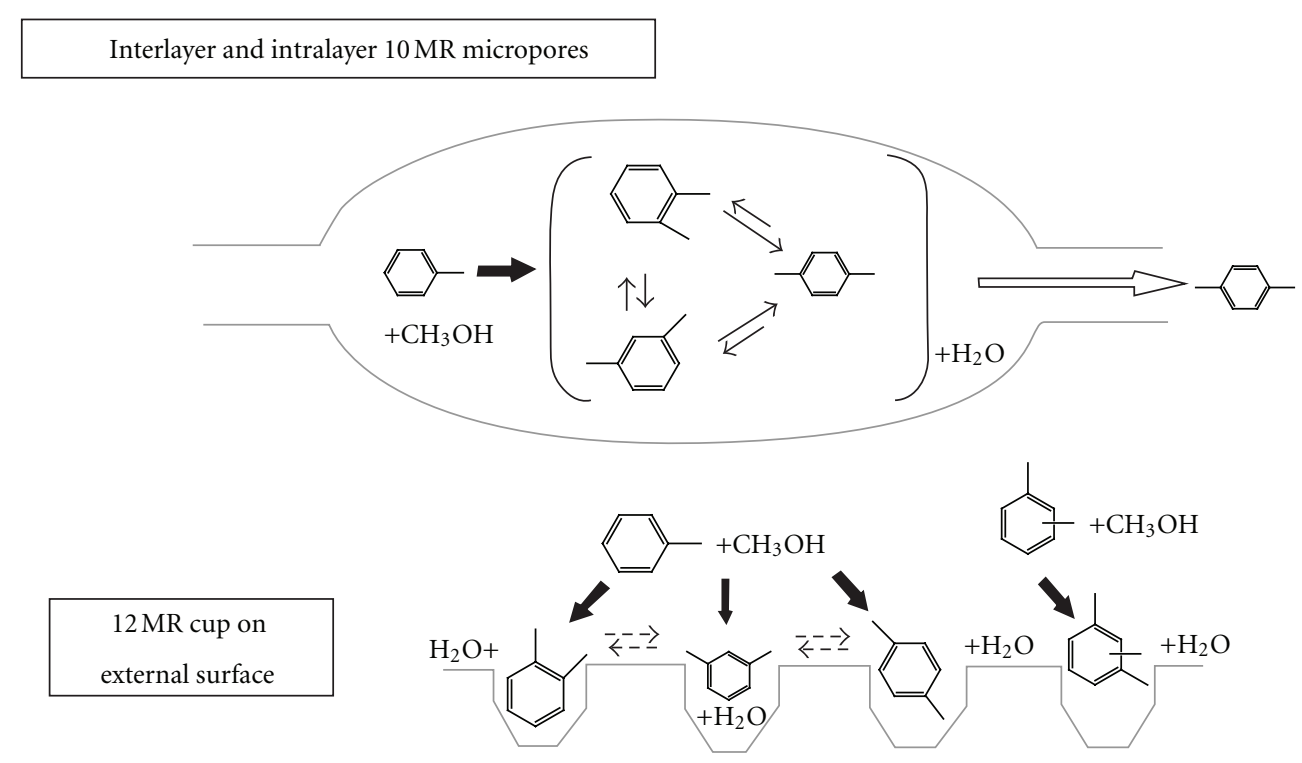

Scheme 5: Alkylation of toluene with methanol on MWW-type individual layers which are forming ITQ-2 delaminated zeolites (according to $[54])$.

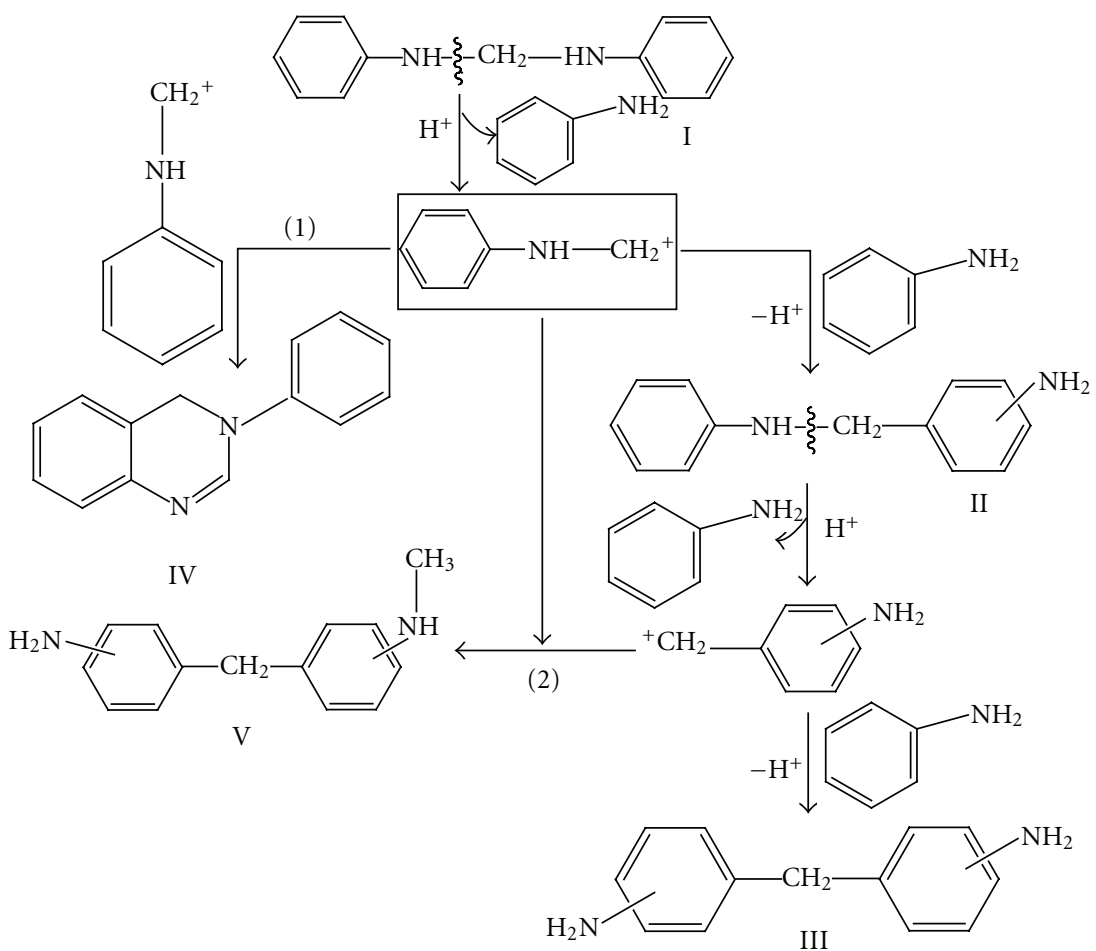

Scheme 6: General reaction scheme for the isomerization of the neutral amine to DADPM over zeolitic materials. Processes (1) and (2) involve several steps (according to [55]).

large reaction intermediates and products, which are difficult to be accommodated within sinusoidal microporous internal channels, are strongly favored $[129,130]$.

On the other hand, interesting catalysts based on $\mathrm{Ni}$ and Co supported on purely siliceous delaminated ITQ-2 zeolites were synthesized and catalytically used for bioethanol steam reforming. The study showed that Ni-ITQ-2 zeolite was the most active material while ITQ-2 zeolite containing cobalt exhibited the highest $\mathrm{H}$ selectivity and the lowest $\mathrm{CO}$ selectivity. Moreover, it was appreciated that coke deposition occurs in both materials, although deactivation was not detected during the reaction. In this case, the structure and physicochemical characteristics of the ITQ-2 zeolites, as accessible supporting matrixes, clearly favor the high activity, 


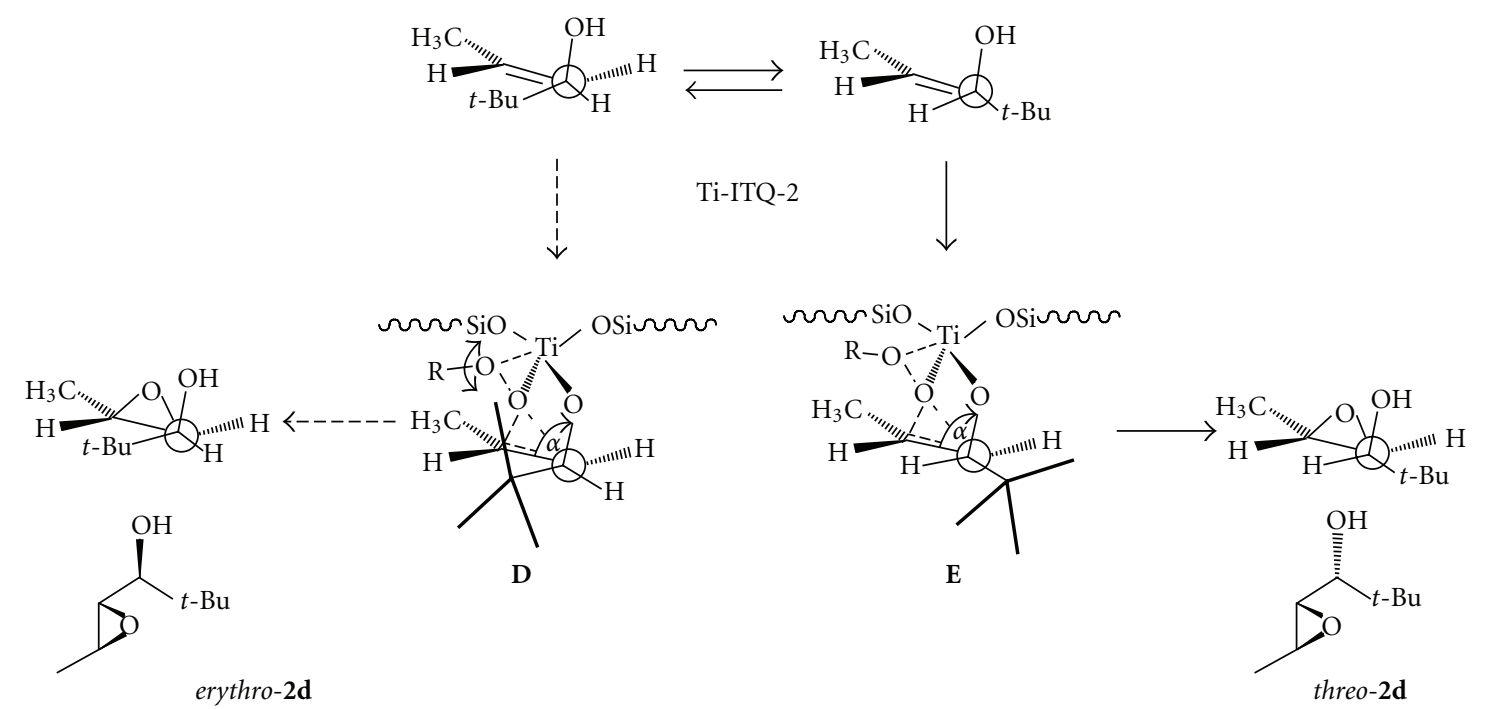

Scheme 7: Transition structures erythro (D) and threo (E) for the epoxidation of the chiral tert-butyl-substituted allylic alcohol with the heterogeneous Ti-ITQ-2/t-BuOOH oxidants (according to [56]).

selectivity, and stability during the steam reforming processes [131].

The advantages associated to the employ of more accessible MWW zeolites as catalysts, combined with their intrinsic acidic strength, could be positive when take part in reactive processes at industrial scale. In this sense, delaminated zeolites derivatives materials were efficient catalysts for the synthesis of diaminodiphenylmethane (DADPM), that is, the polyamine precursor in the production of MDI (methylene diphenylene diisocyanate) for polyurethanes (Scheme 6). The exfoliation methodology increases markedly the accessibility of the active sites to reactant molecules as well as the fast desorption of products, exhibiting the delaminated zeolitic materials higher activity and slower rates of deactivation than their corresponding tridimensional microporous zeolites. Additionally, the topology of the delaminated structure allows modulating the isomer distribution of the products. Indeed, it was possible to produce DADPM crude under industrial production specifications with delaminated zeolites used as catalysts, being this a real opportunity to replace $\mathrm{HCl}$ as conventional catalysts for the industrial generation of DADPM [55].

Recently, the open structure of the delaminated zeolites has been investigated for methanol to olefin conversion (MTO) [132] and dehydrogenation of propane to propylene in the presence of $\mathrm{CO}_{2}$ over ITQ-2 supported gallium oxide and compared with the supported microporous $\mathrm{H}$ ZSM-5. In this last case, ITQ-2 catalysts showed higher selectivity to propylene and better stability due to higher accessibility, minor diffusion problems, and lower amount of strong Brönsted acid sites [133]. Similar conclusions were formulated by Lacarrie et al. for the conversion of methanol to hydrocarbons (MTHs) catalyzed by MCM-36 zeolites where it was observed that the diffusion of bulkier species produced is facilitated which resulted in a lower deactivation rate compared to the purely microporous $3 \mathrm{D}$
MCM-22 catalyst. Moreover, the low density of acid sites in MCM-36 materials avoided secondary by processes, such as aromatization and hydrogen transfer which favor the generation of aromatics and coke precursors [134].

On the other hand, pillared MCM-36 zeolites have also been used as excellent catalysts in bulk chemical processes related with the in situ reduction of $\mathrm{NO}_{x}$ from fluid catalytic cracking (FCC) units with the objective to develop more sustainable chemical processes. In this case, the open and ordered mesoporous structure generated after the intercalation of organic or inorganic spacers between the MWW individual layers makes easier this reduction step during the FCC regeneration. Specifically, MCM-36 materials containing mixed oxide pillars, such as $\mathrm{MgO}-$ $\mathrm{Al}_{2} \mathrm{O}_{3}, \mathrm{BaO}-\mathrm{Al}_{2} \mathrm{O}_{3}, \mathrm{MgO}-\mathrm{Al}_{2} \mathrm{O}_{3}-\mathrm{SiO}_{2}$, or $\mathrm{BaO}-\mathrm{Al}_{2} \mathrm{O}_{3}-\mathrm{SiO}_{2}$, were investigated as additives for this in situ reduction of $\mathrm{NO}_{x}$, showing high $\mathrm{NO}$ conversions $(\sim 85 \%)$ and high $\mathrm{N}_{2}$ yields $(\sim 80 \%)$ under oxygen-deficient reaction conditions [108, 109, 135].

Recently, interesting studies have been performed by Tsapatsis et al. elucidating the catalytic behavior of Brönsted acid sites in MWW zeolites with dual meso- and microporosity, such as MCM-36 derivatives. In this case, ethanol dehydration and monomolecular conversion of propane and isobutane were considered as test reactions. The results clearly corroborated that the rate and activation energy in zeolites possessing dual meso- and microporosity were comparable to conventional microporous 3D-MWW materials, implying this fact that, in pillared zeolites, the catalytic behavior of Brönsted acid sites is preferentially dominated by the microporous environment because it provides a better fit for adsorption of small alkane or alcohol substrates [136].

3.2. Fine Chemical Processes. Taking into account the precedent section, it has been corroborated the benefits of open structure exhibited by the pillared and exfoliated materials 
(1)<smiles>CC(C)(C)c1cc(CCl)cc(C=O)c1O</smiles>

1 eq.<smiles>CCCCCC(=O)c1cc(C(C)(C)C)cc(C=O)c1O</smiles>

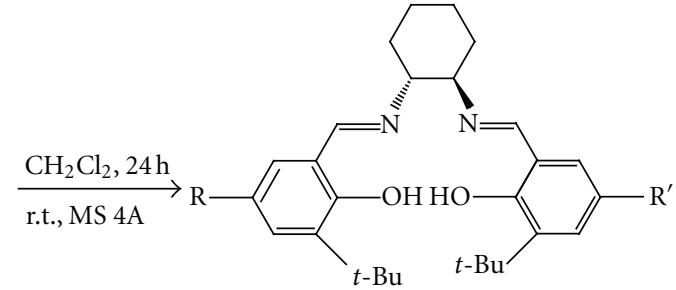

3 eq.

2 eq.
(a) $\mathrm{R}=t-\mathrm{Bu}, \mathrm{R}^{\prime}=t-\mathrm{Bu}$
(b) $\mathrm{R}=t-\mathrm{Bu}, \mathrm{R}^{\prime}=\mathrm{CH}_{2} \mathrm{Cl}$

(c) $\mathrm{R}=\mathrm{CH}_{2} \mathrm{Cl}, \mathrm{R}=\mathrm{CH}_{2} \mathrm{Cl}$

Statistical ratio
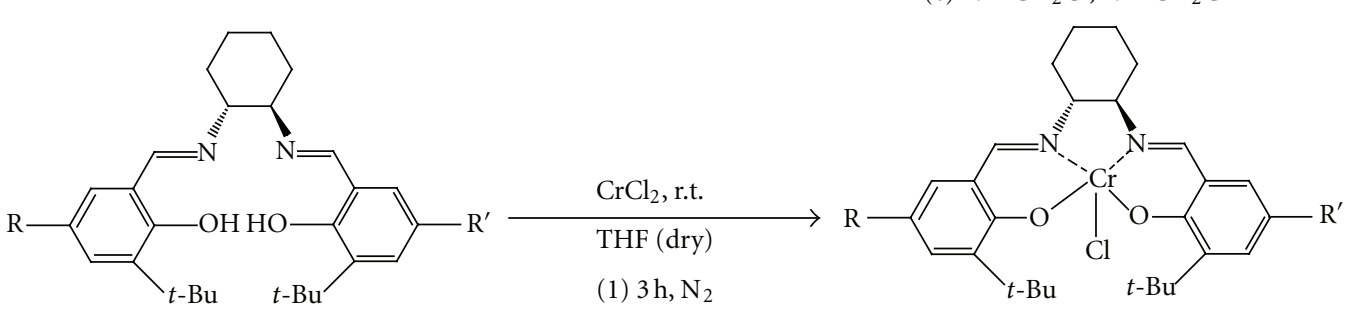

(2) $3 \mathrm{~h}$, air
(a) $\mathrm{R}=t-\mathrm{Bu}, \mathrm{R}^{\prime}=t-\mathrm{Bu}$
(b) $\mathrm{R}=t-\mathrm{Bu}, \mathrm{R}^{\prime}=\mathrm{CH}_{2} \mathrm{Cl}$
(c) $\mathrm{R}=\mathrm{CH}_{2} \mathrm{Cl}, \mathrm{R}=\mathrm{CH}_{2} \mathrm{Cl}$

Statistical ratio

(2)

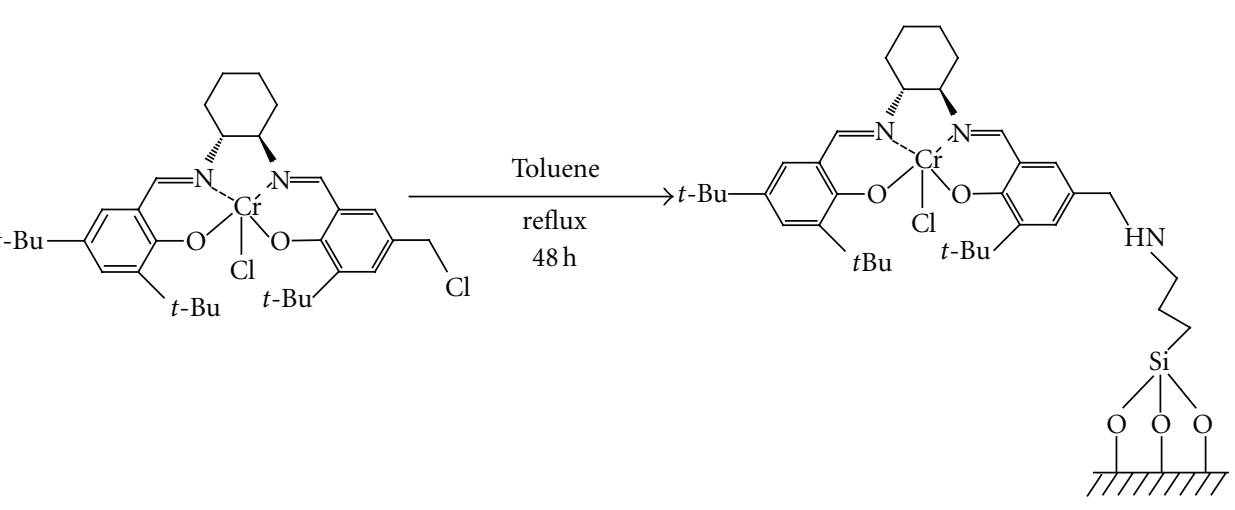

Catalyst 3-7

Scheme 8: (1) Preparation of the asymmetric complex in homogeneous phase complexes, (2) anchoring of a mixture of complexes (according to [57]).

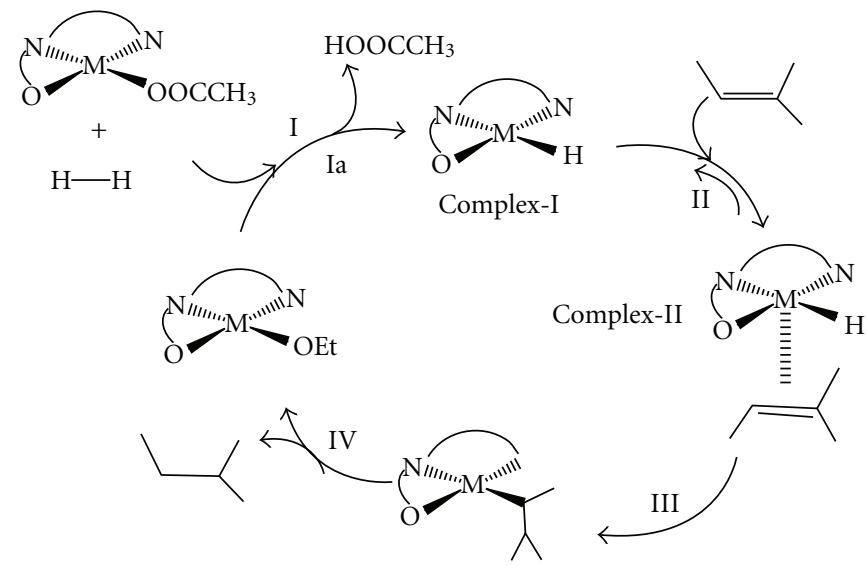

Scheme 9: Stabilization of the transition state by the $\mathrm{H}^{+}$in the reaction media during the hydrogenation of imines (according to [58]). 


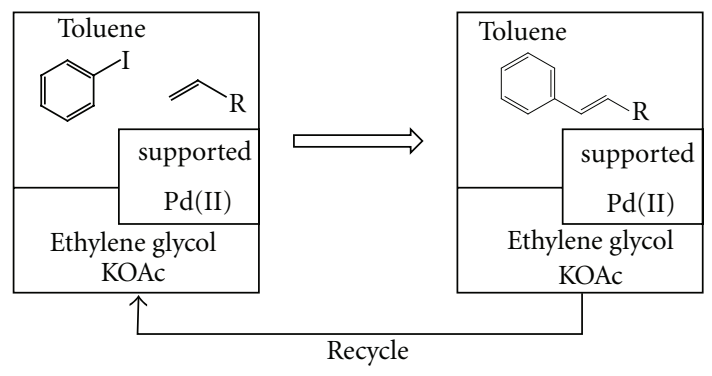

Scheme 10: Heck vinylation reactions performed in a biphasic mode using ethylene glycol and toluene (according to [59]).

derived from MWW precursors in which is successfully combined the high accessibility to active sites without diffusion problems and characteristic of amorphous mesoporous materials, together with the crystallinity, hydrothermal stability, and acid strength exhibited by conventional zeolitic materials. These cooperative properties are evident when bulky molecules take part during the catalytic process, being possible to use both MCM-36 and ITQ-2 derivative materials as efficient catalysts to carry out also Fine Chemistry processes to obtain high value products with application in pharmaceutical, perfumes and fragrances, cosmetic, or food [137].

Inside this research field, delaminated materials obtained by grafting of titanocene was used as an excellent catalyst for epoxidation of olefins, yielding high conversions and selectivity to the desired epoxides [14] such as occurs with the Ti-ITQ-2 zeolites which contained tetrahedrally coordinated titanium after deboronation processes [34]. Related with this topic, comparative study of silane oxidations, olefin epoxidations, and thianthrene 5-oxide sulfoxidations, using the catalysts Ti- $\beta$ and grafted Ti-ITQ-2 with $\mathrm{H}_{2} \mathrm{O}_{2}$ and $\mathrm{t}-\mathrm{BuOOH}$ as oxidants, was carried out. The results showed that the steric constraints of the narrow microporous channels make the Ti- $\beta$ zeolite the most selective. But, the more open structures of the Ti-ITQ-2 materials, where the steric constraints are less acute, exhibited a lower selectivity. However, the catalytic reactivity is comparable for both type of heterogeneous catalysts. It is remarkable that delaminated materials activated $\mathrm{t}-\mathrm{BuOOH}$ for oxygen transfer through a transition structure similar to homogeneous $\mathrm{Ti}\left(\mathrm{O}^{\mathrm{i}} \mathrm{Pr}\right)_{4} / \mathrm{t}-$ $\mathrm{BuOOH}$ oxidant (Scheme 7) [56]. Following this line, the preparation of anchored Ti-ITQ-2 catalysts was improved by combining catalyst characterization, molecules descriptors, and high-throughput techniques for the epoxidation of large olefins and fatty esters, such as methyl oleate, being this approach potentially effective for the efficient design and screening of catalysts with industrial applications $[138,139]$. Similarly, excellent catalytic yields in 1-hexene and propylene epoxidation reactions, using $\mathrm{H}_{2} \mathrm{O}_{2}$ as oxidant agent, were carried out in the presence of Ti-MCM-36 as solid catalyst [140].

The high external surface area, with a big amount of reactive silanol groups, exhibited by the ITQ-2 materials is useful to anchor different organocatalysts, such as chiral salen or Schiff base complexes, obtaining interesting asymmetric catalysts. It is the case of chiral chromium salen compounds which were grafted on previously aminopropylfunctionalized ITQ-2 materials for enantioselective epoxide ring opening reactions. In this study, was confirmed that in the catalysts in which the anchoring was carried out through coordination bonds with the metal, then high enantiomeric excesses were obtained (up to $70 \%$ e.e.), but leaching phenomenon was observed. On the contrary, for the solids in which the complex was covalently attached to the surface then it was not observed leaching, being the e.e. more reduced $(<20 \%)$ compared to those obtained in homogeneous catalysis ( $>50 \%$ ) (Scheme 8) [57].

Into this family of chiral delaminated zeolites, it was observed a cooperative effect between the support (ITQ2 ) and stabilized salen (Pd and Ni) complexes. This matter was studied through the immobilization of chiral salen palladium and nickel complexes [salen $=(\mathrm{R}, \mathrm{R})-\mathrm{N}^{\prime}, \mathrm{N}^{\prime}$-bis(3,5-di-tert-butylsalicylidene)-1,2-cyclohexanediamine] on delaminated ITQ-2 zeolites, being used to catalyze the hydrogenation of imines and alkenes. The high accessibility introduced by the structure of the exfoliated zeolitic supports allowed the preparation of efficient solid catalysts with TOFs of $200 \times 10^{3} \mathrm{~h}^{-1}$. It was appreciated that the presence of slight acidity due to the zeolitic support doubles the catalytic activity by stabilizing the charged transition state compared with the homogeneous catalyst (Scheme 9). Moreover, the chiral catalyst was reused without deactivation after repeated recycling [58, 141]. Related with this type of organic-inorganic materials, González-Arellano et al. prepared catalysts from Pd-complexes supported on siliceous delaminated zeolites which implied the use of the Schiff bases 2-tert-butyl-4-methyl-6\{(E)-[(2S)-1-(1arylmethyl)pyrrolidinyl]imino $\}$ methylphenol (aryl $=\mathrm{Ph}, 1-$ naphthyl, 2-naphthyl) as anchored ligands. The results confirmed the high reactivity and recyclability of these heterogenous catalysts for Heck and Suzuki coupling reactions under phosphine-free conditions (Scheme 10) [59].

Inside this line, Sabater et al. reported that the catalytic behavior and enantioselectivity of three different chiral $\mathrm{Mn}(\mathrm{III})$ salen complexes anchored to ITQ-2-type delaminated zeolitic materials were strongly dependent on the attachment nature established between the complexes and the zeolitic surfaces through chiral equatorial tetradentate salen ligand or via the apical ligand. This conformational factor together with the tuning of the hydrophobicity of the external surface allowed to optimize the selectivity to obtain chiral epoxides. In principle, the attachment of the complex through the equatorial position of the metal complex led to a strong reduction in enantioselectivity. On the contrary, when the complexes were fixed to the respective delaminated supports through the axial coordinating ligand were active and more enantioselective toward epoxidation of several prochiral alkenes (Scheme 11) [60].

Similar approaches were followed by the stable incorporation of chiral vanadyl Schiff base complexes anchored on ITQ-2 delaminated materials as solid enantioselective catalysts for the formation of cyanohydrins, being possible 


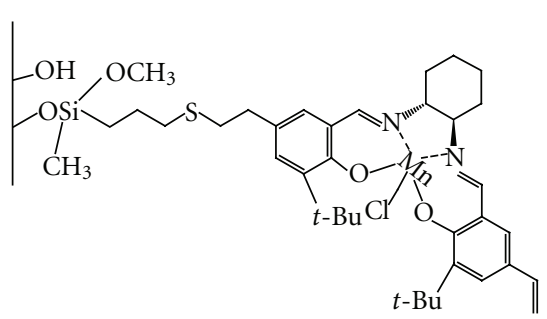

(a)

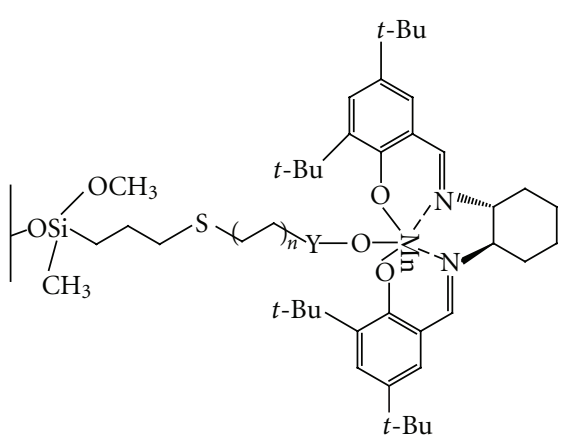

(b)

Scheme 11: Immobilization of chiral manganese salen complexes through equatorial tetradentate salen ligand (a) or apical ligand (b) (according to [60]).

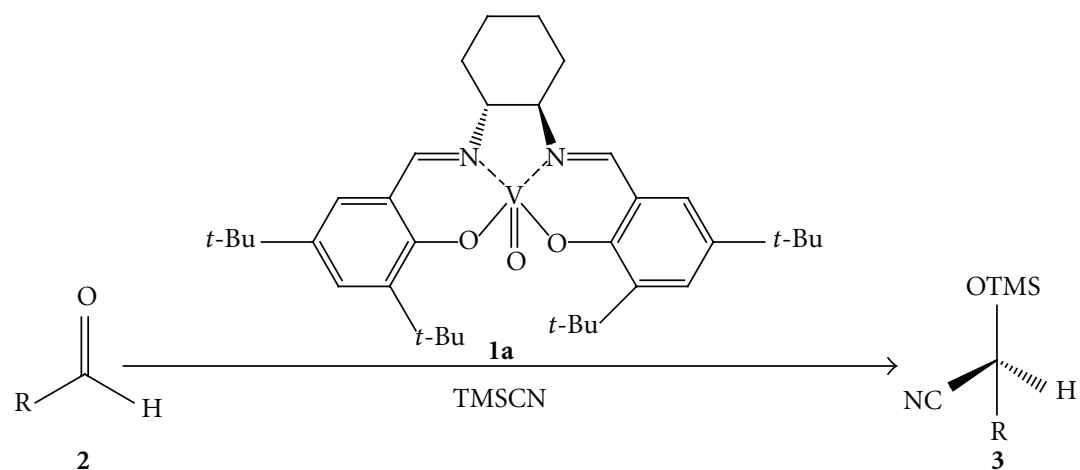

Scheme 12: Reaction scheme of the formation of (a) 2-benzyl-4-hydroxymethyl-1,3-dioxolane (1) and 2-benzyl-5-hydroxy-1,3-dioxane (2) and (b) vanillin propylene glycol acetal (3).

to optimize the asymmetric induction by external surface modification (Scheme 12). Specifically, vanadyl Schiff base complexes, having a terminal carbon-carbon double bond pending alkyl chains of various lengths attached to the para-position of the salen ligand, were previously obtained and anchored on purely siliceous ITQ-2 through mercaptopropylsilyl pended groups. The solids were used as enantioselective catalysts for the reaction of aldehyde with trimethylsilyl cyanide and low ee results, compared to homogeneous catalyst, were observed. However, a strong increase of the enantioselectivity was obtained after the postsynthesis silylation of the external free silanol groups present in the individual MWW sheets. In this case, the achieved enantiomeric excess was $85 \%$, that is similar compared to the $90 \%$ measured for the soluble catalyst [142].

Heterogeneous hybrid materials based on open MWWtype zeolites have not only been formed by the stable and covalent immobilization of organocatalysts such as chiral salen complexes. In this sense, prefixed chiral triaza ligands onto the ITQ-2 external surface allowed the final incorporation of palladium, rhodium, or iridium complexes which were active for olefin hydrogenation reactions. The results obtained for these catalysts showed that the activity and selectivity were higher to that observed under homogeneous conditions owing to support interaction. Additional absorption analyses of the reaction solutions revealed that there is no metal leaching during the catalytic process which corroborated the high stability of the materials (Scheme 13) [61]. Another type of simpler anchored systems directly based on chiral amines, containing pyrrolidine skeleton, was studied to generate ITQ-2 derivatives which were successfully employed as catalysts in the Michael addition of ethyl 2-(oxo)cycloalkanecarboxylic acid esters to acrolein (Scheme 14) [143].

More sophisticated mononuclear N-heterocyclic carbene-gold complexes were also immobilized on delaminated zeolite ITQ-2, exhibiting high performances in the hydrogenation of alkenes and the Suzuki cross-coupling reaction, favoring selectively nonsymmetrical biaryls. The elevated accessibility introduced by the structure of the exfoliated supports facilitated the preparation of highly efficient immobilized catalysts with TOFs up to $400 \mathrm{~h}^{-1}$ (Scheme 15) [62]. Similar gold (I), gold (III), and palladium (II) complexes were heterogenized onto disordered MWW materials and used as effective catalysts for Sonogashira cross-coupling reactions between iodobenzene and arylboronic acids or alkynes [144].

Different examples have above been shown related with the generation of effective hybrid organic-inorganic catalysts by the stable interaction established between suitable soluble organocatalysts and open MWW materials, such as delaminated ITQ-2 zeolites. However, the acid sites homogeneously 


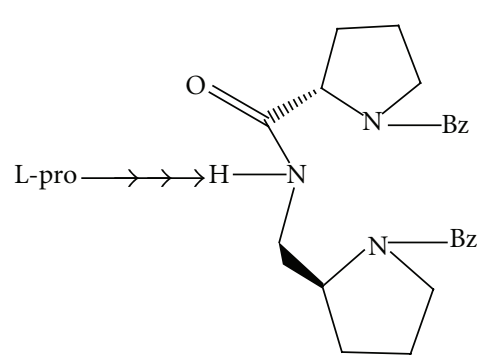

1
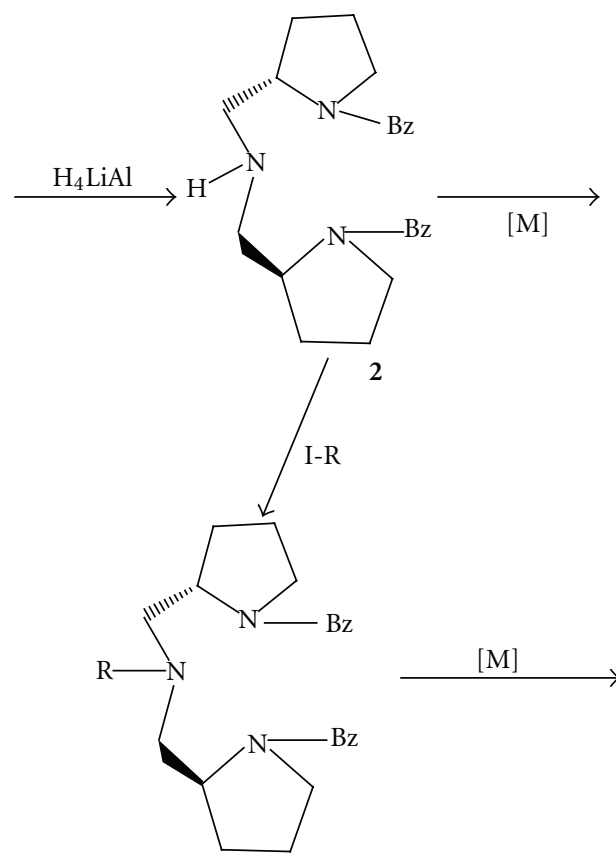

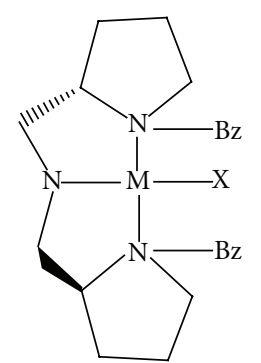

Rh2, Ir2, Pd2

$\mathrm{X}: \mathrm{Cl}, \operatorname{cod}$

(3) $\mathrm{R}=\left(\mathrm{CH}_{2}\right)_{2} \mathrm{CH}_{3}$

Rh3, Ir3, Pd3

Rh4, Ir4, Pd4

(4) $\mathrm{R}=\left(\mathrm{CH}_{2}\right)_{3} \mathrm{Si}(\mathrm{OEt})_{3}$

$[\mathrm{M}]:[\mathrm{RhCl}(\operatorname{cod})]_{2},[\operatorname{IrCl}(\operatorname{cod})]_{2},\left[\mathrm{PdCl}_{2}(\operatorname{cod})\right]$

$\mathrm{X}: \mathrm{Cl}, \operatorname{cod}$

SCHEME 13: Synthesis of paracetamol by Beckmann rearrangement of 4-hydroxyacetophenone oxime.

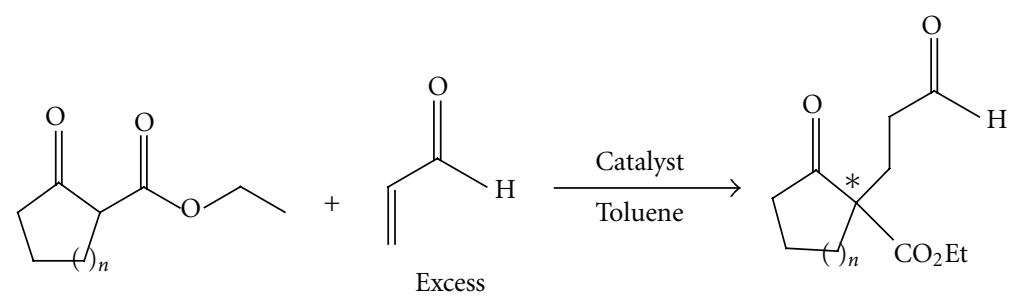

Scheme 14: Cyanohydrins formation from benzaldehyde and trimethylsilyl cyanide (TMSCN).

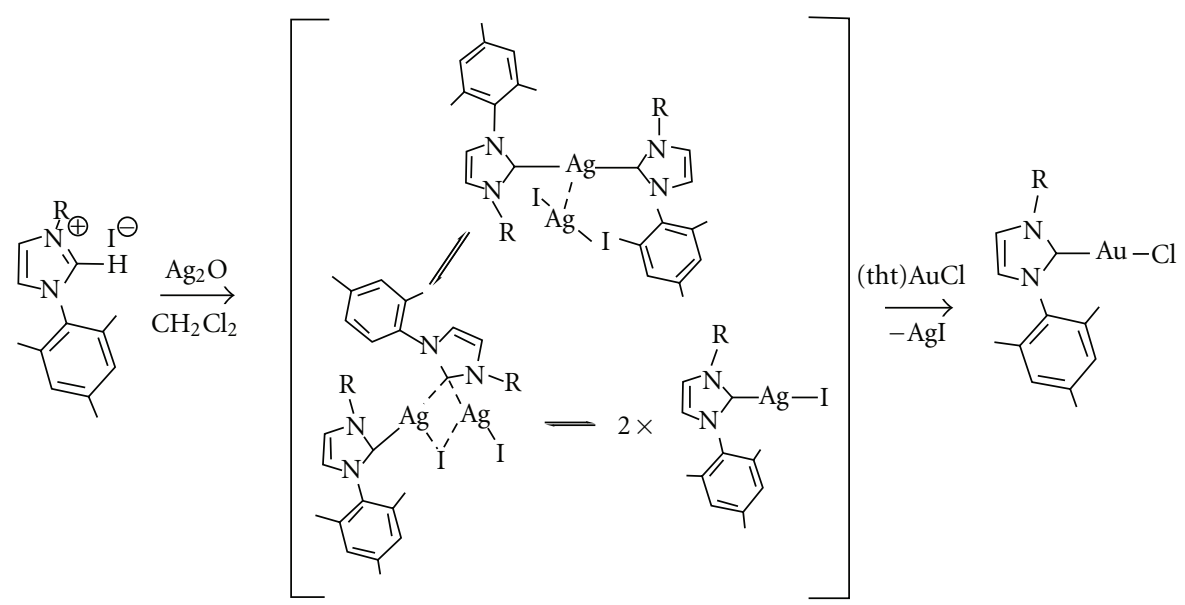

Scheme 15: Synthesis of metal complexes based on chiral triaza backbone ligands (according to [61]). 


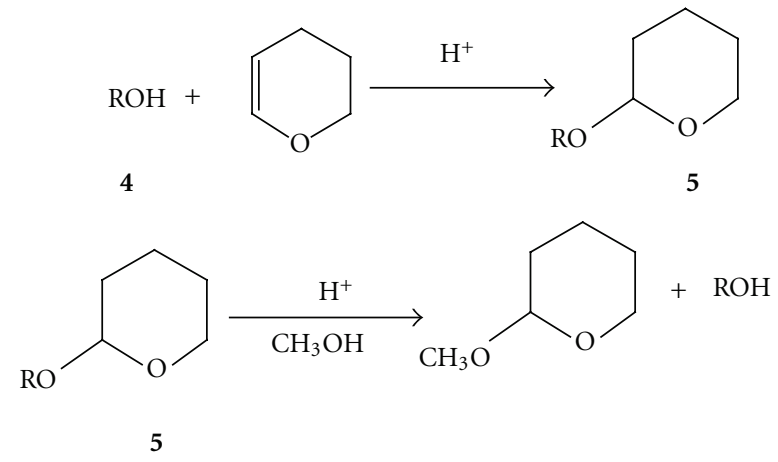

Scheme 16: Catalytic Michael addition of ethyl 2-oxocycloalkanecarboxylate to acrolein.<smiles>O=CCc1ccccc1CC(=O)CC(O)CO</smiles>

(a)<smiles>COc1cc(C=O)ccc1O</smiles><smiles>CC(O)CO</smiles><smiles>C=C</smiles><smiles>COc1cc(C2OCC(C)O2)ccc1O</smiles>

Scheme 17: Synthesis of gold-carbene complexes (according to [62]).

distributed along the network of each individual zeolitic layer allow the direct employ of these accessible zeolites in the production of fine chemicals without any post-synthesis treatment to immobilize additional organic functionalities. For instance, it is the case of the preparation of dimethylacetals and tetrahydropyranylation of alcohol and phenols using ITQ-2 delaminated zeolite as acid catalyst. The results obtained confirmed that when the reactions involved bulky reactants, ITQ-2 exhibited the highest activity owing to the combination of its disordered structure and the presence of strong and accessible acid sites into their framework (Scheme 16) [63, 145].

Into this thematic, interesting acetalization processes were carried out, catalyzed by MWW delaminated materials, for the synthesis of orange blossom and apple fragrances [146]. Similarly, direct synthesis of phenylacetaldehyde glycerol acetals (2-benzyl-4-hydroxymethyl-1,3-dioxolane, 2benzyl-5-hydroxy-1,3-dioxane) and vanillin propylene glycol acetal (2-(4-hydroxy-3-methoxyphenyl)-4-methyl-1,3dioxolane) which are flavoring compounds with hyacinth and vanilla scent fragrances, respectively, was successfully performed by acetalization of phenylacetaldehyde and vanillin with glycerol and propylene glycol, using toluene as solvent and exfoliated zeolites as catalysts (Scheme 17). On the opposite, in the case of bulky acetals, such as 2acetonaphthone propylene glycol acetal with blossom orange<smiles>CC(=O)Nc1ccc(O)cc1</smiles>

Scheme 18: Protection of hydroxyl groups by tetrahydropyranyl ethers (according to [63]).

scent, geometrical constraints, imposed by the microporous channels of conventional zeolites, would be a serious inconvenient to overcome during the acetalization processes. For this, a delaminated zeolite (ITQ-2) with very large, structured, and accessible external surface is an active and selective catalyst for this type of reactions. Additionally, the delaminated zeolite allowed the reaction to be carried out in a solvent-free reaction medium, being possible the generation of acetal fragrances in an environmentally more friendly process [147].

High value products, such as nonsteroidal drugs, with anti-inflammatory and analgesic activities, were obtained through the oximation of acetophenone derivatives, followed by the solid acid-catalyzed Beckmann rearrangement to give the corresponding amides. Delaminated ITQ-2 zeolites were employed as catalysts, being obtained excellent activity and 


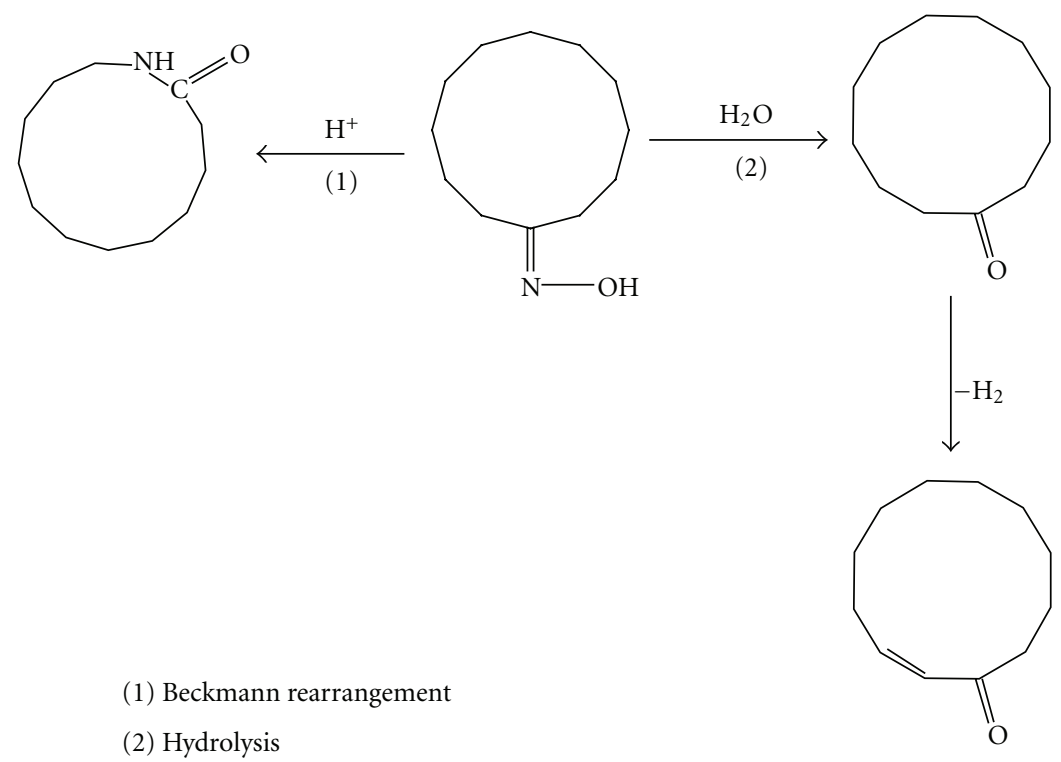

Scheme 19: Liquid-phase Beckmann rearrangement of cyclododecanone oxime into 2-azacyclotridecanone or $\omega$-laurolactam which is the monomer of Nylon-12 (according to [66]).<smiles>COc1ccc2ccccc2c1</smiles><smiles>COc1ccc2ccccc2c1Cc1c(OC)ccc2ccccc12</smiles><smiles>COc1ccc(CC2CC3C=CC2C32CCCCC2)cc1</smiles>

Scheme 20: Products of the condensation of paraformaldehyde with 2-methoxynaphthalene (according to [67]).<smiles>O=C1C=CC(=O)C=C1</smiles><smiles>C1CC1</smiles>$$
4
$$<smiles>O=C1C=CC(=O)[C@H]2C=CC[C@H]1C2</smiles><smiles>CC(C)(C)C</smiles><smiles>C1=CCCC1</smiles><smiles>O=C1[C@H]2[C@@H]3C=C[C@@H](C3)C(=O)[C@@H]2[C@H]2C=C[C@H]1C2</smiles>

endo-anti-endo<smiles>CC(C)(C)C1CCCC1</smiles>

exo-anti-exo
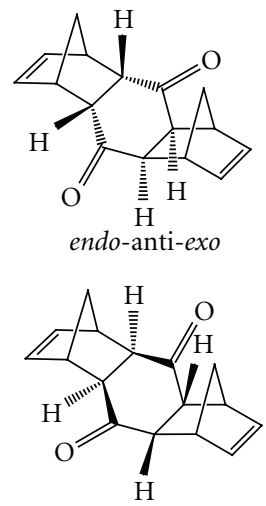

exo-anti-endo

Scheme 21: Distribution of products in the Diels-Alder reaction between cyclopentadiene and p-benzoquinone (according to [68]).

selectivity for amides when both accessibility of the reactants to the active sites and the surface polarity of the catalysts were optimized (Scheme 18) [148]. Beckmann rearrangement of the relatively bulky cyclododecanone oxime was also performed both in batch and fixed-bed continuous reactors, using ITQ-2 as catalyst. The results confirmed that the solid acid catalyst formed by MWW nanolayers of zeolitic nature was more active and selective than either a nanocrystalline microporous Beta zeolite or a mesoporous MCM-41 material, and the amount of organic derivatives which remained adsorbed on the catalyst after reaction is smaller in the exfoliated catalyst because the diffusion problems were minimized (Scheme 19) [66].

Analysis of the peculiar structure of the delaminated materials and its influence on the catalytic reactivity was also evaluated through the performances of a different solid acids 


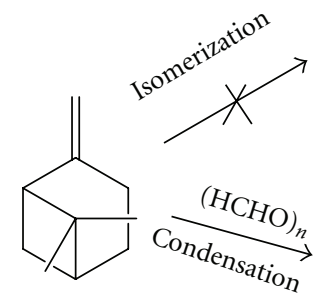

$\beta$-pinene

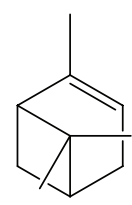

$\alpha$-pinene

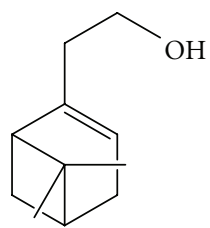

Nopol
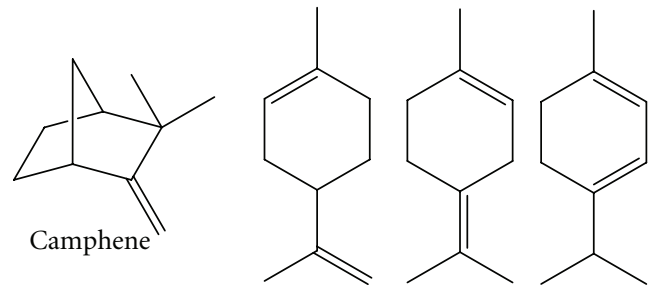

Limonene Terpinolene Terpinene

Scheme 22: Synthesis of Nopol through $\beta$-pinene condensation (according to [69]).

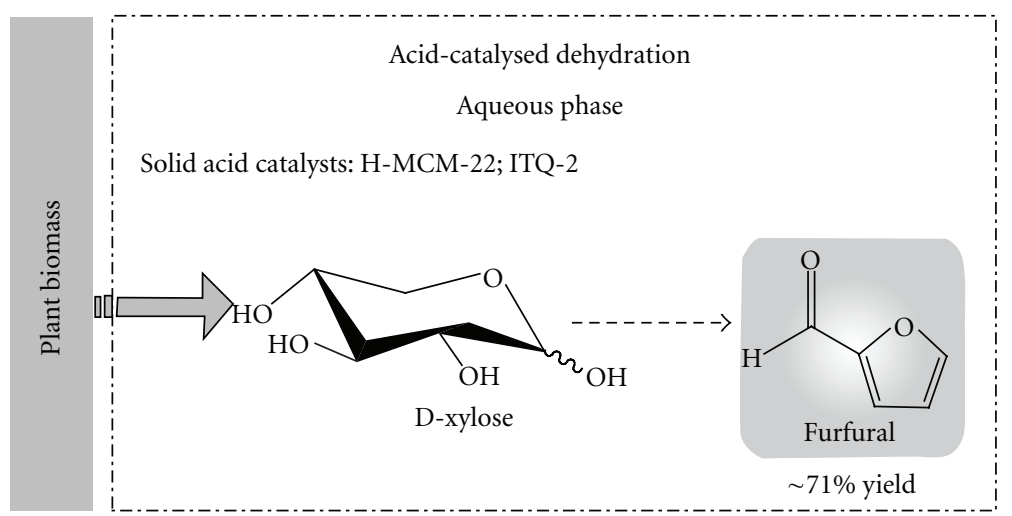

Scheme 23: Simplified representation of the conversion of carbohydrate biomass into furfural (according to [70]).

including conventional zeolites (HY, mordenite, and ZSM5), mesoporous Al-MCM-41 materials, and amorphous silica-aluminas compared with the layered zeolite ITQ-2 for the liquid-phase condensation of 2-methoxynaphthalene and naphthalene with paraformaldehyde to form dinaphthylmethane derivatives (Scheme 20). The results obtained showed that ITQ-2 exhibited the highest catalytic activity, being the ITQ-2 catalytic efficiency attributed to the suitable combination of higher acid strength than Al-MCM-41 and silica-aluminas and easier accessibility of its sites than for microporous zeolites [67].

Another interesting fine chemical processes, such as Diels-Alder and retro-Diels-Alder reaction between cyclopentadiene and $p$-benzoquinone (Scheme 21) [68], Prins condensation of $\beta$-pinene with paraformaldehyde for Nopol production (Scheme 22) [69] or, recently, aqueous phase dehydration of xylose to furfural (Scheme 23) [70], was successfully performed with open MWW structures (delaminated ITQ-2 and pillared MCM-36 zeolites), favored by the accessible presence of exposed acid sites stabilized from the zeolitic framework.

3.3. Other Processes. The benefits of the open zeolitic structures, derived from MWW layered precursors, can be exploited in other catalytic fields, more related with electro- or photo-catalysis. It is the case of the delaminated materials in which were supported and heterogenized metalloporphyrins containing Co or Fe, being active as catalysts for electrochemical oxygen reduction without detecting catalysts desorption from the electrode [149].

Inside the photochemistry field, it is important the generation of electron transfer species with high stability and durability. In this sense, the prevalence of the external surface over the internal porosity in the delaminated zeolites (ITQ2) favors the spontaneous generation of tetrathiafulvalene radical cations. This effect is strongly marked in MWW open structures compared with conventional microporous $\mathrm{Y}$, mordenite, and ZSM-5 zeolites as well as to Al-MCM-41 and amorphous silica-alumina. Moreover, through selective silylation of the external cups in the surface of individual MWW sheets, it was found that the formation of a significant concentration of stable organic radical cations occurred within these open cups rather than inside the sinusoidal internal 10 MR channels (Figure 31(a)) [77]. Similarly, the ability of ITQ-2 to generate organic radical cations was also confirmed through the external immobilization of $\alpha, \omega$-diphenyl-polyenes. In this case, alternative laser flash photolysis strongly favored the formation of 1-phenylnaphthalene radical cations as the intermediate formed after the adsorption of polyenes onto MWW layers, as consequence of the 


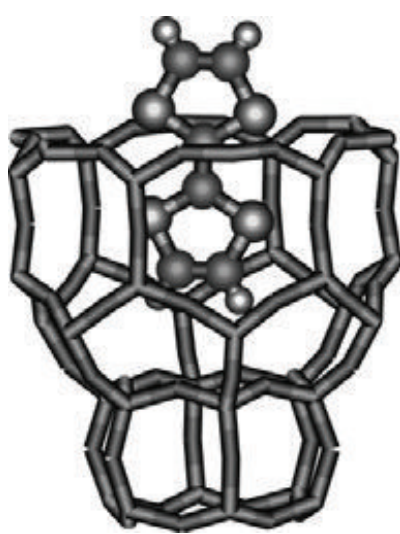

(a)

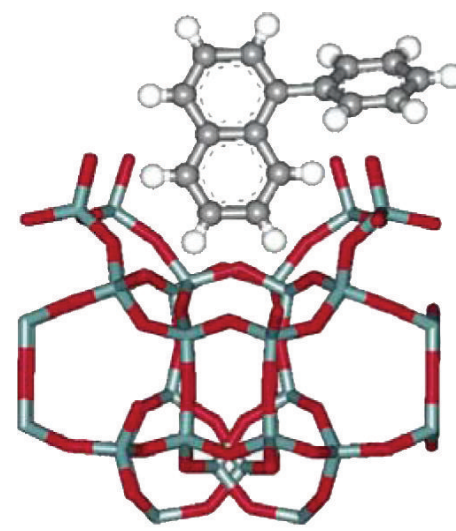

(b)

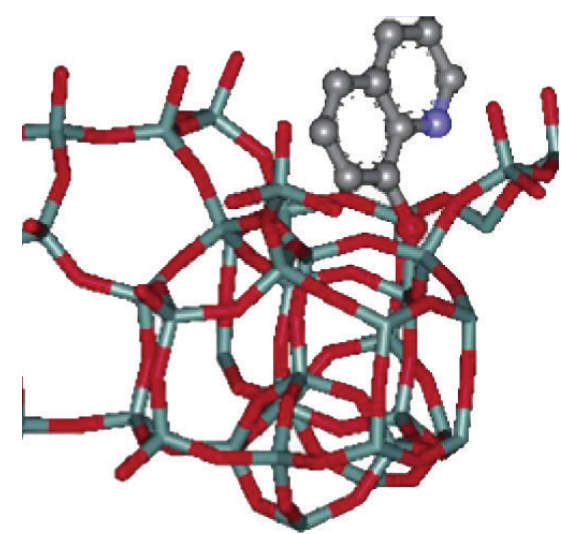

(c)

Figure 31: Representation of the best docking of tetrathiafulvalene (a), 1-phenyl-naphtalene (b), and hydroxyquinolate ligands inside the open cups of ITQ-2 (c) (according to [77-79], resp.).

uniqueness of ITQ-2 topology (Figure 31(b)) [78]. Into this line, photoinduced electron transfer species were also produced after the treatment of ITQ-2 zeolites, with previously immobilized $\mathrm{Ru}(\mathrm{bpy})^{32+}$, methylviologen, or blue lightemitting hydroxyquinolinate ligands onto the external cups, through emission and time-resolved laser flash photolysis (Figure 31(c)) [150, 151]. This technique was also useful to characterize titanium atoms present into the lamellar framework of disordered zeolites, such as Ti-ITQ-2 [79].

On the other hand, interesting biocatalysts can be obtained using delaminated zeolites as supports of enzymes. This type of zeolitic disordered materials exhibits suitable physicochemical properties such as a very high, hydroxylated, and ordered external surface together with elevated thermal stability. So, the preparation of catalysts based on zeolitic sheets with immobilized enzymes onto their external surface area was viable, being noticeable the improved activity and stability of the final products compared with the action of soluble enzymatic compounds. Specifically, the enzymes were supported either by means of ionic or covalent bonds, improving the stability of the enzymes without reactivity loss. Moreover, after reaction, the zeolitic supports can be recycled and reused to immobilize additional enzymes. Definitively, these results have opened the possibility of using open zeolitic structures for processes which involve enzymes as catalysts (Scheme 24) [152-155].

Alternatively, open MWW structures have been used as sensors by the covalent anchoring of fluorophore compounds, such as pyrene, being the resulting solid a selective heterogeneous sensor for iodide in the presence of other halides in the medium (Scheme 25) [80]. Finally, pillared and delaminated materials have successfully been used to adsorb and capture gases, such as $\mathrm{CO}_{2}$ or $\mathrm{SO}_{2}$. For this application, it is necessary the incorporation of $\mathrm{SO}_{x}$ storage component ( $\mathrm{Ba}, \mathrm{Al}$, and $\mathrm{Mg}$ ) by impregnation or pillaring with the corresponding metal oxides and with an oxidant component $(\mathrm{Pt})$. The results showed that the MWW materials which contain $\mathrm{Ba}$ and $\mathrm{Al}$ exhibited a higher $\mathrm{SO}_{x}$ uptake compared to the samples containing $\mathrm{Mg}$.
Moreover, for pillared MCM-36 zeolites a direct correlation between the surfaces area and the $\mathrm{SO}_{x}$ sorption capacities was detected [156]. Similarly, MWW derivative materials (ITQ-2 and MCM-36) were evaluated as a $\mathrm{CO}_{2}$ capturing agent with or without postgrafting amine functionalization. The $\mathrm{CO}_{2}$ fixation capacity was measured from isotherms at different adsorption temperatures and the corresponding heats of adsorption. The data obtained showed that the amount of adsorbed $\mathrm{CO}_{2}$ varied in the sequence of $\mathrm{NH}_{2}$ ITQ-2 > ITQ-2 > MCM-36> NH - MCM-36 at $298 \mathrm{~K}$. It was confirmed that for the zeolites without amine-grafting, aluminum content was the decisive factor which determines the adsorption capacity. On the contrary, aminegrafting on zeolites resulted in an increase in $\mathrm{CO}_{2} / \mathrm{N}_{2}$ selectivity, and more elevated heats of $\mathrm{CO}_{2}$ adsorption implied a strong reduction in $\mathrm{CO}_{2}$ capture capacity. Specifically, $\mathrm{NH}_{2}$-ITQ-2 showed exceptionally high $\mathrm{CO}_{2} / \mathrm{N}_{2}$ selectivity combined with the best separation capacity among the studied MWW-type zeolites [157-161].

\section{Conclusions and Outlook}

Into the catalysis field, zeolites have promoted a revolution as acid catalysts. Moreover, their microporosity introduces shape selectivity in reactive processes and this matter will influence on reaction products. This apparent advantage can represent, in some cases, a serious inconvenient, since in a large number of processes take part molecules of elevated size, which are not feasible with microporous catalysts of restricted accessibility. This problem can be avoided with innovative zeolitic materials, with their characteristic acidity, but with a higher accessibility in order to facilitate the reactive molecules access to active sites, overcoming the difficulties imposed by their conventional microporosity.

This proposal has successfully carried out with bidimensional MWW layered zeolitic precursors which are delaminated or exfoliated with the objective to obtain new delaminated materials, ITQ-2 zeolites, composed by 


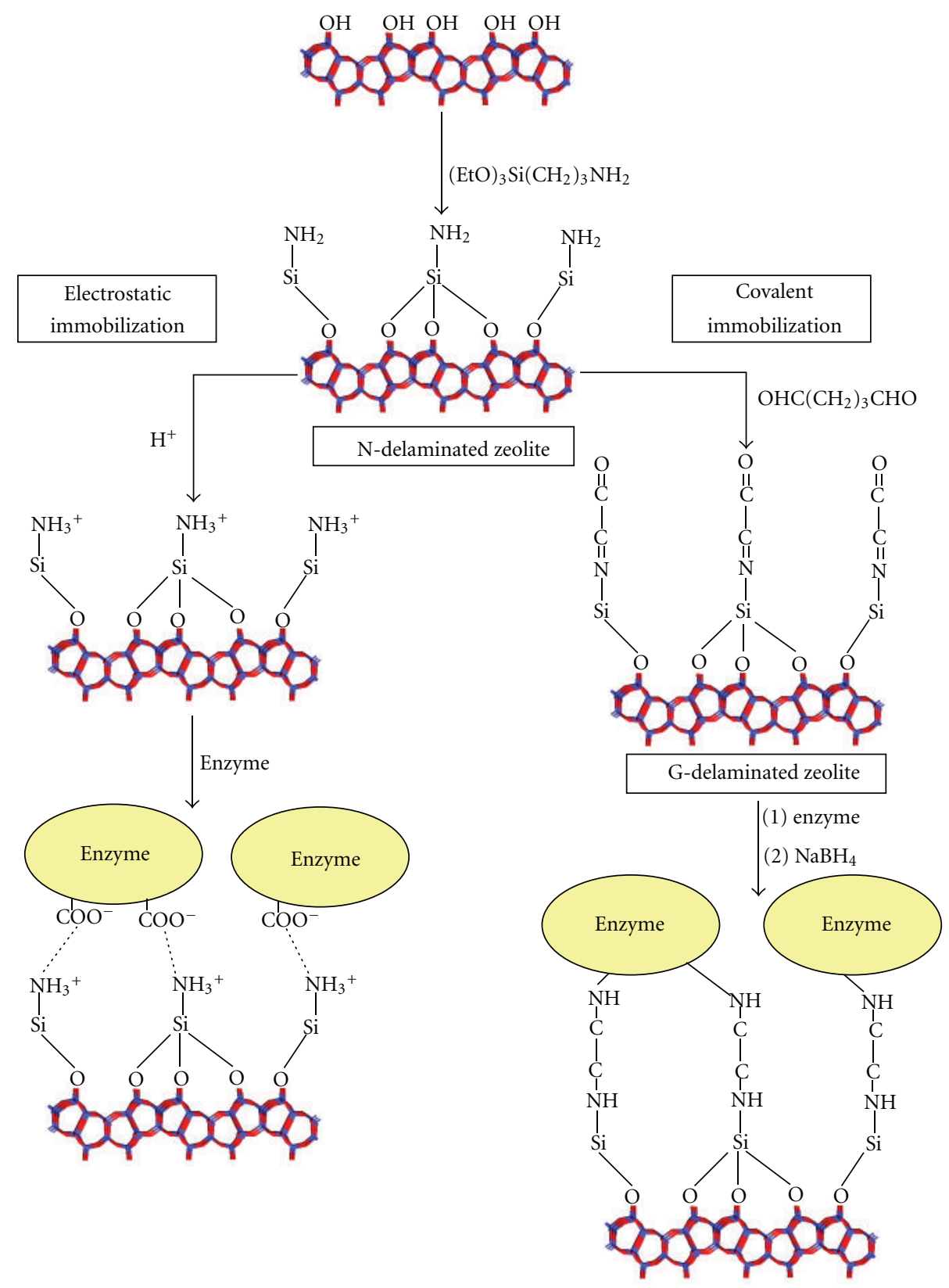

Scheme 24: Covalent or electrostatic immobilization of enzymes onto delaminated zeolites used as inorganic supports.

disordered layers, and characterized by an elevated and accessible external surface area. on the other hand, when the layered MWW precursors are pillared, innovative materials with high accessibility are obtained, but formed by interlayered mesoporous galleries, called MCM-36 zeolites. Both MWW materials families are currently being employed in interesting applications related with catalytic reactions of industrial relevance inside petrochemistry and Fine Chemistry. Furthermore, they are excellent inorganic supports of functional molecules, as enzymes or specific organocatalysts, owing to their elevated hydrothermal stability, structural homogeneity, and high external surface area.
These peculiar characteristics would allow the stable incorporation, onto the individual MWW sheets, of several and suitable organic, organometallic, and/or metal functional species. These active and accessible sites could even be combined with additional centers included into the framework of the individual inorganic layers. The consequence would be the generation of organic-inorganic multifunctional hybrid catalysts to carry out multicomponent or cascade reactions in one-pot processes, using only one heterogeneous and recyclable catalytic system (Figure 32). This fact would imply an important advance into the catalysis field because reaction steps number, intermediates isolation, 


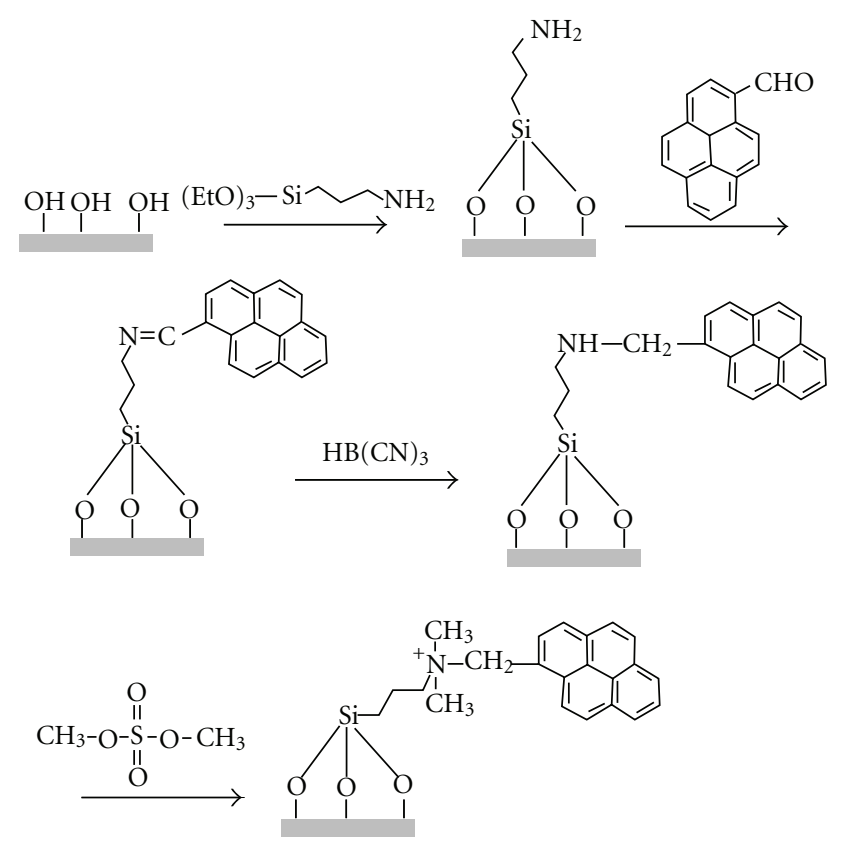

Scheme 25: Procedure to anchor pyrene fluorophore onto ITQ-2 individual layers (according to [80]).

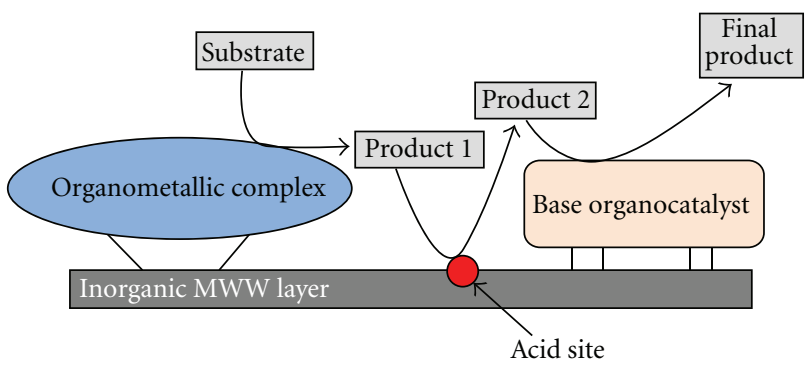

FIGURE 32: Schematic representation of cascade reaction catalyzed by multifunctional materials based on individual zeolitic layers which contain several active groups.

organic solvents amount, or residual compounds could strongly be reduced which would be useful to develop more sustainable and efficient chemical processes.

\section{Acknowledgment}

The author thanks the Spanish Government (Consolider Ingenio 2010-MULTICAT (CSD2009-00050) and MAT2011-29020-C02-01) for the financial support.

\section{References}

[1] T. J. Pinnavaia, "Nonporous layered materials," Advances in Chemistry, vol. 245, pp. 283-300, 1995.

[2] G. Alberti, C. Dionigi, E. Giontella, S. Murcia-Mascarós, and R. Vivani, "Formation of colloidaldispersions of layered $\gamma$ zirconium phosphate in water/acetone mixtures," Journal of Colloid and Interface Science, vol. 188, no. 1, pp. 27-31, 1997.
[3] T. Sasaki, M. Watanabe, H. Hashizume, H. Yamada, and H. Nakazawa, "Macromolecule-like aspects for a colloidal suspension of an exfoliated titanate. Pairwise association of nanosheets and dynamic reassembling process initiated from it," Journal of the American Chemical Society, vol. 118, no. 35, pp. 8329-8335, 1996.

[4] J. M. Troup and A. Clearfield, "Mechanism of ion exchange in zirconium phosphates. 20. Refinement of the crystal structure of .alpha.-zirconium phosphate," Inorganic Chemistry, vol. 16, pp. 3311-3314, 1977.

[5] G. Lagaly, "Interaction of alkylamines with different types of layered compounds," Solid State Ionics, vol. 22, no. 1, pp. 4351, 1986.

[6] S. B. Pergher, "Materiales de transición entre arcillas pilareadas y zeolitas: Zeolitas expandidas," [Doctoral thesis], Instituto de Tecnología Química (UPV-CSIC), Universidad Politécnica de Valencia, 1997.

[7] A. J. Jacobson, "Colloidal dispersions of compounds with layer and chain structures," Materials Science Forum, vol. 152153, pp. 1-12, 1994.

[8] H. Van Olphen, "Clay colloid chemistry," A Wiley-Interscience Publication, John Wiley \& Sons, 1963.

[9] T. E. Mallouk and J. A. Gavin, "Molecular recognition in lamellar solids and thin films," Accounts of Chemical Research, vol. 31, no. 5, pp. 209-217, 1998.

[10] K. S. Suslick and G. J. Price, Annual Review of Materials Research, vol. 29, pp. 295-396, 1999.

[11] S. Nicolopoulos, J. M. Gonzalez Calbet, M. Vallet Regí et al., "Use of Electron Microscopy and microdiffraction for zeolite framework comparison," Journal of American Chemical Society, vol. 119, pp. 11000-11005, 1997.

[12] P. Wu, T. Tatsumi, T. Komatsu, and T. Yashima, "Hydrothermal synthesis of a novel titanosilicate with MWW topology," Chemistry Letters, no. 7, pp. 774-775, 2000.

[13] P. Wu, T. Tatsumi, T. Komatu, and T. Yashima, "A novel Titanosilicate with MWW structure: II catalytic properties in the selective oxidation of alkenes," Journal of Catalysis, vol. 202, pp. 245-255, 2002.

[14] J. Ruan, P. Wu, B. Slater, and O. Terasaki, "Structure elucidation of the highly active titanosilicate catalyst TiYNU-1," Angewandte Chemie, vol. 44, no. 41, pp. 6719-6723, 2005.

[15] R. Ravishankar, P. N. Joshi, S. S. Tamhankar, S. Sivasanker, and V. P. Shiralkar, "A novel zeolite MCM-22: sorption characteristics," Adsorption Science and Technology, vol. 16, no. 8, pp. 607-621, 1998.

[16] W. J. Roth and D. L. Dorset, "Expanded view of zeolite structures and their variability based on layered nature of 3D frameworks," Microporous and Mesoporous Materials, vol. 142, pp. 32-36, 2011.

[17] W. J. Roth and J. Cejka, "Two-dimensional zeolites: dream or reality?" Catalysis Science \& Technology, vol. 1, pp. 43-53, 2011.

[18] L. Schereyeck, P. Caullet, J. C. Mougenel, J. L. Guth, and B. Marler, "A layered microporous aluminosilicate precursor of FER-type zeolite," Chem. Commun, vol. 21, pp. 2187-2188, 1995.

[19] L. Schreyeck, P. Caullet, J. C. Mougenel, J. L. Guth, and B. Marler, "PREFER: a new layered (alumino) silicate precursor of FER-type zeolite," Microporous Materials, vol. 6, no. 5-6, pp. 259-271, 1996. 
[20] S. Zanardi, A. Alberti, G. Cruciani, A. Corma, V. Fornés, and M. Brunelli, "Crystal structure determination of zeolite Nu6(2) and its layered precursor Nu-6(1)," Angewandte Chemie, vol. 43, no. 37, pp. 4933-4937, 2004.

[21] M. Choi, K. Na, J. Kim, Y. Sakamoto, O. Terasaki, and R. Ryoo, "Stable single-unit-cell nanosheets of zeolite MFI as active and long-lived catalysts," Nature, vol. 461, pp. 246-249, 2009.

[22] K. Na, M. Chol, W. Park, Y. Sakamoto, O. Terasakl, and R. Ryoo, "Pillared MFI zeolite nanosheets of a single-unit-cell thickness," Journal of the American Chemical Society, vol. 132, no. 12, pp. 4169-4177, 2010.

[23] W. Fan, P. Wu, S. Namba, and T. Tatsumi, "A titanosilicate that is structurally analogous to an MWW-type Lamellar precursor," Angewandte Chemie, vol. 43, pp. 236-240, 2004.

[24] P. Wu, J. Ruan, L. Wang et al., "Methodology for synthesizing crystalline metallosilicates with expanded pore windows through molecular alkoxysilylation of zeolitic lamellar precursors," Journal of the American Chemical Society, vol. 130, no. 26, pp. 8178-8187, 2008.

[25] G. G. Juttu and R. F. Lobo, "Characterization and catalytic properties of MCM-56 and MCM-22 zeolites," Microporous and Mesoporous Materials, vol. 40, no. 1-3, pp. 9-23, 2000.

[26] P. P. Yang, J. F. Yu, Z. L. Wang et al., Catalysis Communications, vol. 6, pp. 107-111, 2005.

[27] M. E. Leonowicz, J. A. Lawton, S. L. Lawton, and M. K. Rubin, "MCM-22: a molecular sieve with two independent multidimensional channel systems," Science, vol. 264, no. 5167, pp. 1910-1913, 1994.

[28] A. Corma, C. Corell, and J. Pérez-Pariente, "Synthesis and characterization of the MCM-22 zeolite," Zeolites, vol. 15, no. 1, pp. 2-8, 1995.

[29] C. A. Emeis, "Determination of integrated molar extinction coefficients for infrared absorption bands of pyridine adsorbed on solid acid catalysts," Journal of Catalysis, vol. 141, no. 2, pp. 347-354, 1993.

[30] B. Onida, L. Borello, B. Bonelli, F. Geobaldo, and E. Garrone, "IR study of the acidity of ITQ-2, an "all-surface" zeolitic system," Journal of Catalysis, vol. 214, no. 2, pp. 191-199, 2003.

[31] M. K. Rubin, "Composition of synthetic porous crystalline material, its synthesis and use," U.S. Patent, 49454325, 1990.

[32] L. Puppe and J. Weisser, "Crystalline aluminosilicate PSH-3 and its process of preparation," U.S. Patent, 4439409, 1984.

[33] I. Ogino, M. M. Nigra, S. J. Hwang et al., "Delamination of layered zeolite precursors under mild conditions: synthesis of UCB-1 via fluoride/chloride anion-promoted exfoliation," Journal of the American Chemical Society, vol. 133, no. 10, pp. 3288-3291, 2011.

[34] P. Wu, D. Nuntasri, J. Ruan et al., "Delamination of Ti-MWW and high efficiency in epoxidation of alkenes with various molecular sizes," Journal of Physical Chemistry B, vol. 108, no. 50, pp. 19126-19131, 2004.

[35] A. Corma, U. Díaz, V. Fornes, J. L. Jorda, M. Domine, and F. Rey, "Ti/ITQ-2, a new material highly active and selective for the epoxidation of olefins with organic hydroperoxides," Chemical Communications, no. 9, pp. 779-780, 1999.

[36] A. Corma, C. Corell, J. Pérez-Pariente et al., "Adsorption and catalytic properties of MCM-22: the influence of zeolite structure," Zeolites, vol. 16, no. 1, pp. 7-14, 1996.

[37] R. Ravishankar, T. Sen, V. Ramaswamy, H. S. Soni, and S. Ganapathy, "Synthesis, Characterization and Catalytic properties of Zeolite PSH-3/MCM-22," Studies in Surface Science and Catalysis, vol. 84, pp. 331-338, 1994.
[38] I. Guray, J. Warzywoda, N. Bac, and A. Sacco, "Synthesis of zeolite MCM-22 under rotating and static conditions," Microporous and Mesoporous Materials, vol. 31, no. 3, pp. 241-251, 1999.

[39] Y. M. Wang, X. T. Shu, and M. Y. He, "Static synthesis of zeolite MCM-22," Studies in Surface Science and Catalysis, vol. 135, p. 194, 2001.

[40] F. Eder, Y. He, G. Nivarthy, and J. A. Lercher, "Sorption of alkanes on novel pillared zeolites; comparison between MCM-22 and MCM-36," Recueil des Travaux Chimiques des Pays-Bas, vol. 115, no. 11-12, pp. 531-535, 1996.

[41] J. O. Barth, J. Kornatowski, and J. A. Lercher, "Synthesis of new MCM-36 derivatives pillared with alumina or magnesiaalumina," Journal of Materials Chemistry, vol. 12, no. 2, pp. 369-373, 2002.

[42] S. Maheshwari, E. Jordan, S. Kumar et al., "Layer structure preservation during swelling, pillaring, and exfoliation of a zeolite precursor," Journal of the American Chemical Society, vol. 130, no. 4, pp. 1507-1516, 2008.

[43] S. I. Zones, “Zeolite SSZ-25,” U.S. Patent, 4826667, 1989.

[44] I. Y. Chan, A. P. Labun, M. Pan, and S. I. Zones, "Highresolution electron microscopy characterization of SSZ-25 zeolite," Microporous and Mesoporous Materials, vol. 3, pp. 409-418, 1995.

[45] J. Aguilar, A. Corma, F. V. Melo, and E. Sastre, "Alkylation of biphenyl with propylene using acid catalysts," Catalysis Today, vol. 55, no. 3, pp. 225-232, 2000.

[46] A. Fuerte, A. Corma, M. Iglesias, E. Morales, and F. Sánchez, "Approaches to the synthesis of heterogenised metalloporphyrins: application of new materials as electrocatalysts for oxygen reduction," Journal of Molecular Catalysis A, vol. 246, no. 1-2, pp. 109-117, 2006.

[47] A. Corma, U. Díaz, T. García, G. Sastre, and A. Velty, "Multifunctional hybrid organic-inorganic catalytic materials with a hierarchical system of well-defined micro- and mesopores," Journal of the American Chemical Society, vol. 132, no. 42, pp. 15011-15021, 2010.

[48] A. Corma, V. Fornes, S. B. Pergher, T. L. M. Maesen, and J. G. Buglass, "Delaminated zeolite precursors as selective acidic catalysts," Nature, vol. 396, no. 6709, pp. 353-356, 1998.

[49] M. A. Camblor, M. J. Díaz-Cabañas, C. Corell, and A. Corma, “Zeolite ITQ-1," U.S. Patent, 6077498, 2000.

[50] M. A. Camblor, C. Corell, A. Corma et al., "A new microporous polymorph of silica isomorphous to zeolite MCM-22," Chemistry of Materials, vol. 8, no. 10, pp. 2415-2417, 1996.

[51] M. A. Camblor, A. Corma, M. J. Díaz-Cabañas, and C. Baerlocher, "Synthesis and structural characterization of MWW type zeolite ITQ-1, the pure silica analog of MCM22 and SSZ-25," Journal of Physical Chemistry B, vol. 102, no. 1, pp. 44-51, 1998.

[52] M. J. Díaz Cabañas, "Síntesis de nuevos polimorfos de $\mathrm{SiO}_{2}$ microporosos de baja densidad de red. Sustitución isomórfica de Si por Al y Ti," [Doctoral thesis], Instituto de Tecnología Química, Universidad Politécnica de Valencia, 1999.

[53] A. Martínez and G. Prieto, "Breaking the dispersionreducibility dependence in oxide-supported cobalt nanoparticles," Journal of Catalysis, vol. 245, no. 2, pp. 470-476, 2007.

[54] S. Inagaki, K. Kamino, E. Kikuchi, and M. Matsukata, "Shape selectivity of MWW-type aluminosilicate zeolites in the alkylation of toluene with methanol," Applied Catalysis A, vol. 318, pp. 22-27, 2007.

[55] P. Botella, A. Corma, R. H. Carr, and C. J. Mitchell, "Towards an industrial synthesis of diamino diphenyl 
methane (DADPM) using novel delaminated materials: a breakthrough step in the production of isocyanates for polyurethanes," Applied Catalysis A, vol. 398, no. 1-2, pp. 143-149, 2011.

[56] W. Adam, A. Corma, H. García, and O. Weichold, “Titaniumcatalyzed heterogeneous oxidations of silanes, chiral allylic alcohols, 3-alkylcyclohexanes, and thianthrene 5-oxide: a comparison of the reactivities and selectivities for the largepore zeolite $\mathrm{Ti}-\beta$, the mesoporous Ti-MCM-41, and the layered alumosilicate Ti-ITQ-2," Journal of Catalysis, vol. 196, no. 2, pp. 339-344, 2000.

[57] C. Baleizão, B. Gigante, M. J. Sabater, H. Garcia, and A. Corma, "On the activity of chiral chromium salen complexes covalently bound to solid silicates for the enantioselective epoxide ring opening," Applied Catalysis A, vol. 228, no. 12, pp. 279-288, 2002.

[58] V. Ayala, A. Corma, M. Iglesias, J. A. Rincón, and F. Sánchez, "Hybrid organic_-inorganic catalysts: a cooperative effect between support, and palladium and nickel salen complexes on catalytic hydrogenation of imines," Journal of Catalysis, vol. 224, no. 1, pp. 170-177, 2004.

[59] C. González-Arellano, A. Corma, M. Iglesias, and F. Sánchez, "Pd(II)-Schiff base complexes heterogenised on MCM-41 and delaminated zeolites as efficient and recyclable catalysts for the heck reaction," Advanced Synthesis and Catalysis, vol. 346, no. 13-15, pp. 1758-1764, 2004.

[60] I. Domínguez, V. Fornés, and M. J. Sabater, "Chiral manganese(III) salen catalysts immobilized on MCM-41 and delaminated zeolites ITQ-2 and ITQ-6 through new axial coordinating linkers," Journal of Catalysis, vol. 228, no. 1, pp. 92-99, 2004.

[61] C. González-Arellano, A. Corma, M. Iglesias, and F. Sánchez, "From homogeneous to heterogeneous catalysis: supported $\mathrm{Pd}(\mathrm{II})$ metal complexes with chiral triaza donor ligands: comparative catalytic study with $\mathrm{Rh}(\mathrm{I})$ and $\operatorname{Ir}(\mathrm{I})$ complexes for hydrogenation reactions," Catalysis Today, vol. 107-108, pp. 362-370, 2005.

[62] A. Corma, E. Gutiérrez-Puebla, M. Iglesias, A. Monge, S. Pérez-Ferreras, and F. Sánchez, "New heterogenized gold(I)heterocyclic carbene complexes as reusable catalysts in hydrogenation and cross-coupling reactions," Advanced Synthesis and Catalysis, vol. 348, no. 14, pp. 1899-1907, 2006.

[63] I. Rodriguez, M. J. Climent, S. Iborra, V. Fornés, and A. Corma, "Use of delaminated zeolites (ITQ-2) and mesoporous molecular sieves in the production of fine chemicals: preparation of dimethylacetals and tetrahydropyranylation of alcohols and phenols," Journal of Catalysis, vol. 192, no. 2, pp. 441-447, 2000.

[64] G. Bellusi, G. Perego, M. G. Cierici, and A. Giusti, "ERB1 layered borosilicate precursor," European Patent, 293032, 1988.

[65] R. Millini, G. Perego, W. O. Parker, G. Bellussi, and L. Carluccio, "Layered structure of ERB-1 microporous borosilicate precursor and its intercalation properties towards polar molecules," Microporous Materials, vol. 4, no. 2-3, pp. 221230, 1995.

[66] P. Botella, A. Corma, S. Iborra, R. Montón, I. Rodríguez, and V. Costa, "Nanosized and delayered zeolitic materials for the liquid-phase Beckmann rearrangement of cyclododecanone oxime," Journal of Catalysis, vol. 250, no. 1, pp. 161-170, 2007.

[67] A. Corma, H. García, and J. Miralles, "High activity of layered zeolite ITQ-2 as catalyst for the hydroxyalkylation of 2-methoxynaphthalene and naphthalene with paraformaldehyde. Comparison of its performance with that of conventional zeolites or mesoporous A1/MCM-41," Microporous and Mesoporous Materials, vol. 43, no. 2, pp. 161-169, 2001.

[68] M. V. Gómez, Á. Cantín, A. Corma, and A. De La Hoz, "Use of different microporous and mesoporous materials as catalyst in the Diels-Alder and retro-Diels-Alder reaction between cyclopentadiene and p-benzoquinone: activity of Al-, Ti- and Sn-doped silica," Journal of Molecular Catalysis A, vol. 240, no. 1-2, pp. 16-21, 2005.

[69] J. Wang, S. Jaenicke, G. K. Chuah, W. Hua, Y. Yue, and Z. Gao, "Acidity and porosity modulation of MWW type zeolites for Nopol production by Prins condensation," Catalysis Communications, vol. 12, no. 12, pp. 1131-1135, 2011.

[70] M. M. Antunes, S. Lima, A. Fernandes, M. Pillinger, M. F. Ribeiro, and A. A. Valente, "Aqueous-phase dehydration of xylose to furfural in the presence of MCM-22 and ITQ-2 solid acid catalysts," Applied Catalysis A, vol. 417-418, pp. 243-252, 2012.

[71] C. B. Khouw and M. E. Davis, "Catalytic activity of titanium silicates synthesized in the presence of alkali-metal and alkaline-earth ions," Journal of Catalysis, vol. 151, no. 1, pp. 77-86, 1995.

[72] P. Wu and T. Tatsumi, "Preparation of B-free Ti-MWW through reversible structural conversion," Chemical Communications, pp. 1026-1027, 2002.

[73] P. Wu, Y. Liu, M. He, and T. Tatsumi, "A novel titanosilicate with MWW structure catalytic properties in selective epoxidation of diallyl ether," Journal of Catalysis, vol. 228, pp. 183191, 2004.

[74] T. Tatsumi, W. Peng, and T. Katsuyuki, "MWW type zeolite substance, precursor substance therefor, and process for producing these substances," U.S. Patent, US7326401B2, 2008.

[75] S. Inagaki and T. Tatsumi, "Vapor-phase silylation for the construction of monomeric silica puncheons in the interlayer micropores of Al-MWW layered precursor," Chemical Communications, no. 18, pp. 2583-2585, 2009.

[76] L. Wang, Y. Wang, Y. Liu et al., "Alkoxysilylation of TiMWW lamellar precursors into interlayer pore-expanded titanosilicates," Journal of Materials Chemistry, vol. 19, no. 45, pp. 8594-8602, 2009.

[77] A. Corma, V. Fornés, M. S. Galletero, H. García, and C. J. Gómez-García, "Prevalence of the external surface over the internal pores in the spontaneous generation of tetrathiafulvalene radical cation incorporated in the novel delaminated ITQ-2 zeolite," Physical Chemistry Chemical Physics, vol. 3, no. 7, pp. 1218-1222, 2001.

[78] M. S. Galletero, A. Corma, B. Ferrer, V. Fornés, and H. García, "Confinement effects at the external surface of delaminated zeolites (ITQ-2): an inorganic mimic of cyclodextrins," Journal of Physical Chemistry B, vol. 107, no. 5, pp. 11351141, 2003.

[79] P. Atienzar, A. Corma, H. García, and J. C. Scaiano, "Diffuse reflectance laser flash photolysis study of titaniumcontaining zeolites," Chemistry of Materials, vol. 16, no. 6, pp. 982-987, 2004.

[80] A. Corma, M. S. Galletero, H. García, E. Palomares, and F. Rey, "Pyrene covalently anchored on a large external surface area zeolite as a selective heterogeneous sensor for iodide," Chemical Communications, vol. 10, pp. 1100-1101, 2002.

[81] S. J. Kim, K. D. Jung, and O. S. Joo, "Synthesis and characterization of gallosilicate molecular sieve with the 
MCM-22 framework topology," Journal of Porous Materials, vol. 11, no. 4, pp. 211-218, 2004.

[82] A. A. Teixeira-Neto, L. Marchese, G. Landi, L. Lisi, and H. O. Pastore, "[V,Al]-MCM-22 catalyst in the oxidative dehydrogenation of propane," Catalysis Today, vol. 133-135, no. 1-4, pp. 1-6, 2008.

[83] Y. Wu, J. Wang, P. Liu, W. Zhang, J. Gu, and X. Wang, "Framework-substituted lanthanide MCM-22 zeolite: synthesis and characterization," Journal of the American Chemical Society, vol. 132, no. 51, pp. 17989-17991, 2010.

[84] J. M. Bennett, C. D. Chang, S. L. Lawton, M. E. Leonowicz, D. N. Lissy, and M. K. Rubin, "Synthetic porous crystalline MCM-49, its synthesis and use," U.S. Patent, US5236575, 1993.

[85] S. L. Lawton, A. S. Fung, G. J. Kennedy et al., "Zeolite MCM49: a three-dimensional MCM-22 analogue synthesized by in situ crystallization," Journal of Physical Chemistry, vol. 100, no. 9, pp. 3788-3798, 1996.

[86] G. J. Kennedy, S. L. Lawton, A. S. Fung, M. K. Rubin, and S. Steuernagel, "Multinuclear MAS NMR studies of zeolites MCM-22 and MCM-49," Catalysis Today, vol. 49, no. 4, pp. 385-399, 1999.

[87] A. L. S. Santos-Marques, J. L. F. Monteiro, and H. O. Pastore, "Static crystallization of zeolites MCM-22 and MCM-49," Microporous and Mesoporous Materials, vol. 32, pp. 131-145, 1999.

[88] A. S. Fung, S. L. Lawton, and W. J. Roth, U.S. Patent, US5362697, 1994.

[89] A. Corma, M. J. Díaz-Cabanas, M. Moliner, and C. Martínez, "Discovery of a new catalytically active and selective zeolite (ITQ-30) by high-throughput synthesis techniques," Journal of Catalysis, vol. 241, no. 2, pp. 312-318, 2006.

[90] W. J. Roth, D. L. Dorset, and G. J. Kennedy, "Discovery of new MWW family zeolite EMM-10: identification of EMM$10 \mathrm{P}$ as the missing MWW precursor with disordered layers," Microporous and Mesoporous Materials, vol. 142, no. 1, pp. 168-177, 2011.

[91] A. Corma, V. Fornés, and S. B. C. Pergher, "Zeolite ITQ-2," World Patent, WO9717290A1, 1997.

[92] A. Corma, V. Fornés, J. Martínez-Triguero, and S. B. Pergher, "Delaminated zeolites: combining the benefits of zeolites and mesoporous materials for catalytic uses," Journal of Catalysis, vol. 186, no. 1, pp. 57-63, 1999.

[93] M. A. Springuel-Huet, A. Nossov, F. Guenneau et al., "Characterization of delaminated zeolites by 129Xe NMR with laser- hyperpolarized xenon," Studies in Surface Science and Catalysis, vol. 154, pp. 1204-1211, 2004.

[94] L. Borello, B. Onida, B. Bonelli, and E. Garrone, "Differences between isolated silanols in all-silica ITQ-2 and MCM-41," Studies in Surface Science and Catalysis, vol. 154, pp. 15321538, 2004.

[95] A. Corma, U. Díaz, V. Fornés, J. M. Guil, J. MartínezTriguero, and E. J. Creyghton, "Characterization and catalytic activity of MCM-22 and MCM-56 compared with ITQ-2," Journal of Catalysis, vol. 191, no. 1, pp. 218-224, 2000.

[96] A. Corma, V. Fornés, J. M. Guil, S. Pergher, T. L. M. Maesen, and J. G. Buglass, "Preparation, characterisation and catalytic activity of ITQ-2, a delaminated zeolite," Microporous and Mesoporous Materials, vol. 38, no. 2-3, pp. 301-309, 2000.

[97] R. Schenkel, J.-O. Barth, J. Kornatowski, and J. A. Lercher, "Chemical and structural aspects of the transformation of the MCM-22 precursor into ITQ-2," Studies in Surface Science and Catalysis, vol. 142, pp. 69-76, 2002.
[98] P. Frontera, F. Testa, R. Aiello, S. Candamano, and J. B. Nagy, "Transformation of MCM-22(P) into ITQ-2: the role of framework aluminium," Microporous and Mesoporous Materials, vol. 106, no. 1-3, pp. 107-114, 2007.

[99] V. V. Narkhede and H. Gies, "Crystal structure of MCM22 (MWW) and Its delaminated zeolite ITQ-2 from highresolution powder X-Ray diffraction data: an analysis using rietveld technique and atomic pair distribution function," Chemistry of Materials, vol. 21, no. 18, pp. 4339-4346, 2009.

[100] D. L. Dorset, W. J. Roth, and C. J. Gilmore, "Electron crystallography of zeolites - the MWW family as a test of direct 3D structure determination," Acta Crystallographica, vol. 61, pp. 516-527, 2005.

[101] G. Sastre, C. R. A. Catlow, A. Chica, and A. Corma, "Molecular dynamics of C7 hydrocarbon diffusion in ITQ2. The benefit of zeolite structures containing accessible pockets," Journal of Physical Chemistry B, vol. 104, no. 3, pp. 416-422, 2000.

[102] A. Corma, U. Díaz, M. E. Domine, and V. Fornés, "New aluminosilicate and titanosilicate delaminated materials active for acid catalysis, and oxidation reactions using $\mathrm{H}_{2} \mathrm{O}_{2}$," Journal of the American Chemical Society, vol. 122, no. 12, pp. 2804-2809, 2000.

[103] C. T. Kresge, "Crystalline oxide material," U.S. Patent, 5229341, 1993.

[104] C. T. Kresge, W. J. Roth, K. G. Simmons, and J. C. Vartuli, "Acid oxide with micro and mesoporous characteristics: MCM-36," World Patent, WO92/11934, 1992.

[105] W. J. Roth, C. T. Kresge, J. C. Vartuli, M. E. Leonowicz, A. S. Fung, and S. B. McCullen, "MCM-36: the first pillared molecular sieve with zeoliteproperties," Studies in Surface Science and Catalysis, vol. 94, pp. 301-308, 1995.

[106] Y. J. He, G. S. Nivarthy, F. Eder, K. Seshan, and J. A. Lercher, "Synthesis, characterization and catalytic activity of the pillared molecular sieve MCM-36," Microporous and Mesoporous Materials, vol. 25, no. 1-3, pp. 207-224, 1998.

[107] D. L. Dorset and W. J. Roth, "Electron crystallography of MWW zeolites-filling the missing cone," Zeitschrift fuer Kristallographie-Crystalline Materials, vol. 226, pp. 254-263, 2011.

[108] J. O. Barth, A. Jentys, E. F. Iliopoulou, I. A. Vasalos, and J. A. Lercher, "Novel derivatives of MCM-36 as catalysts for the reduction of nitrogen oxides from FCC regenerator flue gas streams," Journal of Catalysis, vol. 227, no. 1, pp. 117-129, 2004.

[109] J. Kornatowski, J.-O. Barth, and J. A. Lercher, "New modifications of layered MCM-36 molecular sieve pillared with various mixed oxides: facts and perspectives," Studies in Surface Science and Catalysis, vol. 156, pp. 349-356, 2005.

[110] J. O. Barth, Jenyts, J. Kornatowski, and J. A. Lercher, "Control of Acid-Base Properties of New Nanocomposite Derivatives of MCM-36 by Mixed Oxide Pillaring," Chemistry of Materials, vol. 16, pp. 724-730, 2004.

[111] R. Schenkel, J. O. Barth, J. Kornatowski, A. Jentys, and J. A. Lercher, "Adsorption of methanol on MCM-36 derivatives with strong acid and base sites," Studies in Surface Science and Catalysis, vol. 154, pp. 1598-1605, 2004.

[112] P. Chlubná, W. J. Roth, A. Zukal, M. Kubů, and J. Pavlatová, "Pillared MWW zeolites MCM-36 prepared by swelling MCM-22P in concentrated surfactant solutions," Catalysis Today, vol. 179, no. 1, pp. 35-42, 2012.

[113] W. J. Roth, J. C. Vartuli, and C. T. Kresge, "Characterization of mesoporous molecular sieves: differences between M41s 
and pillared layered zeolites," Studies in Surface Science and Catalysis, vol. 129, pp. 501-508, 2000.

[114] A. Corma, "Inorganic solid acids and their use in acidcatalyzed hydrocarbon reactions," Chemical Reviews, vol. 95, no. 3, pp. 559-614, 1995.

[115] A. Corma, M. S. Grande, V. González-Alfaro, and A. V. Orchillés, "Cracking activity and hydrotermal stability of MCM-41 and its comparison with amorphous silica, alumina and USY zeolite," Journal of Catalysis, vol. 159, pp. 357-382, 1996.

[116] J. Wang, X. Tu, W. Hua, Y. Yue, and Z. Gao, "Role of the acidity and porosity of MWW-type zeolites in liquid-phase reaction," Microporous and Mesoporous Materials, vol. 142, no. 1, pp. 82-90, 2011.

[117] A. Corma, V. González-Alfaro, and A. V. Orchillés, "Decalin and tetralin as probe molecules for cracking and hydrotreating the light cycle oil," Journal of Catalysis, vol. 200, no. 1, pp. 34-44, 2001.

[118] A. Corma, A. Martínez, and V. Martínez-Soria, "Catalytic performance of the new delaminated ITQ-2 zeolite for mild hydrocracking and aromatic hydrogenation processes," Journal of Catalysis, vol. 200, no. 2, pp. 259-269, 2001.

[119] G. Prieto, A. Martínez, P. Concepción, and R. MorenoTost, "Cobalt particle size effects in Fischer-Tropsch synthesis: structural and in situ spectroscopic characterisation on reverse micelle-synthesised Co/ITQ-2 model catalysts," Journal of Catalysis, vol. 266, no. 1, pp. 129-144, 2009.

[120] P. Concepción, C. López, A. Martínez, and V. F. Puntes, "Characterization and catalytic properties of cobalt supported on delaminated ITQ-6 and ITQ-2 zeolites for the Fischer-Tropsch synthesis reaction," Journal of Catalysis, vol. 228, no. 2, pp. 321-332, 2004.

[121] A. Martínez, S. Valencia, R. Murciano, H. S. Cerqueira, A. F. Costa, and E. F. S.-Aguiar E.F., "Catalytic behavior of hybrid $\mathrm{Co} / \mathrm{SiO} 2$-(medium-pore) zeolite catalysts during the onestage conversion of syngas to gasoline," Applied Catalysis A, vol. 346, no. 1-2, pp. 117-125, 2008.

[122] A. Martínez, E. Peris, and G. Sastre, "Dehydroaromatization of methane under non-oxidative conditions over bifunctional Mo/ITQ-2 catalysts," Catalysis Today, vol. 107-108, pp. 676-684, 2005.

[123] P. Wu, Q. Kan, D. Wang, H. Xing, M. Jia, and T. Wu, "The synthesis of Mo/H-MCM-36 catalyst and its catalytic behavior in methane non-oxidative aromatization," Catalysis Communications, vol. 6, pp. 449-454, 2005.

[124] M. Lallemand, O. A. Rusu, E. Dumitriu, A. Finiels, F. Fajula, and V. Hulea, "NiMCM-36 and NiMCM-22 catalysts for the ethylene oligomerization: effect of zeolite texture and nickel cations/acid sites ratio," Applied Catalysis A, vol. 338, no. 1-2, pp. 37-43, 2008.

[125] M. Lallemand, O. A. Rusu, E. Dumitriu, A. Finiels, F. Fajula, and V. Hulea, "Ni-MCM-36 and Ni-MCM-22 catalysts for the ethylene oligomerization," Studies in Surface Science and Catalysis, vol. 174, pp. 1139-1142, 2008.

[126] H. J. Jung, S. S. Park, C.-H. Shin, Y.-K. Park, and S. B. Hong, "Comparative catalytic studies on the conversion of 1butene and n-butane to isobutene over MCM-22 and ITQ-2 zeolites," Journal of Catalysis, vol. 245, no. 1, pp. 65-74, 2007.

[127] J. Aguilar, S. B. C. Pergher, C. Detoni, A. Corma, F. V. Melo, and E. Sastre, "Alkylation of biphenyl with propylene using MCM-22 and ITQ-2 zeolites," Catalysis Today, vol. 133-135, no. 1-4, pp. 667-672, 2008.
[128] Y. Zhang, H. Xing, P. Yang et al., "Alkylation of benzene with propylene over MCM-36: a comparative study with MCM22 zeolite synthesized from the same precursors," Reaction Kinetics and Catalysis Letters, vol. 90, no. 1, pp. 45-52, 2007.

[129] D. Meloni, E. Dumitriu, R. Monaci, and V. Solinas, "Liquidphase alkylation of phenol with t-Butanol over H-MCM22, H-ITQ-2 and H-MCM-36 catalysts," Studies in Surface Science and Catalysis, vol. 174, no. B, pp. 1111-1114, 2008.

[130] E. Dumitriu, I. Fechete, P. Caullet et al., "Conversion of aromatic hydrocarbons over MCM-22 and MCM-36 catalysts," Studies in Surface Science and Catalysis, vol. 142, pp. 951-958, 2002.

[131] A. Chica and S. Sayas, "Effective and stable bioethanol steam reforming catalyst based on $\mathrm{Ni}$ and Co supported on all-silica delaminated ITQ-2 zeolite," Catalysis Today, vol. 146, no. 1-2, pp. 37-43, 2009.

[132] H.-K. Min, M. B. Park, and S. B. Hong, "Methanol-to-olefin conversion over H-MCM-22 and H-ITQ-2 zeolites," Journal of Catalysis, vol. 271, no. 2, pp. 186-194, 2010.

[133] J. Wang, F. Zhang, W. Hua, Y. Yue, and Z. Gao, "Dehydrogenation of propane over MWW-type zeolites supported gallium oxide," Catalysis Communications, vol. 18, pp. 63-67, 2012.

[134] A. Lacarrie, F. Luck, D. Swierczynski, F. Fajula, and V. Hulea, "Methanol to hydrocarbons over zeolites with MWW topology: Effect of zeolite texture and acidity," Applied Catalysis A, vol. 402, pp. 208-217, 2011.

[135] J. Barth, A. Jentys, and J. A. Lercher, "Development of novel catalytic additives for the in situ reduction of $\mathrm{NO}_{x}$ from fluid catalytic cracking units," Studies in Surface Science and Catalysis, vol. 154, pp. 2441-2448, 2004.

[136] D. Liu, A. Bhan, M. Tsapatsis, and S. Al Hashimi, "Catalytic behavior of Brønsted acid sites in MWW and MFI zeolites with dual meso- and microporosity," ACS Catalysis, vol. 1, no. 1, pp. 7-17, 2011.

[137] M. J. Climent, A. Corma, V. Fornés et al., "Novel delaminated zeolites are more active acid catalysts than conventional zeolites and mesoporous AI/MCM-41 for the synthesis of fine chemicals," Studies in Surface Science and Catalysis, vol. 135, p. 194, 2001.

[138] P. Serna, L. A. Baumes, M. Moliner, and A. Corma, "Combining high-throughput experimentation, advanced data modeling and fundamental knowledge to develop catalysts for the epoxidation of large olefins and fatty esters," Journal of Catalysis, vol. 258, no. 1, pp. 25-34, 2008.

[139] L. A. Baumes, P. Serna, and A. Corma, "Merging traditional and high-throughput approaches results in efficient design, synthesis and screening of catalysts for an industrial process," Applied Catalysis A, vol. 381, no. 1-2, pp. 197-208, 2010.

[140] S.-Y. Kim, H.-J. Ban, and W.-S. Ahn, "Ti-MCM-36: a new mesoporous epoxidation catalyst," Catalysis Letters, vol. 113, no. 3-4, pp. 160-164, 2007.

[141] C. González-Arellano, A. Corma, M. Iglesias, and F. Sánchez, "Improved palladium and nickel catalysts heterogenised on oxidic supports (Silica, MCM-41, ITQ-2, ITQ-6)," Advanced Synthesis and Catalysis, vol. 346, no. 11, pp. 1316-1328, 2004.

[142] C. Baleizão, B. Gigante, H. Garcia, and A. Corma, "Chiral vanadyl Schiff base complex anchored on silicas as solid enantioselective catalysts for formation of cyanohydrins: optimization of the asymmetric induction by support modification," Journal of Catalysis, vol. 215, no. 2, pp. 199-207, 2003. 
[143] A. Fuerte, A. Corma, and F. Sánchez, "Heterogenised chiral amines as environmentally friendly base catalysts for enantioselective Michael addition," Catalysis Today, vol. 107-108, pp. 404-409, 2005.

[144] A. Corma, C. González-Arellano, M. Iglesias, S. PérezFerreras, and F. Sánchez, "Heterogenized gold(I), gold(III), and palladium(II) complexes for C-C bond reactions," Synlett, vol. 11, pp. 1771-1774, 2007.

[145] C. C. Aquino, H. O. Pastore, A. F. Masters, and T. Maschmeyer, "An ITQ-2/TUD-1 micro-/mesoporous composite: in situ delamination as a tool for the preparation of innovative materials," ChemCatChem, vol. 3, no. 11, pp. 1759-1762, 2011.

[146] M. J. Climent, A. Corma, and A. Velty, "The design of zeolites catalysts for the synthesis of organe blossom and apple fragrances," Studies in Surface Science and Catalysis, vol. 135, pp. 3727-3735, 2001.

[147] M. J. Climent, A. Corma, and A. Velty, "Synthesis of hyacinth, vanilla, and blossom orange fragrances: the benefit of using zeolites and delaminated zeolites as catalysts," Applied Catalysis A, vol. 263, no. 2, pp. 155-161, 2004.

[148] M. J. Climent, A. Corma, and S. Iborra, "Synthesis of nonsteroidal drugs with anti-inflammatory and analgesic activities with zeolites and mesoporous molecular sieve catalysts," Journal of Catalysis, vol. 233, no. 2, pp. 308-316, 2005.

[149] A. Fuerte, A. Corma, M. Iglesias, E. Morales, and F. Sánchez, "A cooperative effect between support and the heterogenised metalloporphyrins on electrocatalytic oxygen reduction," Catalysis Letters, vol. 101, no. 1-2, pp. 99-103, 2005.

[150] A. Corma, V. Fornés, M. S. Galletero, H. Garcia, and J. C. Scaiano, "Evidence for through-framework electron transfer in intrazeolite photochemistry. Case of $\mathrm{Ru}(\mathrm{bpy}) 32+$ and methylviologen in novel delaminated ITQ-2 zeolite," Chemical Communications, no. 4, pp. 334-335, 2002.

[151] A. Corma, U. Díaz, B. Ferrer, V. Fornés, M. S. Galletero, and H. García, "Controlling the emission of blue-emitting complexes by encapsulation within zeolite cavities," Chemistry of Materials, vol. 16, no. 7, pp. 1170-1176, 2004.

[152] A. Corma, V. Fornes, and F. Rey, "Delaminated zeolites: an efficient support for enzymes," Advanced Materials, vol. 14, no. 1, pp. 71-74, 2002.

[153] A. Corma, V. Fornés, J. L. Jordá et al., "Electrostatic and covalent immobilisation of enzymes on ITQ-6 delaminated zeolitic materials," Chemical Communications, vol. 5, pp. 419-420, 2001.

[154] A. Macario, A. Katovic, G. Giordano et al., "Immobilization of Lipase on microporous and mesoporous materials: studies of the support surfaces," Studies in Surface Science and Catalysis, vol. 155, pp. 381-394, 2005.

[155] E. Dumitriu, F. Secundo, J. Patarin, and I. Fechete, "Preparation and properties of lipase immobilized on MCM-36 support," Journal of Molecular Catalysis B, vol. 22, no. 3-4, pp. 119-133, 2003.

[156] H. Dathe, C. Sedlmair, A. Jentys, and J. A. Lercher, "Adsorption of SO2 on different metal impregnated zeolites," Studies in Surface Science and Catalysis, vol. 154, pp. 3003-3009, 2004.

[157] S.-T. Yang, J.-Y. Kim, J. Kim, and W.-S. Ahn, " $\mathrm{CO}_{2}$ capture over amine-functionalized MCM-22, MCM-36 and ITQ-2," Fuel, vol. 97, pp. 435-442, 2012.

[158] J. Pawlesa, A. Zukal, and J. Čejka, "Synthesis and adsorption investigations of zeolites MCM-22 and MCM-49 modified by alkali metal cations," Adsorption, vol. 13, no. 3-4, pp. 257265, 2007.

[159] I. Domínguez, J. Pawlesa, A. Zukal, and J. Čejka, "Ferrierite and MCM-22 for the $\mathrm{CO}_{2}$ adsorption," Studies in Surface Science and Catalysis, vol. 174, pp. 603-606, 2008.

[160] A. Zukal, J. Pawlesa, and J. Čejka, "Isosteric heats of adsorption of carbon dioxide on zeolite MCM-22 modified by alkali metal cations," Adsorption, vol. 15, no. 3, pp. 264270, 2009.

[161] A. Zukal, I. Dominguez, J. Mayerová, and J. Čejka, "Functionalization of delaminated zeolite ITQ-6 for the adsorption of carbon dioxide," Langmuir, vol. 25, no. 17, pp. 1031410321, 2009. 

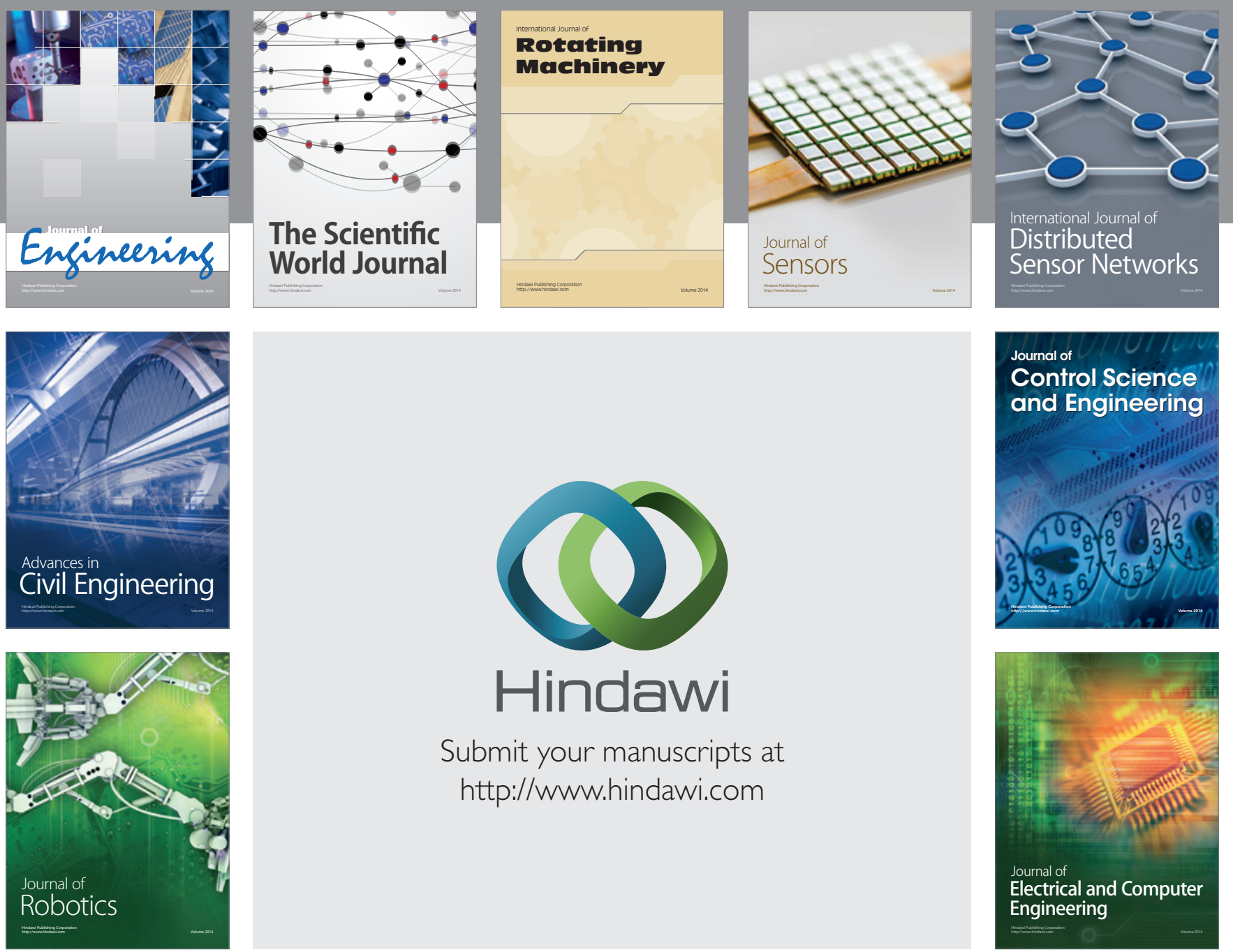

Submit your manuscripts at

http://www.hindawi.com
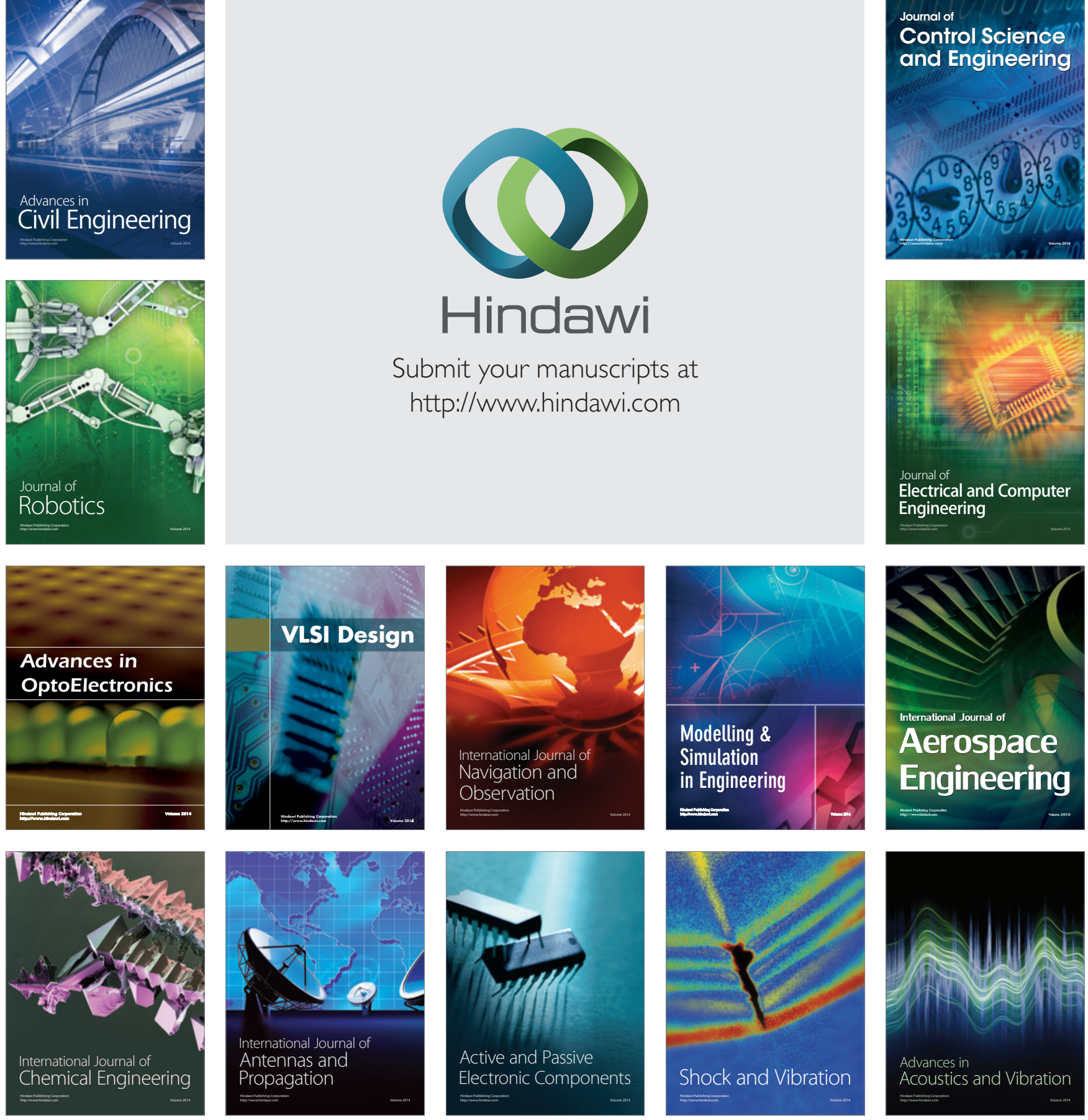